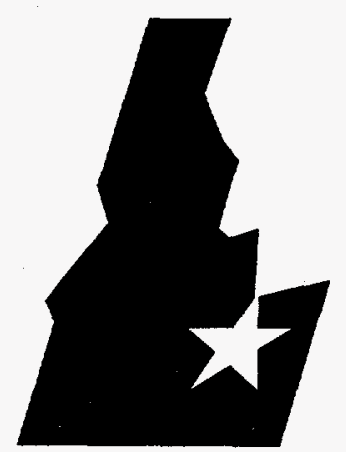

Idaho National Engineering Laboratory

\title{
INEL BNCT Research Program Annual Report
}

1995

\section{RECEIVED JUL 291996 \\ OSTI}

Edited by

$J$. R. Venhuizen

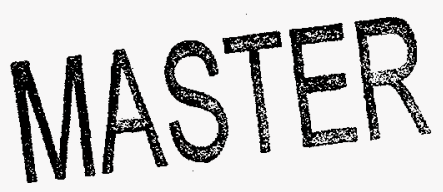

DISTRIBUTION OF THIS DOCUMENT IS UNIIHTH

zhlockheed

Idaho Technologles company

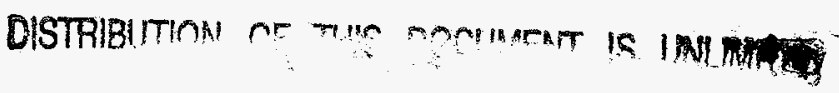




\title{
INEL BNCT Research Program Annual Report 1995
}

\author{
Edited by
}

J. R. Venhuizen

Published April 1996

\section{Idaho National Engineering Laboratory Lockheed Idaho Technologies Company Idaho Falls, Idaho 83415}

Prepared for the U.S. Department of Energy Office of Energy Research Under DOE Idaho Operations Office Contract DE-AC07-94ID13223 


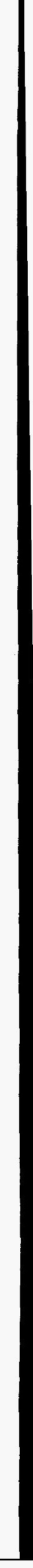


DISCLAIMER

Portions of this document may be illegible in electronic image products. Images are produced from the best available original document. 


\begin{abstract}
This report is a summary of the progress and research produced for the Idaho National Engineering Laboratory (INEL) Boron Neutron Capture Therapy (BNCT) Research Program for calendar year 1995. Contributions from the principal investigators about their individual projects are included, specifically, physics (treatment planning software, real-time neutron beam measurement dosimetry), and radiation biology (large animal models efficacy studies). Design of a reactor based epithermal neutron extraction facility is discussed in detail. Final results of boron magnetic resonance imagining in included for both borocaptate sodium (BSH) and boronophenylalanine (BPA) in rats, and BSH in humans. Design of an epithermal neutron facility using electron linear accelerators is presented, including a treatise on energy removal from the beam target. Information on the multiple fraction injection of BSH in rats is presented.
\end{abstract}

\title{
DISCLAIMER
}

This report was prepared as an account of work sponsored by an agency of the United States Government. Neither the United States Government nor any agency thereof, nor any of their employees, makes any warranty, express or implied, or assumes any legal liability or responsibility for the accuracy, completeness, or usefulness of any information, apparatus, product, or process disclosed, or represents that its use would not infringe privately owned rights. Reference herein to any specific commercial product, process, or service by trade name, trademark, manufacturer, or otherwise does not necessarily constitute or imply its endorsement, recommendation, or favoring by the United States Government or any agency thereof. The views and opinions of authors expressed herein do not necessarily state or reflect those of the United States Government or any agency thereof. 


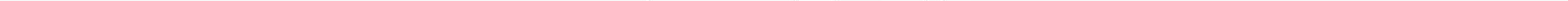




\section{CONTENTS}

ABSTRACT $\ldots \ldots \ldots \ldots \ldots \ldots \ldots \ldots \ldots \ldots \ldots \ldots \ldots \ldots \ldots \ldots \ldots \ldots \ldots$

ACRONYMS AND ABBREVIATIONS $\ldots \ldots \ldots \ldots \ldots \ldots \ldots \ldots \ldots \ldots \ldots \ldots \ldots$ viii

INTRODUCTION $\ldots \ldots \ldots \ldots \ldots \ldots \ldots \ldots \ldots \ldots \ldots \ldots \ldots \ldots \ldots \ldots$

Epithermal Neutron Beam Extraction Facility $\ldots \ldots \ldots \ldots \ldots \ldots \ldots \ldots \ldots \ldots$

Treatment Protocol Development $\ldots \ldots \ldots \ldots \ldots \ldots \ldots \ldots \ldots \ldots \ldots \ldots \ldots$

Boron-11 Magnetic Resonance Imaging in Tumor-Bearing Animals and Humans .... 1

Electron Accelerator Based Epithermal Photoneutron Source $\ldots \ldots \ldots \ldots \ldots \ldots .2$

Conceptual Studies of Target Cooling for an Epithermal Photoneutron Accelerator . . $\quad 2$

Optimization of Treatment Planning for BNCT $\ldots \ldots \ldots \ldots \ldots \ldots \ldots \ldots \ldots 2$

BNCT-RTPE: BNCT Radiation Treatment Planning Environment $\ldots \ldots \ldots \ldots \ldots .3$

Real-Time Patient Monitoring System $\ldots \ldots \ldots \ldots \ldots \ldots \ldots \ldots \ldots \ldots \ldots \ldots$

Repeat Dose Administration to Rats $\ldots \ldots \ldots \ldots \ldots \ldots \ldots \ldots \ldots \ldots \ldots \ldots \ldots$

DESIGN OF THE WSU EPITHERMAL NEUTRON BEAM EXTRACTION

FACILITY FOR BNCT,

J. M. Ryskamp, F. J. Wheeler, C. A. Wemple, K. D. Watts, D. W. Nigg, and P. J. Matonis ...... 5

TREATMENT PROTOCOL DEVELOPMENT,

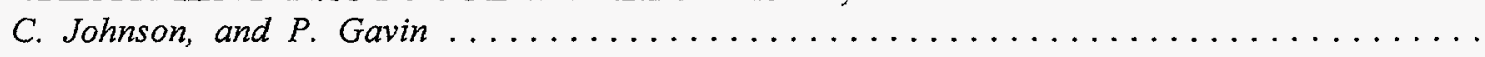

BORON-11 MAGNETIC RESONANCE IMAGING IN TUMOR-BEARING ANIMALS AND HUMANS,

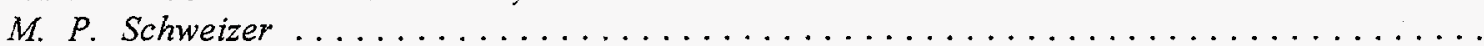

COMPUTATIONAL AND EXPERIMENTAL STUDIES OF AN ELECTRON

ACCELERATOR BASED EPITHERMAL PHOTONEUTRON SOURCE

FACILITY FOR BORON NEUTRON CAPTURE THERAPY,

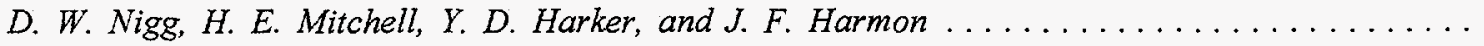

CONCEPTUAL STUDIES OF TARGET COOLING FOR AN EPITHERMAL PHOTONEUTRON ACCELERATOR FOR BORON NEUTRON

CAPTURE THERAPY,

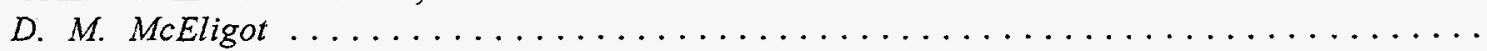

OPTIMIZATION OF TREATMENT PLANNING FOR BNCT TREATMENT PLANNING, 
BNCT-RTPE: BNCT RADIATION TREATMENT PLANNING ENVIRONMENT, D. E. Wessol, R. S. Babcock, J. Evans, M. Frandsen, G. Harkin, D. Starkey, L. Voss,

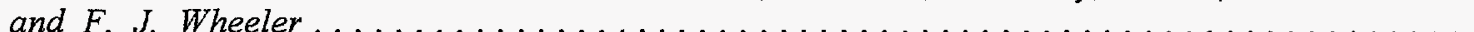

REALTIME PATIENT MONITORING SYSTEM DEVELOPMENT,

$Y$. D. Harker, J. K. Hartwell, and J. R. Venhuizen $\ldots \ldots \ldots \ldots \ldots \ldots \ldots \ldots \ldots$

THE EFFECT OF REPEAT DOSE BSH ADMINISTRATION TO RATS,

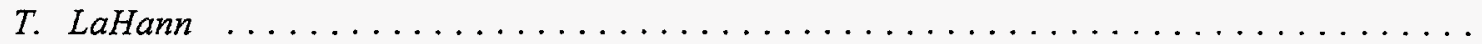

\section{FIGURES}

1. WSU reactor elevation plan $\ldots \ldots \ldots \ldots \ldots \ldots \ldots \ldots \ldots \ldots \ldots \ldots \ldots \ldots \ldots \ldots \ldots \ldots$

2. WSU Reactor Core, Thermal Column and Beam Tubes $\ldots \ldots \ldots \ldots \ldots \ldots \ldots \ldots \ldots$

3. WSU Column Assembly with Epithermal-Neutron Filter $\ldots \ldots \ldots \ldots \ldots \ldots \ldots \ldots \ldots \ldots$

4. WSU Epithermal Beam: DORT Neutron Spectrum $\ldots \ldots \ldots \ldots \ldots \ldots \ldots \ldots \ldots \ldots$

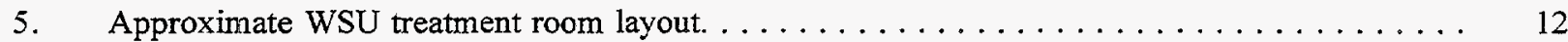

6. WSU Beam Stop Dose Map $(12 / 11 / 95) \ldots \ldots \ldots \ldots \ldots \ldots \ldots \ldots \ldots \ldots \ldots \ldots$

7. T1-weighted axial proton image showing gliosarcoma in canine left parietal lobe. Boron-11

image of BSH uptake at this location, superimposed on filtered proton image ..........

8. Plot of blood ICP-AES boron and boron-11 image derived intensities in tumor and overlaying

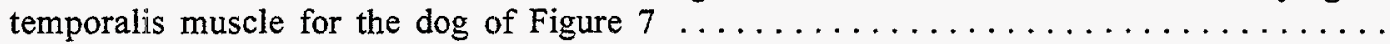

9. T1 weighted axial proton images of resected glioblastoma patient, showing gadolinium enhancement of residual tumor pocket. Boron-11 image of BSH uptake map as well as

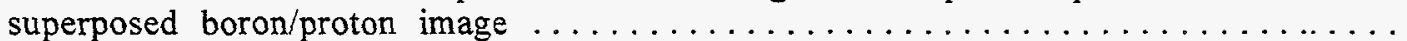

10. Axial proton and boron-11 images for resected oligodendroglioma patient receiving BSH .....

11. Axial proton and boron-11 images of large recurrent glioblastoma multiforme and BSH

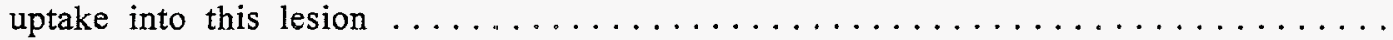

12. Pharmacokinetics of BSH in the blood (ICP-AES) and recurrent glioblastoma using boron-11 image intensity relative to boric acid reference and adjusting for signal attenuation as

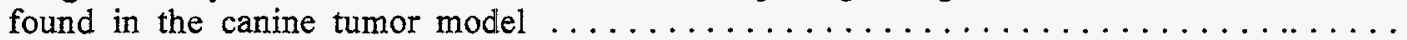

13. Coronal proton and boron- 11 images of a rat bearing a large $9 \mathrm{~L}$ flank tumor, infused with $60 \mathrm{mg} / \mathrm{kg}$ boron (as BSH), i.v.. (Bottom panel, same situation, different tissue level) . . . . . . .

14. Time dependence of boron-11 image intensities for various tissues post i.v. infusion of $60 \mathrm{mg} / \mathrm{kg}$ boron. Intensities related to boric acid reference $\ldots \ldots \ldots \ldots \ldots \ldots \ldots$

15. Coronal proton image of gliosarcoma burdened rat. On the left is a boron-11 image taken a few moments post-i.v. infusion of $10 \mathrm{mg} / \mathrm{kg}$ boron. At the right is the boron-11

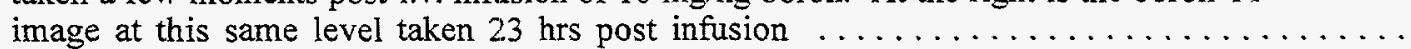

16. Coronal proton and boron- 11 images of a rat given $50 \mathrm{mg} / \mathrm{kg}$ boron 


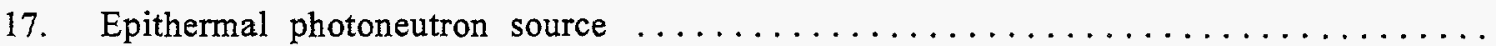

18. Calculational model for initial clinical epithermal photoneutron source concept $\ldots \ldots \ldots \ldots .30$

19. Computational sequence for epithermal photoneutron source evaluations $\ldots \ldots \ldots \ldots \ldots .31$

20. Free field flux spectrum for the conceptual BNCT epithermal neutron source design

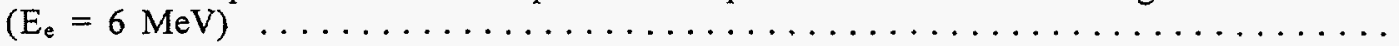

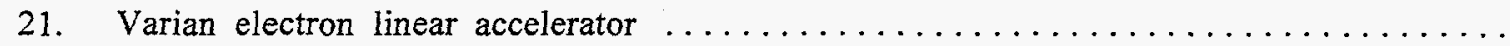

22. Varian electron linear accelerator - detail of the beam tube and target assemblies ..........

23. Varian electron linear accelerator with the collimator and photoneutron production module

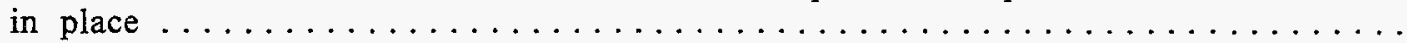

24. Schematic detail of the photoneutron production apparatus $\ldots \ldots \ldots \ldots \ldots \ldots \ldots$

25. Photoneutron production and filtering apparatus, showing the VTT Aluminum Fluoride

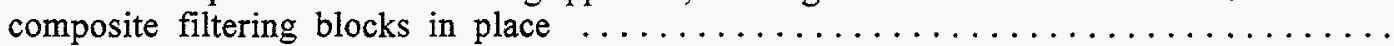

26. Photoneutron production and filtering apparatus, showing the VTT filtering material with the surrounding borated polyethylene isolation shield $\ldots \ldots \ldots \ldots \ldots \ldots \ldots \ldots$

27. Downstream face of the VTT epithermal-neutron filter, showing activation foil and ion

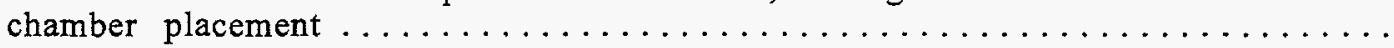

28. Photoneutron production and filtering apparatus, showing the Teflon/Aluminum filtering

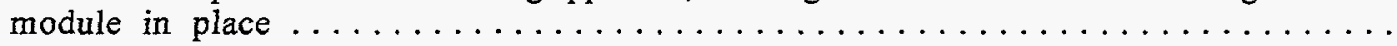

29. Downstream face of the Teflon/Aluminum epithermal-neutron filter, showing activation foil placement as well as the placement of the borated polyethylene isolation shield . . . . . . . . .

30. Photoneutron production and filtering apparatus, with the VTT filtering material oriented such that the neutron source axis of symmetry is at right angles to the electron beam axis ......

31. Side view of the vertical filter apparatus, showing the placement of the ion chamber and

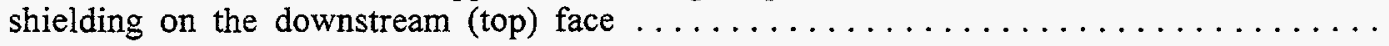

32. View underneath the vertical filter apparatus, looking up the electron beam axis, showing

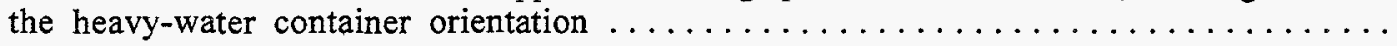

33. Calculated and measured total photoneutron sources for the Varian Photoneutron Experiment

34. A-Priori and Measured Photoneutron Spectra for the 30-cm Aluminum-Aluminum Fluoride Lithium Fluoride Filtering Assembly $\ldots \ldots \ldots \ldots \ldots \ldots \ldots \ldots \ldots \ldots \ldots \ldots$

35. A-Priori and Measured Photoneutron Spectra for the 30-cm Aluminum-Teflon Filtering Assembly

36. Epithermal Photoneutron Source for BNCT $\ldots \ldots \ldots \ldots \ldots \ldots \ldots \ldots \ldots \ldots \ldots \ldots \ldots \ldots$

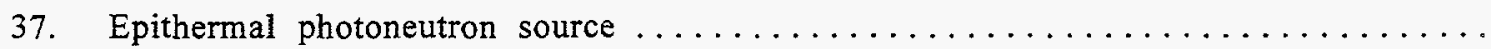

38. Approximate geometry of calculational model for initial clinical epithermal photoneutron

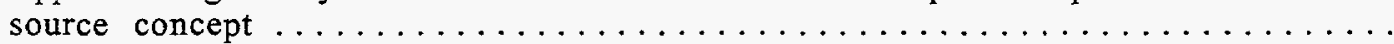


39. Thermal radiation flux between parallel surfaces of tungsten and aluminum $\ldots \ldots \ldots \ldots \ldots$

40. Schematic diagram of revised conceptual target geometry and thermal conditions $\ldots \ldots \ldots \quad 51$

41. Effects of velocity and subcooling on critical heat flux data for the last flush heater element

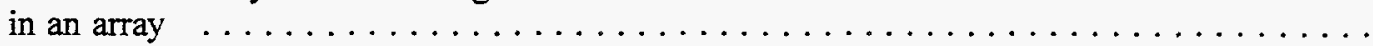

42. Schematic diagrams of types of enhanced cooling techniques considered for application to $\mathrm{BNCT}$ target cooling $\ldots \ldots \ldots \ldots \ldots \ldots \ldots \ldots \ldots \ldots \ldots \ldots \ldots \ldots \ldots \ldots \ldots \ldots \ldots \ldots$

43. Geometry for simulation of large spherical phantom irradiation. . . . . . . . . . 61

44. Fast dose iso-contours at 3.5-cm depth perpendicular to beam for rtt_MC calculation . ..... 61

45. Fast dose iso-contours at 3.5-cm depth perpendicular to beam for $\mathrm{rtt}$ Table Lookup option ... 62

46. Two-dimensional representation of optimizer output $\ldots \ldots \ldots \ldots \ldots \ldots \ldots \ldots \ldots \ldots$

47. Three-dimensional representation of optimizer output $\ldots \ldots \ldots \ldots \ldots \ldots \ldots \ldots \ldots$

48. Two-dimensional depiction of optimizer FS results for a human patient $\ldots \ldots \ldots \ldots \ldots$

49. Isocontours representation of optimizer results for human patient $\ldots \ldots \ldots \ldots \ldots \ldots$

50. Three-dimensional representation of optimizer results for human patient $\ldots \ldots \ldots \ldots \ldots$

51. Real time dosimetry development $\ldots \ldots \ldots \ldots \ldots \ldots \ldots \ldots \ldots \ldots \ldots \ldots \ldots \ldots$

52. Mean Daily Body Burden vs Urinary Excretion of Boron Repeat Dosing of BSH . . . . . 77

53. Boron Pharmacokinetics Cumulative Administration, Excretion, and Retention Repeat

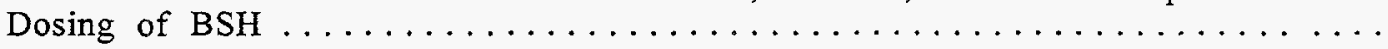

\section{TABLES}

1. Beam parameters at the collimator aperture for a comparison case (focal length $=80.91 \mathrm{~cm}$;

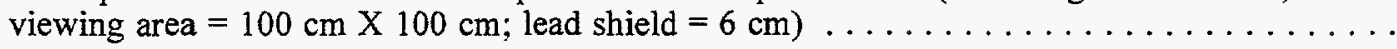

2. Activation foil interactions used in the epithermal photoneutron source experiments ....... 38

3. Estimated values of critical heat flux for some typical situations $\ldots \ldots \ldots \ldots \ldots \ldots$

4. Cooling techniques for BNCT Accelerator Target Source Cooling with estimated CHF

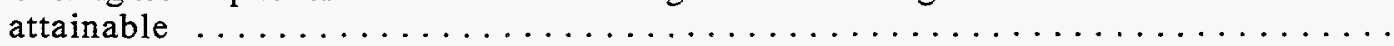

5. Neutron flux levels in the WSU reactor T3 port $\ldots \ldots \ldots \ldots \ldots \ldots \ldots \ldots \ldots \ldots \ldots$

6. Gamma-ray dose rates measured in the WSU reactor T3 beam port as a function of reactor

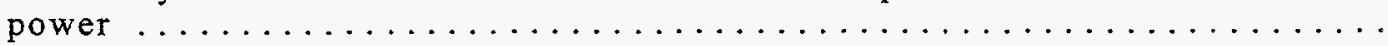

7. Gamma-ray dose rates measured in the WSU reactor T3 beam port as a function of irradiation position at a reactor power of $100 \mathrm{~kW} \ldots \ldots \ldots \ldots \ldots \ldots \ldots \ldots \ldots \ldots$ 


\section{ACRONYMS AND ABBREVIATIONS}

\begin{tabular}{|c|c|c|c|}
\hline ARL & Army Research Laboratory & ISU & Idaho State University \\
\hline BBB & blood-brain barrier & i.v. & intravenous \\
\hline BNCT & Boron Neutron Capture Therapy & $\mathrm{KeV}$ & kilo-electron volt \\
\hline BNL & Brookhaven National Laboratory & KOP & $\begin{array}{l}\text { Siemen's magnetic tape format } \\
\text { (somatom) }\end{array}$ \\
\hline BPA & boronophenylalanine & LINAC & linear accelerator \\
\hline BSH & borocaptate sodium & 1-BPA & 1-boronophenyalanine \\
\hline BSSO & oxidized dimer of $\mathrm{BSH}$ & LITC & $\begin{array}{l}\text { Lockheed Idaho Technologies } \\
\text { Company }\end{array}$ \\
\hline $\mathrm{CAD}$ & computer aided design & LMIT & Lockheed Martin Idaho Technologies \\
\hline $\mathrm{CHF}$ & critical heat flux & MC & Monte Carlo \\
\hline CRADA & $\begin{array}{l}\text { Cooperative Research and Development } \\
\text { Agreement }\end{array}$ & MCNP & Monte Carlo N-particle \\
\hline CT & computed tomography & $\begin{array}{l}\mathrm{MeV} \\
\mathrm{MRI}\end{array}$ & $\begin{array}{l}\text { Million electron volt } \\
\text { magnetic resonance imaging }\end{array}$ \\
\hline CVM & College of Veterinary Medicine & $\mathrm{MSU}$ & Montana State University \\
\hline DC & direct current & MW & megawatt \\
\hline DOE & Department of Energy & NCT & neutron capture therapy \\
\hline DORT & Discrete Ordinate Radiation Transport & NMR & nuclear magnetic resonance \\
\hline FOV & $\begin{array}{l}\text { field of view } \\
\text { electron volt }\end{array}$ & $\mathrm{NRC}$ & Nuclear Regulatory Commission \\
\hline & & NURBS & Non Uniform Rational B-spline \\
\hline FDA & Food and Drug Administration & $\mathrm{p}-\mathrm{BPA}$ & p-boronophenyalanine \\
\hline FLIP & Fuel Lifetime Improvement Program & PFC & plasma facing components \\
\hline Gy & grey-unit of radiation exposure & PI & Principal Investigator \\
\hline HPLC & high-pressure liquid chromatography & PMP & Project Management Plan \\
\hline ICP-AES & $\begin{array}{l}\text { inductively coupled plasma-atomic } \\
\text { emission spectrometry }\end{array}$ & PNNL & Pacific Northwest National Laboratory \\
\hline INEL & Idaho National Engineering Laboratory & ppm & parts per million \\
\hline i.p. & intraperineal & QSH & magnetic tape format for MRI images \\
\hline IST & International Sensor Technology & $\mathrm{RF}$ & radio frequency \\
\hline
\end{tabular}




$\begin{array}{llll}\text { ROI } & \text { region of interest } & \text { TLD } & \text { thermolouminescent dosimeter } \\ \text { Rpte } & \begin{array}{l}\text { Radiation treatment planning } \\ \text { environment }\end{array} & \text { TRIGA } & \begin{array}{l}\text { Transient Reactor Irradiator-General } \\ \text { Atomics }\end{array} \\ \mathrm{rtt} & \text { radiation transport in tissue } & \text { UCLA } & \text { University of California at Los Angeles } \\ \mathrm{SD} & \text { standard deviation } & \text { U of U } & \text { University of Utah } \\ \text { SNR } & \text { signal-to-noise ratio } & \text { WSU } & \text { Washington State University } \\ \text { SRS } & \text { Savannah River Site } & \text { 3DPR } & \text { 3D Projection Reconstruction } \\ \text { TCP } & \text { turnor control probability } & & \end{array}$




\section{INEL BNCT RESEARCH PROGRAM ANNUAL REPORT 1995}

\section{INTRODUCTION}

The Idaho National Engineering Laboratory (INEL) Boron Neutron Capture Therapy (BNCT) Research Program completed its $9^{\text {th }}$ year as a Department of Energy (DOE) funded program with a continuing increase in interest from the medical community, as evidenced by the negotiation of a Cooperative Research and Development Agreement (CRADA) with a medical startup company (Ionix) and Washington State University (WSU). This CRADA represents an attempt to move the INEL research from the national laboratory setting into the private sector. The Program goal remains: to move BNCT into a clinically useful therapy through applications of supportive research. This publication summarizes the research accomplished during calendar year 1995. Calendar year 1994 was the last year the INEL Program funded university research, but some of the studies were not fully reported in the 1994 Annual Report. This remaining research, including magnetic resonance imaging, some large animal studies and borocaptate sodium (BSH) toxicity, is also included in this report. References are inciuded at the end of each section for that section.

\section{EPITHERMAL NEUTRON BEAM EXTRACTION FACILTTY}

An advanced epithermal neutron beam extraction facility for BNCT research, including a neutron filter and a treatment room, is planned for construction at the WSU Nuclear Research Center reactor. INEL has developed a conceptual design and an integrated Project Management Plan (PMP) describing the activities that support design and construction of this facility. This project is a key piece of a large CRADA with Ionix and WSU.

The research reactor at WSU will be modified to produce a research-quality epithermal neutron beam. WSU will provide pharmacological and toxicological support, and will make its state-of-the-art veterinary school facilities available for clinical testing. The epithermal-neutron beam at WSU will be used to study treatments for primary malignant gliomas of the brain (glioblastoma multiforme), metastatic brain tumors (e.g. from breast and lung cancer), and head and neck cancers.

The neutron beam at WSU will contain incident neutron energies predominantly in the epithermal energy range. The graphite will be removed from the thermal column, and a neutron filtering material installed to produce the epithermal neutron beam. INEL physicists have designed the neutron filtering media; INEL will purchase the filtering material; and Ionix will fund the actual construction of the filter. The filter design is discussed in detail in this document.

\section{TREATMENT PROTOCOL DEVELOPMENT}

WSU researchers report that the three tumor dogs treated at Brookhaven National Laboratory (BNL) with boronophenylalanine (BPA)-fructose are doing fine as of February 1996. Two of the three tumor dogs had surgery prior to BNCT. Normal tissue tolerance dogs treated with four BNCT fractions are being monitored for late effects of the treatment. There have been some neurological changes, enough that two of the dogs were euthanzied within five months of treatment. The single fraction tolerance studies were also completed at the lower doses, and those dogs are being monitored for neurological and physical changes. This will complete the normal tissue tolerance studies.

\section{BORON-11 MAGNETIC RESONANCE IMAGING IN TUMOR-BEARING ANIMALS AND HUMANS}

The final report from researchers at the University of Utah (U of U) highlights progress within 1995 as well as serving as a summary of the major accomplishments during the five years of support to $U$ of U from INEL. Three major areas are considered: 1) Determination of BSH pharmacokinetics in the canine brain tumor model; the major accomplishment was the development of a non-invasive quantitative method for BSH pharmacokinetics, 2) BSH pharmacokinetics in human patients with high grade brain tumors; the major accomplishment was the demonstration of the ability to non-invasively follow BSH uptake and elimination in high grade human brain tumors, and 3) Boron-11 magnetic resonance imaging (MRI) of several BNCT agents in rats; the major accomplishment was direct, on-line, noninvasive observations of pharmacokinetics of several BNCT agents in tumors and organs of elimination 
the in the rat model. Images from all three areas are included to show the ability to image boron-11 in dogs, rats and humans.

All imaging work was carried out on a clinical scanner in the $U$ of U Department of Radiology MRI Center. Coils of the appropriate dimensions incorporated the inductively driven quadrature birdcage design. All boronated compounds examined were natural abundance ( $80 \%$ boron-11 isotope).

\section{ELECTRON ACCELERATOR BASED EPITHERMAL PHOTONEUTRON SOURCE}

BNCT research in the United States and Europe has been focused on the use of an epithermal-neutron beam as the most effective method for generating the necessary thermal neutron field in deep-seated treatment volumes. Epithermal-neutron beams can be generated by small nuclear reactors and by acceleratorbased neutron sources. So far, only reactors have actually been used to produce therapeutically-useful epithermal-neutron beams for BNCT. Some lowintensity prototypes of accelerator-based sources, generally featuring the use of proton or deuteron beams and beryllium or lithium targets, have been constructed. Scaling of these devices to output levels suitable for clinical application will in many cases require additional developments in the relevant accelerator technology, as well as the resolution of some rather difficult issues associated with target cooling. This report describes an alternate approach to the realization of a clinically-useful acceleratorbased source of epithermal neutrons for BNCT that reconciles the often-conflicting objectives of target cooling, neutron beam intensity, and neutron beam spectral purity via a two-stage photoneutron production process driven by an electron linear accelerator rather than by a heavy-particle accelerator. A description of the basic concept is provided and the results of initial proof-of-principal experiments using a low-current benchtop model of the proposed device are presented.

\section{CONCEPTUAL STUDIES OF TARGET COOLING FOR AN EPITHERMAL PHOTONEUTRON ACCELERATOR}

Accelerator-based epithermal-neutron sources may constitute the basis for a more deployable technology for BNCT than reactor-based sources in the long term. However, accelerator target cooling is a potential Achilles heel of this concept. Current estimates are that the target cooling system must remove energy at a rate of about $12 \mathrm{Mw} / \mathrm{m}^{2}$ or more to be successful. This heat flux is an order-ofmagnitude above typical critical heat flux (CHF) in saturated pool boiling.

The report on target cooling examines the question whether it is possible to provide adequate cooling of the accelerator targets in the INEL photoneutron source concept and, if so, how it might be done. The current study has examined the orders-of-magnitude of heat fluxes attainable via some possible approaches. It is anticipated that the thermal energy transfer from the target to the water must be by subcooled nucleate boiling in order for the target to survive. Therefore, the $\mathrm{CHF}$ of the technique chosen must exceed $12 \mathrm{Mw} / \mathrm{m}^{2}$ by a safe margin. Cooling techniques considered include wall jets, Hypervapotrons, modified flow channels and impinging jets. From this review, it appears that it should be possible cool the targets adequately but that it will not be an easy task.

\section{OPTIMIZATION OF TREATMENT PLANNING FOR BNCT}

Treatment planning for epithermal neutron capture therapy (NCT) applications to date has relied on rigorous Monte Carlo calculations for dose predictions. Although many improvements have been made, the Monte Carlo process still requires a large amount of computer time and planning labor. With single-field, fixed-aperture irradiations, a near-optimum field can be found with an intuition-aided trial and error approach, however methods to more rapidly determine an optimum irradiation configuration will significantly aid the planning process. As treatment efforts become more aggressive, with the ability to select aperture size and number of fields, it will be a tremendous effort to manually find the optimum plan for a given patient. Also, as the modality moves to clinical applications, patient throughput will not permit the labor resource-expenditure currently utilized in clinical trials.

An approach to improvement in the planning process has been initiated. Improvement requires: 1) a rapid method to calculate (or closely approximate) three-dimensional dose patterns; 2) an organized method to investigate variation in aperture size and beam orientation for one or more fields; 3) validation of the results of the optimization and; 4) a method of presenting results to the evaluator (oncologist).

Currently, evaluation of various plans relies on detailed inspection of dose contours and dose/volume histograms. For the optimization search, an integral measure is required so the process can be automated. 
For the study presented, the integral measure used is the tumor control probability (TCP). As a trial study, the optimization has been tried for actual patients at BNL. The optimizer agreed with the previously determined beam locator. Work still needs to be done to address the multifield irradiations.

\section{BNCT-RTPE: BNCT RADIATION TREATMENT PLANNING ENVIRONMENT}

Several improvements have been developed for the $\mathrm{BNCT}$ radiation treatment planning environment (BNCT_Rtpe) during 1995 and incorporated into version 1.2 and version $2 . x$. These versions also include the non-proprietary NURBS (Non Uniform Rational B Spline) library and data structures.

In version 2.x of BNCT_Rtpe all of the $U$ of $U$ proprietary NURBS libraries were replaced with a non-proprietary set derived from the ARL-CAD (Army Research Laboratory) (Computer Aided Design) distribution. A new ray tracer based entirely on searching a nested hierarchy of bounding volumes enclosing the point of intersection was developed using the new NURBS libraries. This is a much faster method of testing and determining the intersection point than the method which employs a coarser hierarchy of bounding volumes coupled with Newton iteration. All of the Utah data structures, display lists, and macro functions were also replaced in version $2 . x$.

Several improvements were made to the BNCT dose contouring function, which displays the radiation transport in tissue, Monte Carlo ( $\mathrm{rtt}$ MC) dose data. New colormap manipulation utilities have been included.

A new magnetic media (QSH) format conversion utility was developed which includes raw, QSH and Siemen's (KOP) formats. The dicom 3 standard format will also be incorporated. New image colormap, contrast, and brightness tools have been developed along with a vertically and horizontally scrollable image container widget.

\section{REAL-TIME PATIENT MONITORING SYSTEM}

The objective of this work is to develop a small neutron dosimetry system that can be remotely monitored in real time, so that medical personnel can monitor BNCT patient doses in real time during a therapeutic irradiation. Presently available neutron dosimeters either are so bulky that their presence would perturb the therapeutic beam, or they cannot be monitored in real time.

Two candidate real time neutron dosimetry system were tested in 1995. INEL and Pacific Northwest National Laboratory (PNNL) researchers, along with representatives of International Sensor Technology (IST) Corporation (Pullman, WA) conducted initial tests on two candidate real time dosimetry systems.

The PNNL system uses a small neutron sensitive fiber optic scintillation detector that has been successful in other applications. In this device, a short $(1$ to $3 \mathrm{~cm}$ ) length of neutron-sensitive glass fiber with a diameter of a few hundred micrometers is coupled to a fiber optic transmission line. Neutron (and gamma-ray) interactions in the scintillating fiber create light pulses that are transmitted to a set of detection electronics which scale the pulses and determine their rate. The detection rate is proportional to the neutron (and gamma-ray) dose rate.

A system marketed by IST consists of a small thermoluminescent dosimeter (TLD) chip located at the probe end of a fiber-optic transmission cable. The opposite end of the cable is coupled to a set of optical equipment that incorporates a small laser. It is designed to expose the TLD and then remotely read out its response using a laser to heat the TLD. The fiber optic cable serves to both transport the laser light to the TLD to heat the phosphor and to transport the thermo-luminescence light emitted by heating the TLD back to a photo-multiplier tube. The IST TLD chips used in this measurement work were made from magnesium metaborate. To accentuate the separation between neutron and gamma-ray response, one set of chips were enriched in neutron-sensitive ${ }^{10} \mathrm{~B}$, while another set was enriched in neutron-insensitive ${ }^{11} \mathrm{~B}$. The electronics system is well packaged and supported by a personal computer.

Experiments were conducted at WSU to test both probes under irradiation conditions. These experiments were successful to the point that additional experiments are being planned.

\section{REPEAT DOSE ADMINISTRATION TO RATS}

Initial U.S. clinical evaluations of BSH mediated BNCT are likely to employ BSH doses similar to those used in Japan and Europe, i.e., BSH doses no greater than $100 \mathrm{mg} / \mathrm{kg}$. BSH has been administered clinically in both Japan and Europe (typically at doses less than $100 \mathrm{mg} / \mathrm{kg}$ ), and experience suggests that single doses of BSH in amounts less than 100 
$\mathrm{mg} / \mathrm{kg}$ are reasonably safe for healthy volunteers and for the brain tumor patient populations evaluated to date. There are biological reasons to believe that BNCT clinical protocols utilizing fractionated therapy (including repeat dosing of $\mathrm{BSH}$ ) may be superior to those using a single fraction (single dose of BSH). However, the toxicological and pharmacokinetic effects of repeat dosing of BSH are largely unknown. Idaho State University (ISU) researchers report that rats tolerated multiple injections of $\mathrm{BSH}$ at levels comparable to those expected for human therapy. Rats were followed for 7 days after the infusion of BSH stopped. The main concern as a result of these studies is that there is a build up on boron in tissue of the rats, and it is not readily apparent what tissue is "storing" the boron. Results of the experiments on the elimination by the rat of BSH from multiple injections is reported. 


\section{DESIGN OF THE WSU EPITHERMAL NEUTRON BEAM EXTRACTION FACILITY FOR BNCT}

\author{
J. M. Ryskamp, F. J. Wheeler, C. A. Wemple, \\ K. D. Watts, D. W. Nigg, and P. J. Matonis, \\ (INEL)
}

An advanced epithermal neutron beam extraction facility for BNCT research, including a neutron filter and a treatment room, is planned for construction at the WSU Nuclear Research Center reactor. INEL has developed a conceptual design and an integrated PMP describing the activities that support design and construction of this facility.

This project is a key piece of a large CRADA. The purpose of this CRADA is to work with the private sector in determining the effectiveness of BNCT as a treatment for a variety of different types of cancer. Highly-advanced boronated pharmaceuticals will be used that promise a significantly greater efficacy than has heretofore been possible with the agents currently in use for BNCT. Activities under the CRADA that support this overall goal include radiobiological testing of BNCT in animal models, development of human biodistribution data for advanced pharmaceuticals, and the development of certain supporting technologies and protocols. These activities will be focused on bringing all of the relevant science and technology to the point where human clinical trials can be conducted in a controlled scientific study.

The research reactor at WSU will be modified to produce a research-quality epithermal neutron beam. WSU will provide pharmacological and toxicological support, and will make its state-of-the-art veterinary school facilities available for clinical testing. The epithermal-neutron beam at WSU will be used to study treatments for primary malignant gliomas of the brain (glioblastoma multiforme), metastatic brain tumors (e.g. from breast and lung cancer), and head and neck cancers.

The neutron beam at WSU will contain incident neutron energies predominantly in the epithermal [0.5 electron volts $(\mathrm{eV})$ to 10 kilo-electron volts $(\mathrm{keV})]$ energy range. Epithermal neutrons are surface sparing; they penetrate a few centimeters into tissue before producing the peak thermal-neutron flux.

\section{REQUIREMENTS}

The epithermal neutron flux level must be high enough to provide an acceptable dose delivery rate while keeping the fast and thermal neutron flux, and gamma dose to an acceptable minimum. The epithermal neutron flux level at the patient position should be greater than $10^{9} \mathrm{n} \mathrm{cm}^{-2} \mathrm{~s}^{-1}$, while the fast neutron dose per unit incident flux at this position should be less than $5 \times 10^{-11} \mathrm{cGy}^{2} \mathrm{~cm}^{2} \mathrm{~s}$, and the

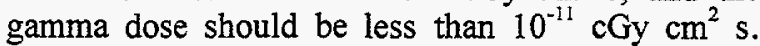
Neutrons with energies above $10 \mathrm{keV}$ (fast neutrons) are very damaging to healthy tissue due to the recoil protons produced when neutrons undergo elastic scatter reactions with hydrogen. Therefore, it is important to design the neutron beam such that the relative intensity of these fast neutrons is low. Also, there are incident gamma rays in any neutron beam due to neutron capture events in the structure, and it is necessary to minimize this component. The thermal-neutron flux in the free beam should also be minimized to reduce surface-tissue damage. A wellcollimated beam is desirable, although not entirely necessary, for effective therapy. The aperture should be variable between 8 and $30 \mathrm{~cm}$ diameter. The collimation (neutron current to flux ratio) should be greater than 0.75 . The whole body dose to the patient during treatment should be less than $1 \mathrm{~Gy}$.

\section{OBJECTIVES}

The main objective of this project is to design and construct an epithermal neutron beam extraction facility in the WSU reactor for BNCT. The PMP details a set of minor objectives or tasks that have been developed to accomplish this objective:

1. Remove the current thermal column graphite at the WSU reactor and prepare this location for insertion of the epithermal neutron filter.

2. Design all the neutron and gamma filtering and shielding components to be installed within the existing WSU thermal column region.

3. Construct and install all of the neutron and gamma filtering and shielding components in the thermal column region.

4. Design a shielded treatment room (beam stop) to be located adjacent to the exit port of the planned epithermal-neutron beam facility.

5. Construct the treatment room to be located adjacent to the exit port of the planned epithermal-neutron beam facility. 
6. Modify the WSU reactor core fuel loading pattern within the established safety limits to achieve a high neutron flux at the core/thermal column interface region.

7. Modify the WSU reactor facility and treatment room as needed to achieve safe operation as required for animal studies and human therapy.

8. Receive all the necessary approvals required for animal studies and human therapy at the facility.

\section{FACILITY DESCRIPTION}

The Nuclear Radiation Center at WSU houses a 1 MW convectively-cooled, light-water, pool reactor. The facility was originally a General Electric reactor, but was later modified to utilize Transient Reactor Irradiator-General Atomics (TRIGA) fuel elements, and is now referred to as a TRIGA facility. A bridge over the pool is used to configure the core and insert experiments. A reactor operator can safely occupy the bridge while the reactor is in operation. Figure 1 is an elevation plan showing the relationship of the pool, core, bridge, thermal column, and beam room.

The TRIGA fuel in the core consists of standard elements (20\% enriched) and FLIP fuel (70\% enriched). The reactor is inherently safe because the fuel elements contain a large amount of zirconium hydride which, when heated, decreases core reactivity, preventing reactor runaway. Figure 2 shows a sketch of the thermal column and reactor core. The bridge is mounted on tracks, allowing the core (suspended from the bridge) to be positioned immediately adjacent to the thermal-column wall, providing a large neutron leakage flux into the thermal column. Likewise, the core can be moved into the center of the pool to reduce the radiation into the thermal column.

The thermal column consists of a graphite blocks in a container sealed to the pool to withstand the pressure of the water. The container is made up of an aluminum cone-shaped transition section near the core and steel sections in the shielding wall. The aluminum section is tapered on the sides so as to not interfere with the beam ports. The thermal column contains (from inside out) many blocks (stringers) of graphite, lead shielding bricks, and a final light-water tank, which is recessed about $15 \mathrm{~cm}$ into a heavyconcrete wall. All of these internals must be removed to make room for the epithermal neutron filter.

\section{THERMAL COLUMN REMOVAL}

The thermal column had not been removed for many years, necessitating an investigation to see how difficult removal would be. Questions on the radiation level inside the liner also needed to be answered. WSU personnel drained and removed the water wall separating the beam room from the thermal column. A few of the tightly fitting lead bricks along the top were then removed, and probes were inserted along the liner as far as possible into the thermal column to measure the radiation levels (the reactor was shut down and moved to the center of the pool). The radiation levels were low enough that workers will be able to work extended periods of time in the thermal column to remove the lead and graphite. The graphite stringers are wedged in tightly and may be difficult to remove, or may break when removed, creating carbon dust which may be contaminated. Therefore, a removal plan including contamination control must be developed before this task can proceed.

After the graphite stringers and lead bricks are removed, the empty thermal column must be cleaned and the inside measured carefully. The actual dimensions must be known before fabricating the filter components. The boral (boron carbide/aluminum) liner that covers the steel liner should be left in place to reduce activation in the steel liner and concrete. The lead thermal shield in the area adjacent to the core should also be left in place to reduce gamma streaming.

\section{NEUTRON FILTER DESIGN}

The goal of the WSU reactor epithermal neutron filter conceptual design effort was to provide a low cost, simple filter design that is easy to fabricate and install while meeting or exceeding the nuclear performance requirements of the BNCT program. A design approach was selected that allows the filter to be pre-assembled to verify interfaces prior to installation at the reactor. The filter will be assembled in layers to allow for easy handling while working in the empty thermal column. The filter can also be easily disassembled and reconfigured to allow for future adjustments in the nuclear performance.

The conceptual neutron filter design is shown in Figure 3. The reactor core is positioned at the far left of the figure, and the patient's head is placed at the far right of the figure against the right end of the collimator. Neutrons and gamma rays born in the core stream through the various filter components before arriving at the patient's head. The final design selected consisted of alternating $6.35 \mathrm{~cm}$ (1/4 inch) 


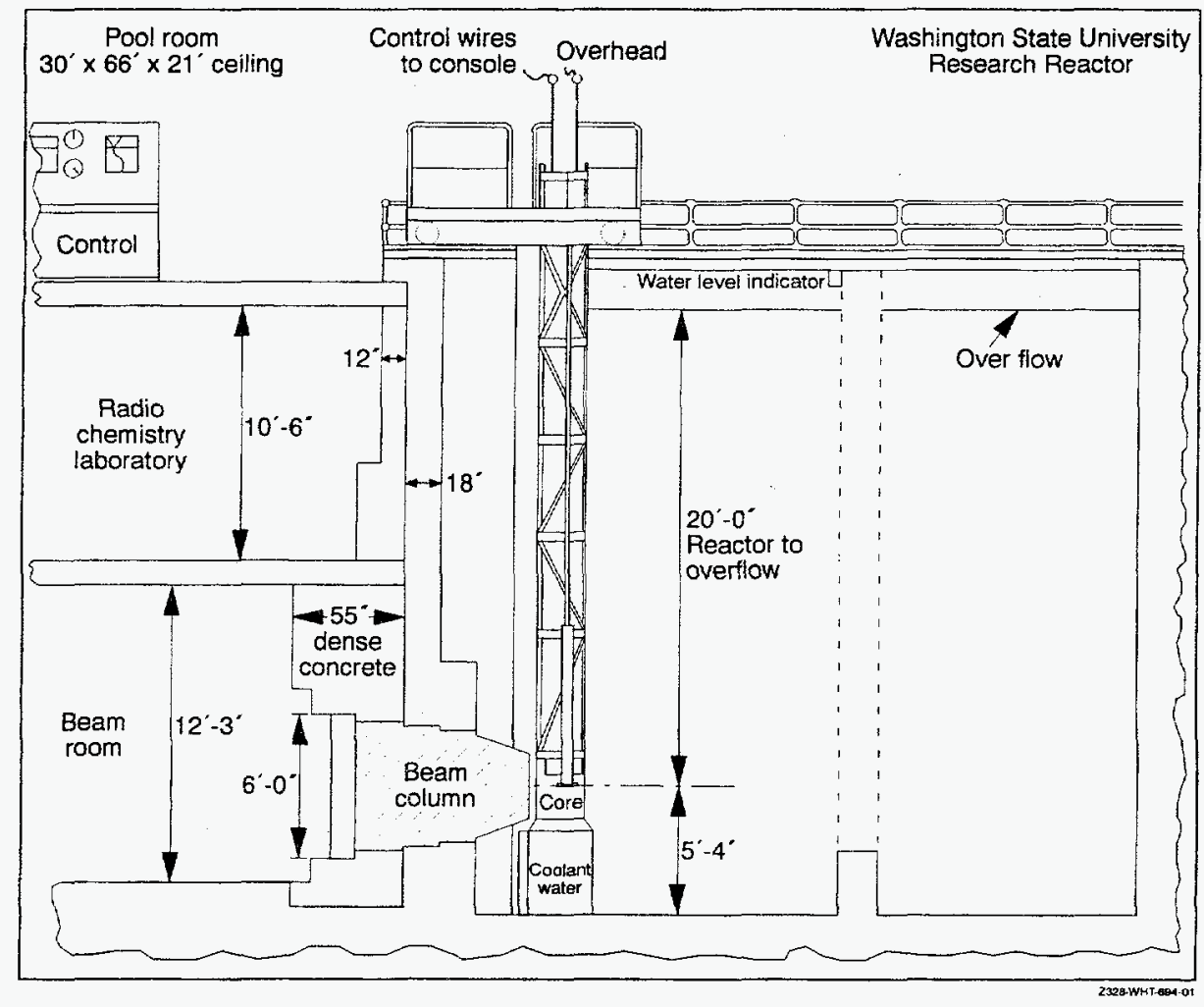

Figure 1. WSU reactor elevation plan.

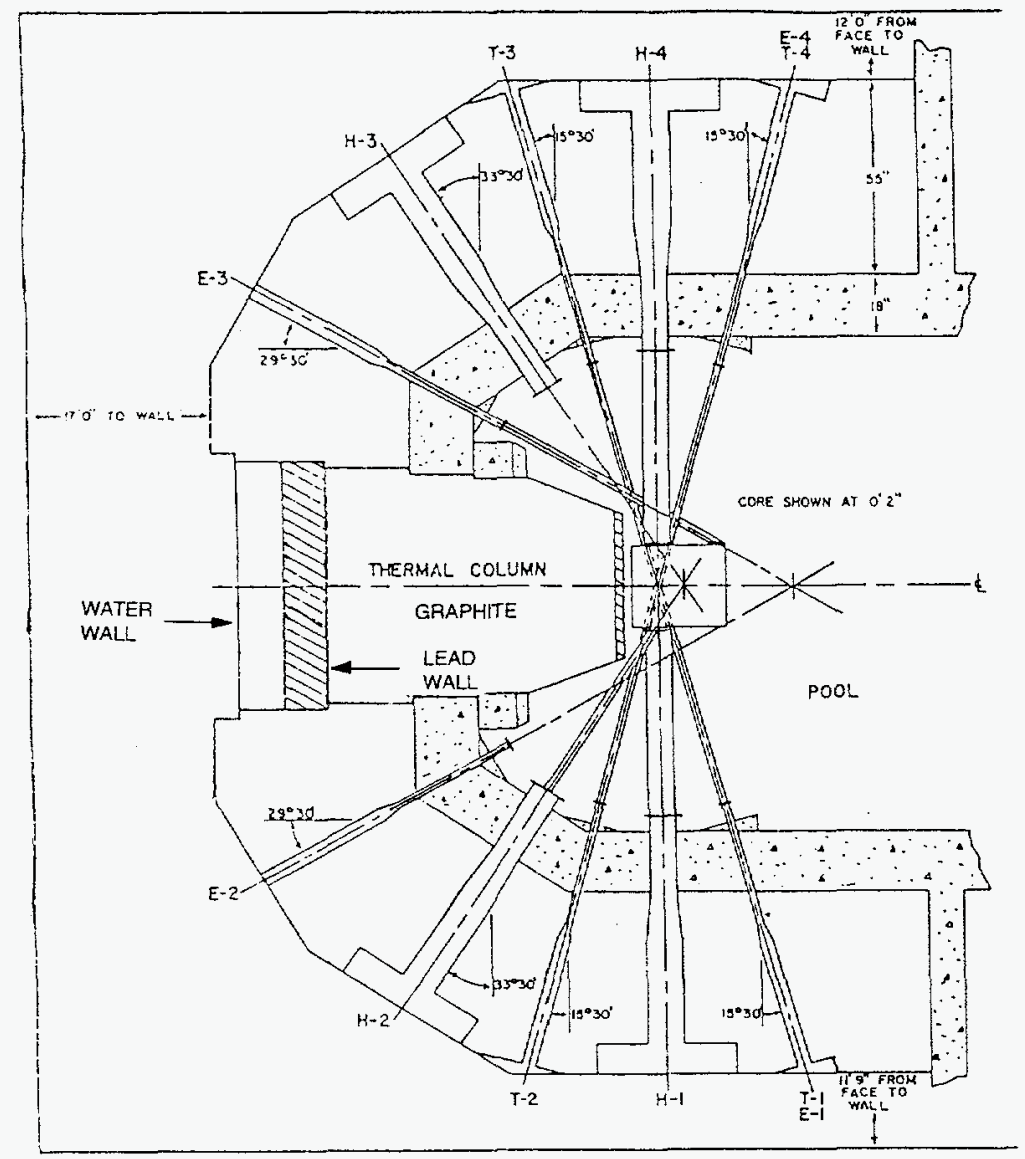

Figure 2. WSU Reactor Core, Thermal Column and Beam Tubes. 


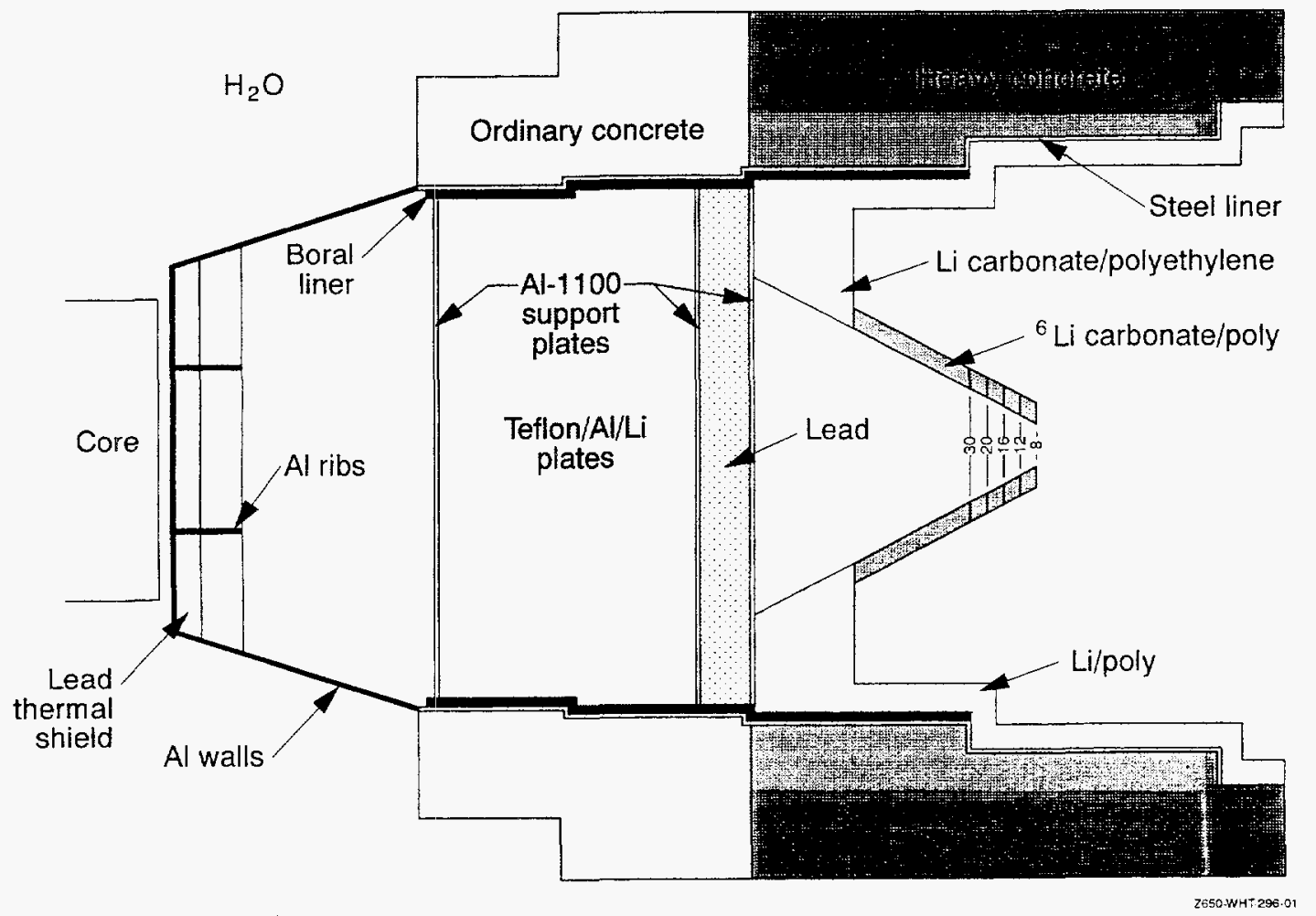

Figure 3. WSU Column Assembly with Epithermal-Neutron Filter.

thick sheets of pure aluminum (Al 1100) and Teflon $\left(\mathrm{CF}_{2}\right)$. Most of the fast neutrons are moderated to epithermal and thermal energies as they scatter through the plates of aluminum and Teflon. Because thermal neutrons are not desired at the surface of the patient, a material that absorbs thermal neutrons is also required in the filter. Similarly, gamma rays are not desired at the patient's head. Many of these gammas will be absorbed in the dense lead shields. The patient then will receive an appropriate dose of epithermal neutrons along with undesirable, but tolerable, doses of fast neutrons, thermal neutrons, and gamma rays.

\section{Purge Lines}

After construction air will fill the empty space between the lead thermal shield and the beginning of the aluminum/Teflon plate assembly. During reactor operation, argon-4l will be produced in this air space. To avoid the argon- 41 production, an air purge system will be installed to remove the air from the space in front of the filter. Nitrogen was selected as the best purge gas to use. Other gases such as helium and neon are too expensive, even though they may be superior from an activation standpoint. Purge tubes will be located in the top and bottom of the filter assembly to allow nitrogen gas to be circulated through the volume. The tubes will be routed through staggered slots in the filter assembly immediately adjacent to the boral liners so that there is no shine path from the reactor to the room.
Ten volume exchanges will be required to effectively remove the air. The exhausted air and nitrogen will be routed to the facility exhaust. The nitrogen will be supplied from compressed gas cylinders.

\section{Filter Component Selection}

The aluminum-Teflon combination was selected because it produces good beam characteristics, and the materials are available and not too expensive. However, consensus about induced radiation damage in the Teflon filter material led to the conclusion that Teflon cannot be depended on for structural strength. In addition, although the basic integrity of Teflon is maintained at the radiation fluence levels expected in the proposed facility, experiments show that some fluorine will be released upon irradiation. The fluorine is expected to quickly bond to the adjacent sheets of aluminum.

A thermal neutron absorber is required in the filter sandwich region to reduce the number of thermal neutrons streaming toward the patient, and to eliminate many of the gamma rays produced by thermal neutron capture in aluminum. Natural lithium was selected as the best thermal neutron absorber because few gamma rays are released in the process (neutron capture in lithium-6 produces tritium). Approximately $2 \%$ by weight of natural lithium is required to provide the absorber. However, an issue remains how to get natural lithium 
in or on the aluminum plates. Alcoa produces aluminum lithium alloy (Al 2090), which is 1.9-2.6 wt \% Li. However, Al-2090 is quite expensive (33 to $78 \$ / \mathrm{kg}$ ) and difficult to form into sheets. About $1000 \mathrm{~kg}$ of Al-2090 will be required, so alternatives were investigated. The Savannah River Site (SRS) has excess lithiated aluminum available. However, the quality assurance records documenting the composition of this material may not be available. In addition, this material is not in the desired form, and would need to be shipped to and fabricated into sheets by a company such as Alcoa. Alcoa considers Al-2090 plates difficult to fabricate (and therefore expensive) because the lithium produces a hard alloy.

An alternative is to spray lithium onto sheets of Al1100. Lithium fluoride (LiF) is available, inexpensive, and can probably be plasma sprayed onto aluminum sheets. Tests of spraying $\mathrm{LiF}$ onto aluminum will establish the feasibility of this process. If the process works well, comparison of the cost of spraying $\mathrm{LiF}$ onto Al-1100 with the cost of purchasing Al-2090 will be made. Other items such as the lithium distribution and the overall time required to obtain the desired product will also be compared.

Finally, if lithium cannot be used within the available budget, thin sheets of cadmium as a thermal neutron absorber can be substituted. Cadmium is an excellent thermal neutron absorber, but hard gammas are given off in the process. Therefore, thicker lead or bismuth shielding would be required to attenuate the gammas, slightly reducing the neutron beam performance.

MCNP calculations were also conducted to evaluate the performance of gadolinium as the thermal neutron absorber in the neutron filter. Based on these calculations, gadolinium is not a suitable thermal neutron absorber for this application.

The thickness of the aluminum plates was examined from the neutronics standpoint. The region containing aluminum, lithiated aluminum, and Teflon plates was originally analyzed as homogeneous in the neutronics models. Heterogeneous calculations show that the homogeneous model is reasonable accurate, and that the use of $6.35 \mathrm{~mm}$-thick plates is acceptable. This means that thinner plates are not required, easing the problem of assembly.

For the first filter constructed at WSU, lead will probably be used instead of bismuth to provide gamma shielding. Lead performs almost as well as bismuth, is less expensive, and is easier to handle after irradiation. The bismuth supply currently exists as cast ingots, which are not square and cannot be stacked. The bismuth must be melted, cast into larger blocks, then clad with aluminum. The cladding is desired because polonium-210 is produced upon irradiation of bismuth. It may be difficult to find a foundry willing to perform this task, and the task could be expensive. Lead bricks are already available at WSU, but they should be tested to determine the neutron activation from the impurities.

\section{Filter Construction and Assembly}

The filter will be assembled by attaching the front aluminum support plate in the thermal column penetration. The front support plate will have a rim welded to all four sides to form a "U-like" assembly, which can be attached to the existing reactor penetration boral liner. The attachment is made using screws that pass through pre-drilled holes in the front support plate and are secured in the boral liner, with great care taken not to penetrate the water seal. The screws are located along the entire perimeter of the support plate. The front support plate must be aligned perpendicular to the penetration. Any gaps between the front support plate and the reactor penetration walls will be filled with lead wool to eliminate streaming paths.

After the front support plate is in place and aligned, the filter "sandwich" can be assembled one plate at a time. The filter sandwich plates are $6.35 \mathrm{~mm}$ thick and are assembled in the following repeating order: $\mathrm{Al}, \mathrm{CF}_{2}, \mathrm{Al}+2 \% \mathrm{Li}, \mathrm{CF}_{2}, \mathrm{Al} ; \mathrm{Al}, \mathrm{CF}_{2}, \mathrm{Al}+2 \%$ $\mathrm{Li}, \mathrm{CF}_{2}, \mathrm{Al}, \ldots \mathrm{Al}$. There are 44 aluminum 1100 plates, 22 aluminum $/ 2 \%$ lithium plates, and 44 Teflon plates. Each aluminum plate will be attached to the previous aluminum plate with aluminum screws. The two piece construction is required because of the $1.2 \mathrm{~m}$ limits on the size of material that can be procured. The joints and the screws are staggered for each successive layer of the filter to avoid streaming paths. In addition, any gaps between the filter sandwich and the reactor penetration wall will be filled with lead wool to avoid streaming paths. The steel and boral liners are stair-stepped, which will also help reduce streaming paths from the reactor.

The filter could be prefabricated and assembled off site if the interior column measurements are accurately known, then disassembled and transported to WSU for re-assembly. The process of fabricating and putting the sandwich together will be labor intensive because of all the plates that must be cut and the many holes that must be drilled and tapped. Pre-assembled multi-layer sandwiches quickly become too heavy to manually be positioned inside the thermal column. Vacuum handles will be used to lift each plate into place in the thermal column. Fastening all layers together with screws will create a structurally sound block. 


\section{Lead Gamma Shield}

The next section to be installed will be the lead shielding. This section is $10.16 \mathrm{~cm}$ thick and is constructed of bricks that are $6.35 \times 10.16 \times 20.32$ $\mathrm{cm}$ in size. The bricks will be stacked behind the last aluminum plate in the filter sandwich. Because the stack of bricks will be about $1.5 \mathrm{~m}$ high, a small amount of silicone adhesive will be used to adhere the bricks to themselves and to the aluminum plate. This approach should ensure that the stack does not fall down during assembly. After the lead brick shield is in place, the back support plate will be positioned adjacent to it to provide permanent support to the bricks. The back support plate (aluminum 1100) is fastened to the boral liner with screws in the same way as the front support plate.

\section{Collimator Assembly}

The next item to be installed will be the collimator assembly. The collimator directs epithernal neutrons towards the aperture and absorbs thermal neutrons. The collimator will be constructed of lithium 6 loaded polyethylene slabs. The lithium- 6 is contained in highly enriched lithium carbonate $\left(\mathrm{Li}_{2} \mathrm{CO}_{3}\right)$ distributed within polyethylene. The hydrogen in the polyethylene moderates neutrons to thermal energies, and the Li- 6 absorbs the thermal neutrons without producing undesirable gamma rays.

Since polyethylene slabs are much easier to fabricate than a large polyethylene cone, the collimator will be made of 4 flat sheets of the lithium- 6 enriched polyethylene fastened together at the edges with polyethylene screws to form a pyramid shape. The bottom sheet will be supported by a polyethylene structure that holds the entire assembly in place against the filter. The support structure will have built-in slots to allow the collimator assembly to be handled with a forklift and be placed in the reactor penetration. The final section of the filter is the lithium- 6 enriched polyethylene sections that set the final diameter (delimiter) of the epithermal-neutron beam. These sections are $7.62 \mathrm{~cm}$ thick, are square on the outside and have a tapered round hole on the inside. The outlet hole diameters are $8,12,16,20$ and $24 \mathrm{~cm}$. These sections will be attached to the collimator using polyethylene screws at the four corners. The collimator will be locked into place via screws in the boral liner.

A series of calculations were performed to analyze the performance of different collimator designs. The collimator design with flat plates is acceptable, however, a circular cone is needed at the very end. The end tip should come out at a constant cone angle. Excess material on the outer edges of the cone tip should be removed to allow better positioning of the patient. The calculations indicate that an excellent beam can be obtained recessed some distance into the thermal column. There are two significant disadvantages, however, to the recessed beam: (1) patient positioning capability, and (2) higher background-dose exposure to patient and therapist.

Optimization studies were conducted on the shape and size of the collimator. Several collimator configurations were examined and compared to the base case to determine if the gains justified the expense involved in manufacturing and materials.

The different collimator geometries are characterized by two parameters: the focal length and the viewing area. The focal length is defined as the distance from the base of the collimator to the apex of the inner pyramid. The viewing area is the area of the base of the inner pyramid. The performance parameters of interest are the current-to-flux ratio at the aperture (which measures the forward-bias of the beam), the thermal and fast flux to epithermal flux ratios (which measure the beam contamination levels), the beam intensity (defined here as the epithermal flux), and the neutron and gamma doses in brain tissue at the aperture (which define the performance in actual irradiations).

The viewing area was varied at constant focal length to determine whether simply viewing more of the exiting neutrons from the filter could increase the beam intensity. The beam epithermal flux and aperture neutron dose increase as the viewing area increases. The focal length was also increased to place the aperture at the entrance to the beam stop to improve the current-to-flux ratio. These results demonstrate that the beam performance cannot be easily enhanced by simple variations of the collimator configuration. Either the beam intensity or the current-to-flux ratio can be improved slightly, but there is always a penalty paid on the other parameter. For example, extending the aperture out to the beam stop entrance increases the current-to-flux ratio by about $10 \%$, but at the cost of a factor of three loss in beam intensity, primarily because of the increase in focal length. The present collimator design provides a reasonable match to the design goals.

Other calculations show that enriched lithium must be used at the aperture end of the collimator. The design goal for gamma dose cannot be achieved with only natural lithium/polyethylene. The use of $\mathrm{Li}-6$ in the collimator will substantially improve the filter performance.

\section{Column Wall Lining}

The reactor penetration perimeter (column wall) adjacent to the collimator must be lined on all four 
sides with $5.08 \mathrm{~cm}$ of natural lithium/polyethylene sheets to prevent neutron interaction with the reactor concrete and other structural materials. The bottom will be lined first, followed by the sides and the top. The pieces will be fastened together using polyethylene screws. The side sections will be stepped to allow the top sections to interlock and be supported by these sections. Additional sheets of natural lithium/polyethylene will then be placed as needed up against the lead wall, surrounding the base of the collimator. This will help reduce the neutron whole body dose to the patient.

\section{Calculated Performance}

The neutron spectrum at the collimator aperture is shown in Figure 4. A high epithermal neutron flux is achieved with minimum fast and thermal neutron contamination. Table 1 presents the calculated values of several parameters at the aperture. Reasonable agreement is achieved between the MCNP Monte Carlo code and the DORT discrete ordinates code.

\section{Treatment Room Design}

A treatment room, or beam stop, must be constructed around the beam facility to isolate the radiation field and reduce radiation to acceptable levels in all other areas of the facility. The radiation dose rates outside the treatment room must be less than $1 \mathrm{mR} / \mathrm{hr}$ at the viewing window, $5 \mathrm{mR} /$ day at the side wall of the treatment room, and $10 \mathrm{mR} / \mathrm{hr}$ at the back wall of the treatment room (exclusion zone).

The dimensions of the treatment room are shown in Figure 5. The entry does not require a heavy door shield because this area is an exclusion zone (no personnel other than the patient may enter during reactor operation), and an earthen berm rests against the outside of the building. The room walls and ceiling will be cast-in-place normal concrete containing a neutron absorbing boron compound (borosilicate glass). The thick-walled room will therefore be permanent. The room size was selected based on shielding calculations, the need for patient access, and the need for a hallway around the treatment room for construction and patient maneuvering.

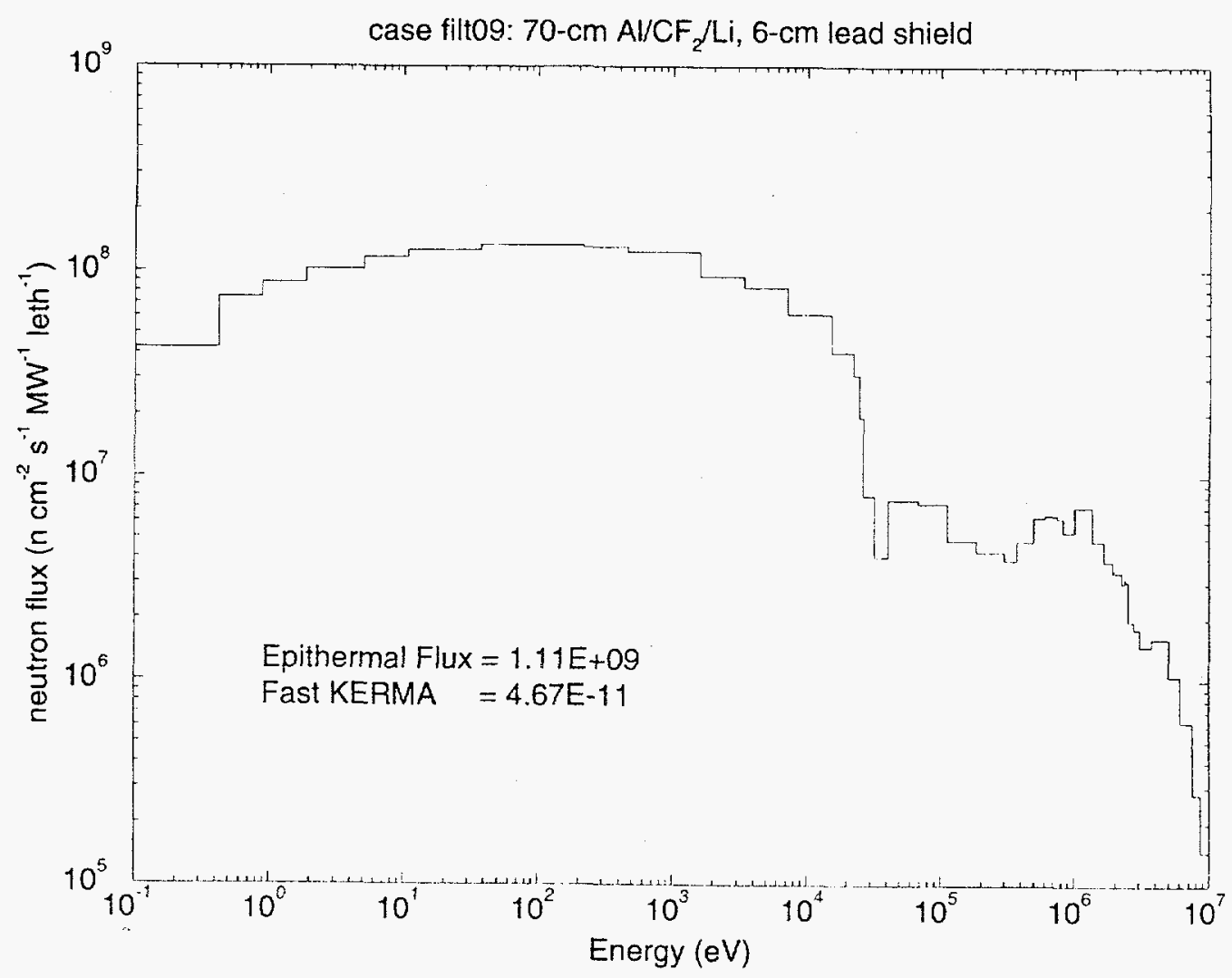

Figure 4. WSU Epithermal Beam: DORT Neutron Spectrum. 
Table 1. Beam parameters at the collimator aperture for a comparison case (focal length $=80.91 \mathrm{~cm}$; viewing area $=100 \mathrm{~cm} \times 100 \mathrm{~cm}$; lead shield $=6 \mathrm{~cm}$ ).

\begin{tabular}{lll} 
Parameter & MCNP & DORT* \\
\hline $\begin{array}{l}\text { Thermal flux } \\
\left(\mathrm{cm}^{-2} \mathrm{~s}^{-1}\right)\end{array}$ & $1.087 \times 10^{8}$ & $1.991 \times 10^{8}$ \\
$\begin{array}{l}\text { Epithermal flux } \\
\left(\mathrm{cm}^{-2} \mathrm{~s}^{-1}\right)\end{array}$ & $1.085 \times 10^{9}$ & $1.106 \times 10^{9}$ \\
$\begin{array}{l}\text { Fast flux } \\
\left(\mathrm{cm}^{-2} \mathrm{~s}^{-1}\right)\end{array}$ & $6.249 \times 10^{7}$ & $7.205 \times 10^{7}$ \\
$\begin{array}{l}\text { ICRU brain tissue } \\
\text { neutron dose (cGy/hr) }\end{array}$ & 234.8 & 185.82 \\
$\begin{array}{l}\text { ICRU brain tissue } \\
\text { gamma dose (cGy/hr) } \\
\text { Current to flux ratio }\end{array}$ & 131.9 & 132.3 \\
\hline * Case 9 results; current to flux ratio crudely estimated from balance tables. & \\
\hline
\end{tabular}

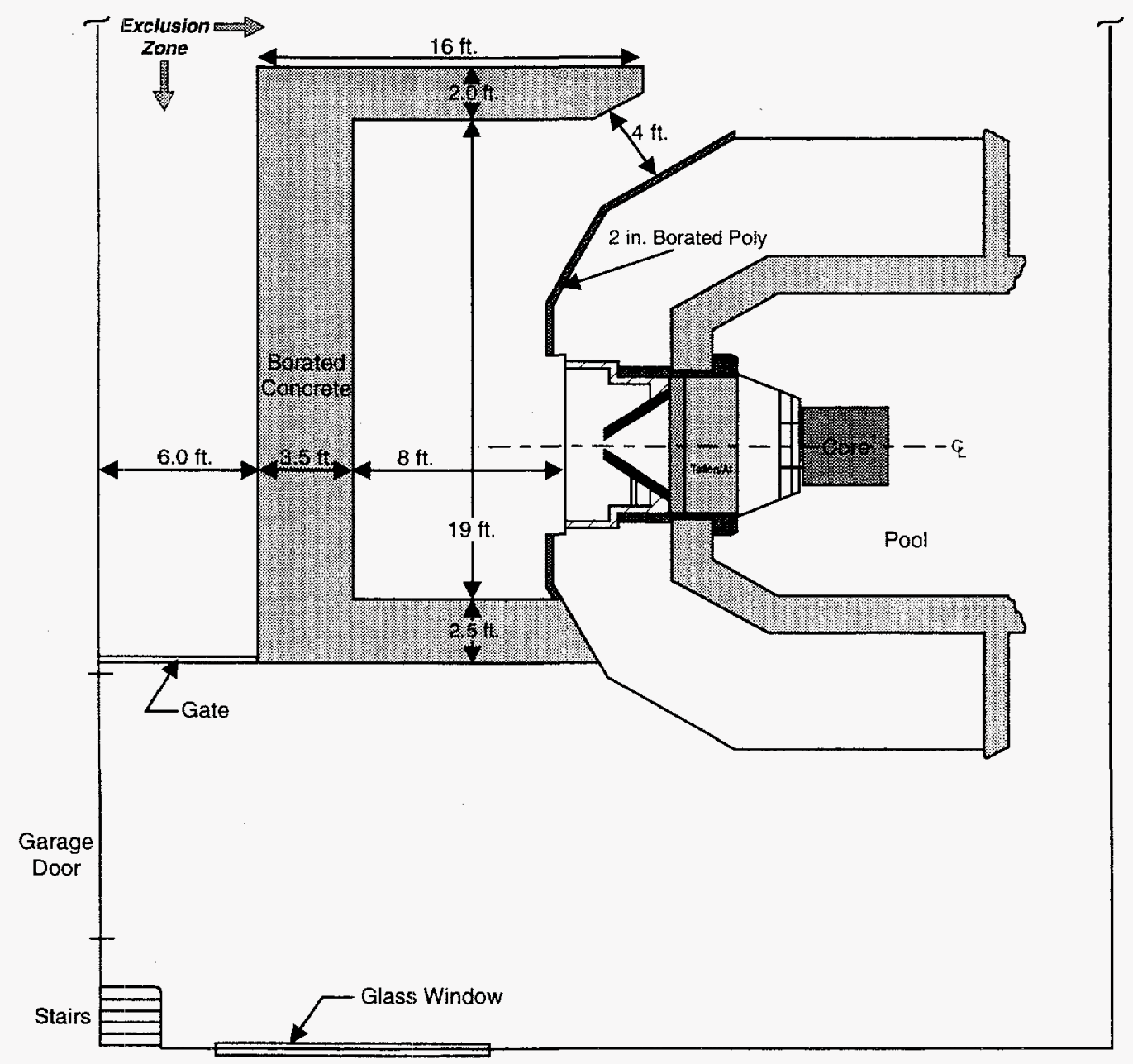

Figure 5. Approximate WSU treatment room layout. 
Seismic requirements preclude the use of nonreinforced concrete blocks for the treatment room shielding. Normal concrete is less expensive than high density concrete and is more easily poured. Normal concrete can be pumped into the treatment room walls and ceiling. High density concrete requires increased manual labor to place and may be susceptible to voids, which affects its shielding capabilities. Therefore, normal concrete with borosilicate glass is desired. A geotechnical engineering evaluation is proposed to assess the subsurface soil conditions in the treatment room area and to provide recommendations that assist project planning and design. About $1 \mathrm{~m}$ by $1 \mathrm{~m}$ trenches of existing soil may need to be excavated before the wall foundations can be placed. This should not be a big problem, but it could be labor intensive due to the limited heavy equipment access within the building. Preliminary investigation indicates that undisturbed soil under the existing concrete floor can remain in place. The site soil can be evaluated by drilling 4 borings within the current beam room. Additionally, the compressive strength of the existing concrete can be assessed.

Jack hammers may be required to break up parts of the existing concrete floor in order to pour the concrete walls. This could cause vibration in the thermal column area that could possibly lead to the collapse of the filter sandwich components. This can be avoided placing the concrete before installing the neutron filter. This will also reduce the dust in the neutron filter. The $12.7 \mathrm{~cm}$ thick floor slab is independent of the thick high density concrete around the thermal column. This will help reduce the vibration in the thermal column area. The cast-inplace concrete must be cured, unloaded, typically for 1-2 weeks.

Steel beams could be used to support the ceiling, but they would become activated. A $30.5 \mathrm{~cm}$ thick reinforced concrete ceiling can span $3.66 \mathrm{~m}$. Therefore, the use of structural steel beams will be avoided. The reinforcing steel in the concrete can be placed $8 \mathrm{~cm}$ from the inner concrete surface, which will greatly reduce its activation.

A detailed three-dimensional MCNP model of the treatment room layout has been developed. Calculations of neutron dose and gamma dose at various positions outside the treatment room are presented in Figure 6. These doses are acceptable, especially if the exclusion zone keeps personnel away from the treatment room opening. Further calculations will be performed to ensure that the skyshine to the floor above the beam room are acceptable. Good agreement between MCNP and DORT was obtained for neutron and gamma dose rates along the outer back wall of earlier versions of the treatment room. This provides good confidence for the shielding calculations.

\section{NEW FUEL LOADING PATTERN}

A new fuel loading pattern that increases the neutron flux on the surface of the reactor core facing the neutron filter has been selected. Preliminary calculations on the new core configuration surrounded by water were performed using the EXTERMINATOR II diffusion code. There are several features to check with calculations to make sure that the core would not violate the reactor Technical Specifications and would be viable. First, the calculated core excess reactivity was $\$ 6.56$, which meets the requirement to be $<\$ 8.00$. Second, the ratio between the power in the hottest fuel element relative to the instrumental fuel element has to be < 1.5. It was calculated to be 1.437 in the worst case. Third, the distribution of thermal flux is acceptable for the instrumentation on the core comers. Fourth, the distribution of flux on the control blades is acceptable. Finally, the thermal flux in the irradiation tubes, although a little lower, is acceptable.

MCNP calculations show the reactivity impact of moving the reactor (with the new fuel configuration) away from the thermal column and towards the center of the pool. The core reactivity drops slightly and is relatively insensitive to core movement. This implies that it is safe to move the operating reactor away from the thermal column, but not toward it.

\section{REACTOR FACILITY MODIFICATIONS}

Several modifications must be made to the reactor facility before using it for human therapy. For example, the Nuclear Regulatory Commission (NRC) suggests using shutters on neutron filters to stop the radiation during an emergency (independent of reactor scram). There is no beam shutter in the present facility, and it would be a major campaign to construct a large shutter. It is deemed not necessary to have a shutter for the WSU concept because the reactor can be scrammed to a small percentage of full power in a matter of seconds. The reactor core then can be retracted several feet back into the center of the pool and away from the thermal column in just a few seconds to reduce the gamma field even more. The reactor bridge and core movement can be made automatic by installing an electric motor drive system. A shutter device (possibly flooding the cone or rotating the filter) could be designed, but it may not be very practical. 


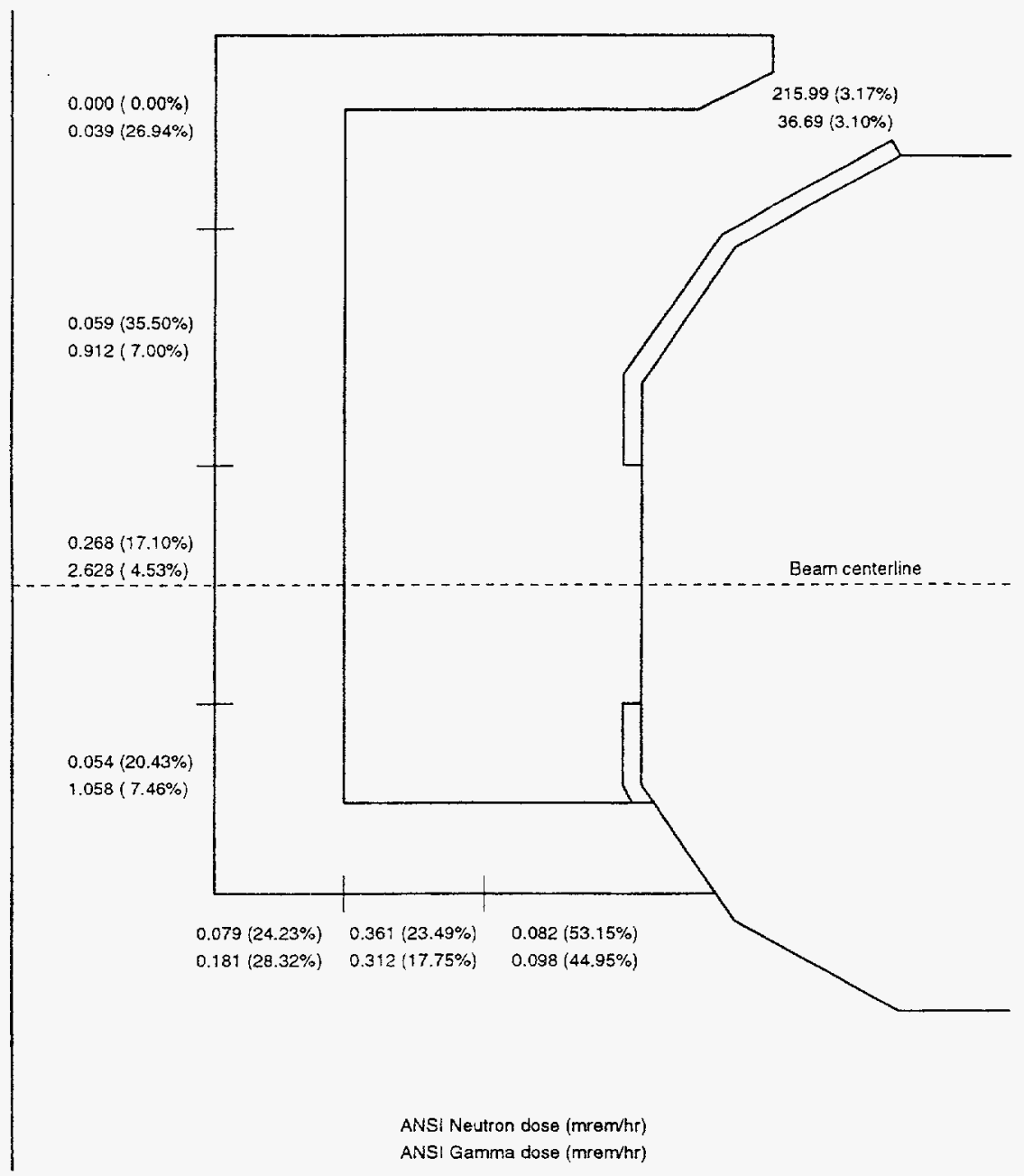

Figure 6. WSU Beam Stop Dose Map (12/11/95).

The NRC has requested additional information on the proposed revision to the WSU TRIGA Technical Specifications. The most difficult questions are: "How rapidly must the bridge move to shut off the neutron beam compared, for example, to a shutter? What are the design criteria for this function?" The traverse time of the shutter at Brookhaven National Laboratory is 10 to 11 seconds. This is negligible compared with patient treatment times of several tens of minutes. By exerting a steady force of 44 Newtons $(10 \mathrm{lb}$.) on the bridge crank at WSU, the bridge can be moved $30 \mathrm{~cm}$ in 8 seconds. MCNP calculations show that the neutron flux drops by two orders of magnitude as the core moves back $30 \mathrm{~cm}$ (at full power). With reactor scram, the drop will be much greater. The $30 \mathrm{~cm}$ of water will also decrease the gamma flux by about a factor of 2 . With a lower number of neutrons in the filter region, even fewer gammas will be produced from neutron capture in the filter. Thus, movement of the bridge with concurrent reactor scram provides an effective method of reducing the dose to the patient in an emergency.

\section{FACILITY APPROVALS}

Several approvals must be received from different groups. The WSU Reactor Safeguards Committee has approved the new fuel loading and the addition of a beam room scram button to the SCRAM chain. Approvals must also be obtained from the NRC and Food and Drug Administration (FDA) before human therapy can be performed.

\section{SUMMARY}

A conceptual design has been developed for the WSU epithermal neutron beam extraction facility. This facility will be used first for animal studies of Boron Neutron Capture Therapy and then eventually for human clinical trials. This design contains novel features that have not been used in other neutron filter designs. The design achieves (calculated) an acceptable epithermal neutron flux within tolerable neutron and gamma whole body doses. Except for changing the fuel loading pattern, no core modifications are required. A treatment room with 
thick concrete walls and ceiling will be constructed to keep the radiation dose to the outside facility walls and staff at an acceptable level. No technical or procurement obstacles are foreseen that would prevent completion of this project. Completion of these modifications will lead to a world-class facility for BNCT research. 


\section{TREATMENT PROTOCOL DEVELOPMENT}

\author{
C. Johnson, P. Gavin, DVM, PhD, PI, WSU, \\ College of Veterinary Medicine (CVM)
}

\section{Tumor Treatment Dogs}

Three dogs with spontaneously occurring brain tumors were treated with BNCT in CY 1995. All three dogs had p-BPA-fructose infusion prior to their neutron irradiation treatment. As of February 1996, all 3 dogs are doing well. The first dog had BNCT alone (no surgery). The nine month MRI scan revealed an area of enhancement, which is either slow regrowth of the tumor or scar tissue from an earlier surgery. The twelve month scan will tell more. The second dog received a combination of surgical debulking of the tumor followed by BNCT. At six months the dog was clinically normal and the MRI revealed the enhancement area regressing. The third dog also received a combination of surgical debulking and $\mathrm{BNCT}$, and was clinically normal at two months post treatment.

An earlier dog treated with BNCT (no surgery) in October of 1989 was euthanzied 5.3 years post treatment due to return of neurological symptoms which were not controllable with medications. A second dog which received BNCT with p-BPAfructose alone is stable at $1+$ years post treatment.

\section{Normal Tissue Tolerance Dogs}

Research continued on normal tissue tolerance by using non-tumor bearing dogs. Three groups of dogs were used. The first group completed the fractional BNCT studies. These dogs were irradiated in four factions, 24 hours apart, to a peak physical dose of 2392 - 2423 cGy, with average blood boron concentrations $24-33 \mathrm{ug} / \mathrm{g}$. An intravenous infusion of BSH at $25 \mathrm{mg} / \mathrm{kg}$ body weight was administered prior to each irradiation. These four dogs had skin biopsies at sites on the edge of the radiation field immediately following irradiation on days two, three and four. The skin biopsies revealed a trend toward higher skin boron concentration on each subsequent treatment. The hair regrowth at the biopsy sites was sparser than rest of the head in all four dogs. All four dogs at three and half months had CT scans due to slight behavioral changes in two of the dogs. These two dogs also had MRI scans, due to enhancing areas on the CT. These same two dogs were euthanzied due to neurological changes, one at three and half months post treatment and the second one at five months post treatment. The other two dogs had no changes on MRI, CT or neurological exams in three and half months. With the six month MRI, one dog had an enhancing area in the right cerebral cortex. The neurological exam showed a slight sluggishness of proprioception on the left hind leg. The other dog had no changes on MRI or neurological exam. The dog with changes at six months revealed no enhancement of this area on the MRI at twelve months post treatment. Also the neurological exam was normal. The other dog had no changes on the MRI or on neurological exam at twelve months post treatment.

Groups two and three completed the tolerance studies on the lower doses. Four dogs were used in each single dose radiation study. Dogs in the second group were treated to a peak physical dose of 1447 $1460 \mathrm{cGy}$. Dogs in the third group were treated to a peak physical dose of $1231-1259 \mathrm{cGy}$. The average blood boron concentration was between $8-11 \mathrm{ug} / \mathrm{g}$ in both groups. With the higher dose group, two of the dogs have normal MRI and the other two have superficial changes on the MRI at six months post treatment. Three of the dogs have early signs of a cataract in the right eye at six months. The rest of the neurological exams were normal. The lower dose group dogs have no changes on the six month MRI, but three of these dogs have changes on the neurological exams. Two of these dogs have reduced proprioception, one with deficits in both left and right front and hind legs, and one with deficits in the right hind leg. The third dog has early cataract in the right eye, also the menace response is absent in the left eye while the right eye is reduced. The fourth dog had a normal neurological exam.

All of these dogs will be monitored for further changes. 


\section{BORON-11 MAGNETIC RESONANCE IMAGING IN TUMOR-BEARING ANIMALS AND HUMANS}

\author{
M. P. Schweizer, Ph.D., PI, Departments of \\ Medicinal Chemistry and Radiology, University \\ of Utah (U of $U$ )
}

The present report highlights progress within 1995 as well as serving as a summary of the major accomplishments during the five years of support to $\mathrm{U}$ of $\mathrm{U}$ from INEL. Three major areas are considered:

1. Determination of BSH Pharmacokinetics in the Canine Brain Tumor Model. Major accomplishments: development of a noninvasive quantitative method for BSH pharmacokinetics.

2. BSH Pharmacokinetics in Human Patients with HighGrade Brain Tumors. Major accomplishments: demonstrate the ability to non-invasively follow BSH uptake and elimination in high grade human brain tumors.

3. Boron-11 MRI of Several BNCT Agents in Rats. Major accomplishments: focus on the ratmodel permitted direct online observations of pharmacokinetics of several BNCT agents in tumors and organs of elimination non-invasively.

All imaging work was carried out on a General Electric SIGNA clinical MR scanner in the $U$ of $U$ MRI Center of the Department of Radiology. Coils of the appropriate dimensions incorporated the inductively driven quadrature birdcage design. Boron11 image data at a frequency of $20.5 \mathrm{MHz}$ were acquired and reconstructed using the $3 \mathrm{D}$ Projection Reconstruction (3DPR) method ${ }^{3}$. All boronated compounds examined were natural abundance $(80 \%$ boron-11 isotope). The BSH was mostly from Boron Biologicals, obtained from the INEL after thorough purity analysis by Dr. Bill Bauer. INEL also provided all the inductively coupled plasmaatomic emission spectrometry (ICP-AES) analyses. Para-borono-L-phenylalanine (1-BPA) was a gift from Dr. Jeff Coderre, Brookhaven National Labortory. Dr. Fred Hawthorne, University of California, Los Angles supplied liposome encapsulated $\mathrm{B}_{20} \mathrm{H}_{17} \mathrm{NH}_{3}$.

1. BSH Distribution and Pharmacokinetics in the Canine Brain Tumor Model.

\section{Experimental Protocols}

A total of 26 normal and implanted black Labrador Retrievers have been imaged under isoflurane anesthesia. Dogs in the later stages of the studies were under tight respiratory control, with physiological parameters such as end-tidal $\mathrm{CO}_{2}$, mean arterial blood pressure, blood gases and heart rate all monitored and regulated. All were infused into cephalic veins with $100 \mathrm{mg} / \mathrm{kg}$ boron (as BSH) in saline at a dose rate of $3 \mathrm{mg} / \mathrm{kg} / \mathrm{min}$. Boric acid reference tubes were taped to the head. During the 60 minute infusion period standard proton MRIs were recorded for anatomical referencing.

Tumor bearing dogs were prepared via implantation of approximately one million gliosarcoma cells into the parietal parenchyma using injection ready aliquots obtained from Dr. John Hilton, Division of Oncology, The Johns Hopkins Medical School. After periodic proton MRI exams (including gadolinium contrast) to follow tumor growth, boron11 imaging was conducted $8-10$ days postimplantation (when tumor diameters were $1-2 \mathrm{~cm}$ ) using the 3DPR algorithm. Individual time points in the uptake, redistribution and elimination phases were taken at 20 minute intervals, beginning just at the end of infusion and extending several hours postinfusion. Each time point scan required nine minutes, which, with an elimination half-life of around four hours, provided reasonable time resolution. Venous blood, for ICP-AES analysis of boron content, was also periodically drawn. Necropsies were done and tissue boron content determined by ICP-AES analysis.

\section{Results}

Representative image data for a dog with a $2 \mathrm{~cm}$ enhancing lesion in the left parietal lobe is shown in Figure 7 . The axial proton image is at the right, showing the tumor with overlaying surgically traumatized temporalis muscle and the central boric acid reference. On the left is a composite of the boron-11 image (taken at the end of the infusion) data and the filtered proton data. BSH uptake into tumor as well as inflamed temporalis, oral and nasal mucosa, tongue and other vascularized tissue is readily apparent. The intact blood-brain-barrier of normal brain is not breached, as is well known for this ionic borane. Due to the low sensitivity of boron-11 (over one million times less sensitive compared with hydrogen nuclei), the in-plane resolution of the boron images is only $7.5 \mathrm{~mm}$. 

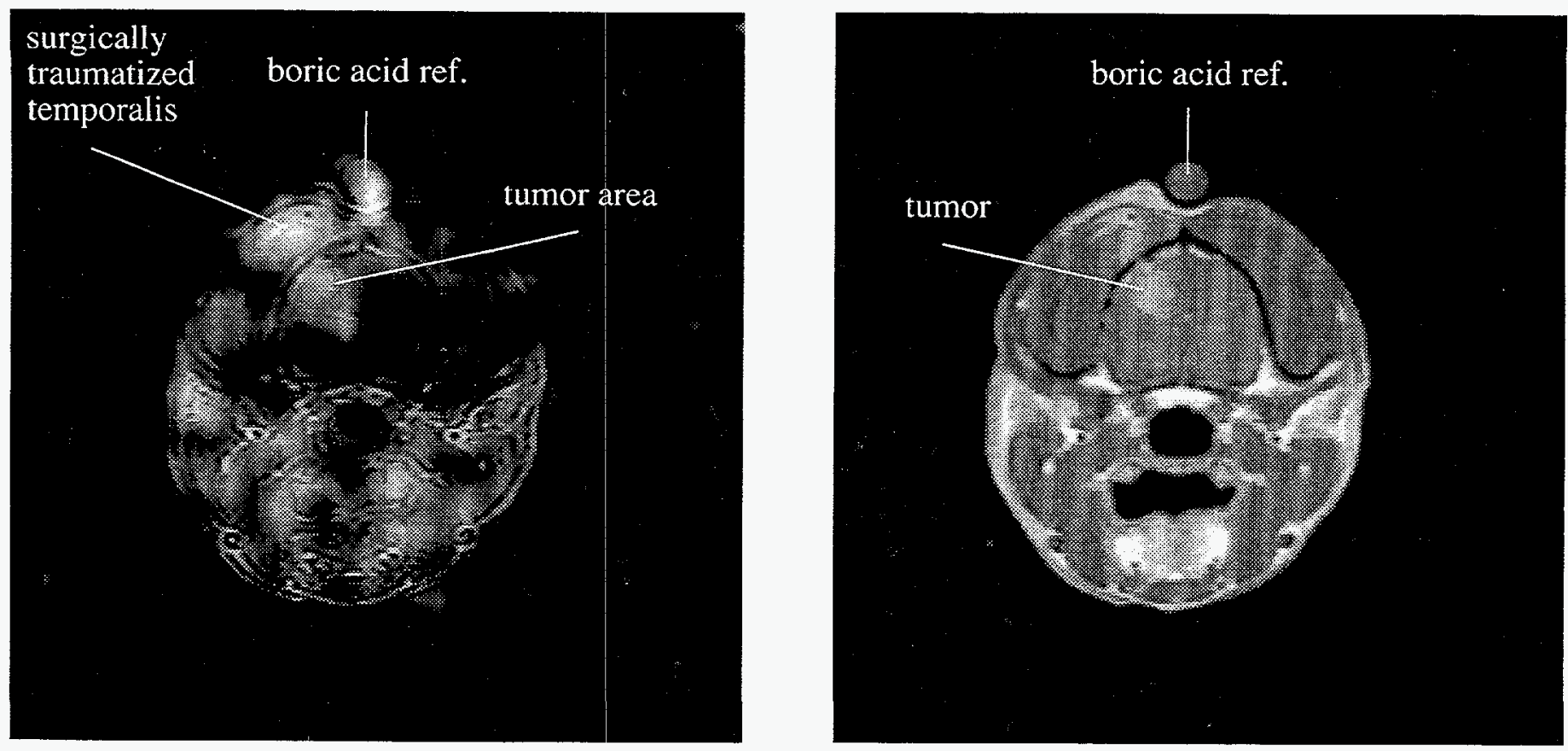

Figure 7. (Right). T1-weighted axial proton image showing gliosarcoma in canine left parietal lobe. (Left) Boron11 image of BSH uptake at this location, superimposed on filtered proton image (in-plane resolution, $7.5 \mathrm{~mm}$ ). BSH dose: $100 \mathrm{mg} / \mathrm{kg}$ boron. Boron-11 image taken at end of drug infusion.

Nevertheless, specific tissue distribution of BSH is readily discernable.

Boron image intensities of selected regions-of-interest (ROIs) within various tissues can be measured versus time. When normalized to the boric acid reference of known boron concentration, these data can be plotted as well as the blood ICP-AES data to obtain a pharmacokinetic profile as shown in Figure 8 . It is important to note that the observed image intensities represent boron- 11 only ( $80 \%$ isotopic abundance). In order to directly compare with ex vivo ICP-AES values of total boron content, the boron image data in all such comparative plots have been increased by $20 \%$ unless otherwise indicated. The results in Figure 8 comes from the same animal as the images in Figure 7. Note the delayed uptake in temporalis muscle and gliosarcoma tumor, with nearly equivalent elimination rates with blood after about one hour post-infusion termination(e.g., after the end of the re-distribution phase).

Semi-quantitative estimates of the tissue boron content are derived from the following relationships ${ }^{2}$ :

$$
C s=C_{c} \frac{I_{s}}{I_{c}} \frac{\left(1-e^{-T R / T i c}\right)}{\left(1-e^{-T R / T l s}\right) B(T)}
$$

Here $s$ and $c$ index sample and control; $C, I$ and $T 1$ are concentration (ppm boron-11), image intensity, and longitudinal relaxation times, respectively. Magnetic field inhomogeneities can be readily

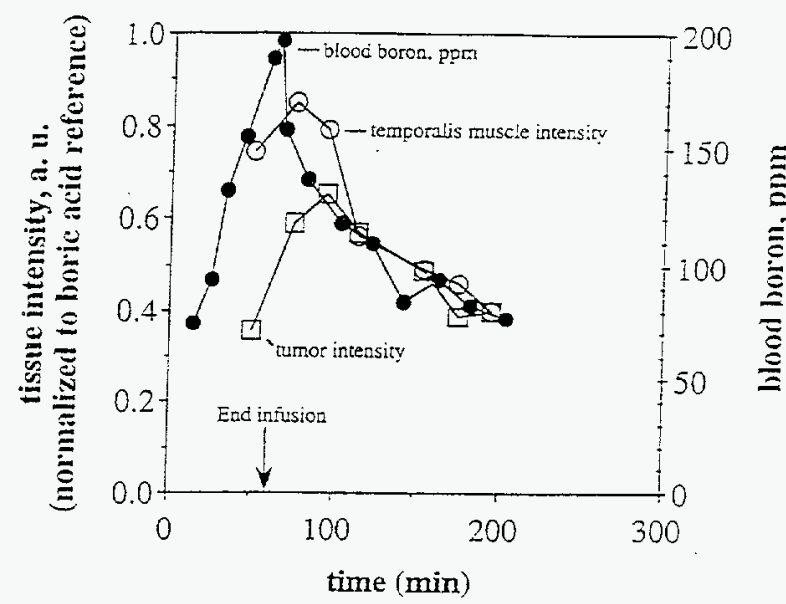

Figure 8. Plot of blood ICP-AES boron and boron11 image derived intensities in tumor and overlaying temporalis muscle for the dog of Figure 7. Boron-11 intensities normalized to boric acid reference.

assessed within the coil volume (leading to slightly altered signal response with change in location) and can account for differences in relaxation properties as they affect image signal intensities for particular acquisition conditions (e.g., intrapulse delay, TR). These factors have been dealt with in the data presented herein.

Not fully characterized at the present time is the individual tissue binding factors, $\mathrm{B}(\mathrm{T})$. One can intuit that $\mathrm{BSH}$, in common with most small drug 
molecules, probably attains some equilibrium between free and bound environments for the time of residence within the biological system. This equilibrium is temperature and concentration dependent The possibility that BSH undergoes covalent binding to particular cellular receptors has been shown not to be in effect, at least for interaction with serum albumins in vitro 5 . One can undoubtedly also intuit that the "visibility" of BSH in the bound state might be lessened since the restricted mobility in such environments leads to broad, low intensity resonance lines. Since each tissue composition is somewhat different, it might be expected that the equilibrium between free and bound BSH (or any other small effector molecule) would be tissue specific. Thus for a given concentration of BSH, the image intensity might be affected differently in one tissue versus another. For example, if the binding interactions were stronger in a particular tissue, the boron-11 image intensity would undoubtedly be lower at a given concentration than in another tissue where the binding was weaker. In an attempt to relate image intensity and $\mathrm{BSH}$ concentration in different tissue environments, the following experiments were performed in four canines whose respiration and hemodynamic functions were tightly controlled. Two of these animals carried mature gliosarcomas in the left parietal lobe. BSH in saline, at $100 \mathrm{mg} / \mathrm{kg}$ boron (as BSH) was administered as usual. Twenty-five $\mathrm{mL}$ arterial blood samples were withdrawn into heparinized containers every 10-20 minutes beginning 20 minutes into the infusion and ending 120 minutes post infusion termination. Boron-11 images were collected from these samples and a boric acid reference using a 3 inch diameter birdcage coil right after blood withdrawal, with temperature monitoring. After euthanasia, boron images of the whole head were recorded. Tissue taken at necropsy as well as the arterial blood samples were analyzed for boron content by ICP. AES.

Comparison of the ICP-AES and image derived concentration estimates using the relationship above, it was determined that an approximate $26 \%$ attenuation in blood and tumor e.g. $\mathrm{B}(\mathrm{T})=1.26$, whereas temporalis muscle gives $\mathrm{B}(\mathrm{T})=1.0$. Although the data is quite limited, it suggests that, at least in these canine gliosarcomas, the need to multiply the estimated concentration by 1.26 in order to more accurately reflect tumor BSH content. Full accounts of this research appear in references 3 and 4.

\section{BSH Pharmacokinetics in Human Patients with High Grade Brain Tumors (IRB \#4395-93). More complete accounts of this work appear in references 2 and 6.}

In order to evaluate the boron-11 imaging method as a non-invasive means of assessing boron drug pharmacokinetics in humans, several (5) brain tumor patients from $U$ of $U$ Neurosurgery and Neurooncology services have been studied. The pathology of the tumors is as follows: glioblastoma multiforme (2), anaplastic astrocytoma (1), anaplastic oligodendroglioma (1) and gemistocytic astrocytoma (1).

\section{Experimental Protocols}

The quadrature birdcage coil design was scaled to accommodate the human head (ca $24 \mathrm{~cm}$ diameter, 23 $\mathrm{cm}$ in length). Slots in the plexiglas cylinder between conductive copper elements were cut out for ventilation and copper endcaps (mesh works better than solid sheet) were attached to increase signal-to noise (SNR). Vials of boric acid reference solution were taped (one running vertically, the other horizontally) at the temples. Standard T1 and T2 weighted proton images were collected prior to introduction of $50 \mathrm{mg} / \mathrm{kg}$ boron (as BSH) in 11 $\mathrm{mL} / \mathrm{kg}$ saline. Some patients had gadolinium contrast scans immediately prior to $\mathrm{BSH}$ introduction, whereas others had this tumor enhancing analysis performed $24 \mathrm{hrs}$ in advance. Interestingly, only those receiving gadolinium the day prior to the boron study produced high quality boron images. This finding suggests gadolinium/BSH competition, a consideration worth further study.

All BSH preparations were carried out by the $U$ of $U$ i.v. prep service, which included sterile filtration through 0.22 micron microbiological filters and assays for pyrogens. The BSH solutions were infused through anticubital veins at a dose rate of 3 $\mathrm{mg} / \mathrm{kg} / \mathrm{min}$. Venous blood was drawn periodically from the opposite arm for subsequent ICP-AES analysis and urine was collected several times during the approximately three hour procedure. All patients were instrumented so that heart rate, mean arterial blood pressure, and hemoglobin oxygenation could be monitored.

\section{Results}

No adverse physiological events were experienced. One patient experienced mild transient nausea. Figure 9 contains axial proton and boron-11 image data from a patient who had undergone surgical resection of a glioblastoma in the left frontal lobe several weeks prior to the boron imaging (the sidedness is reversed since the patients are viewed from the feet toward the head). In the top panel TI weighed proton images before (a) and after (b) gadolinium enhancement (this gado scan was taken the day prior to the boron run) clearly show the resection volume and the residual ring-enhancing piece of tumor which was not removed due to 


\section{gadolinium enhancement}

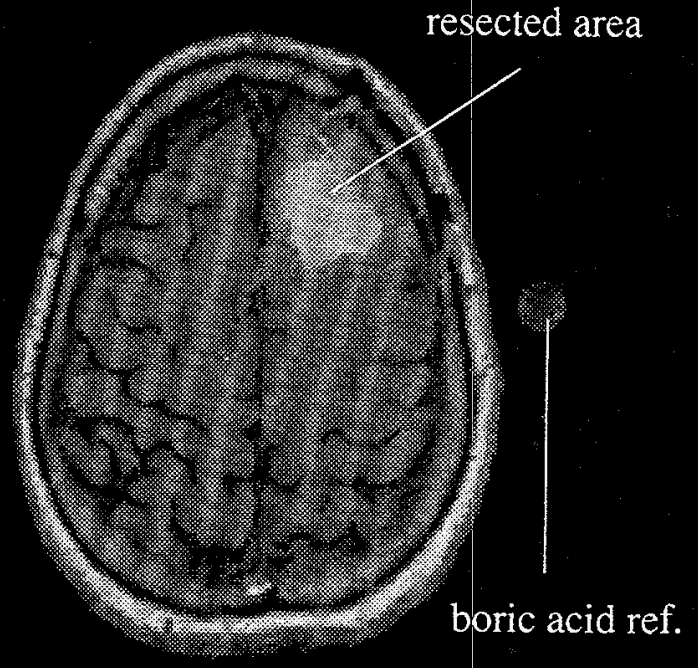

(a)

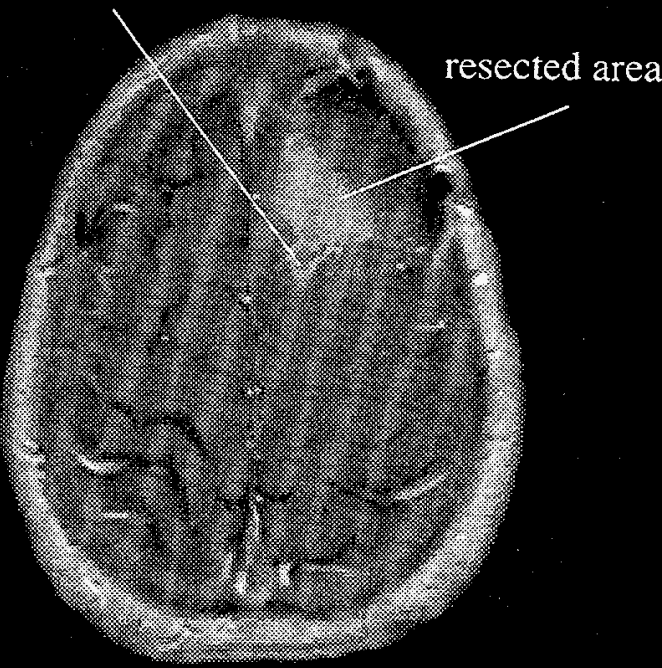

(b)
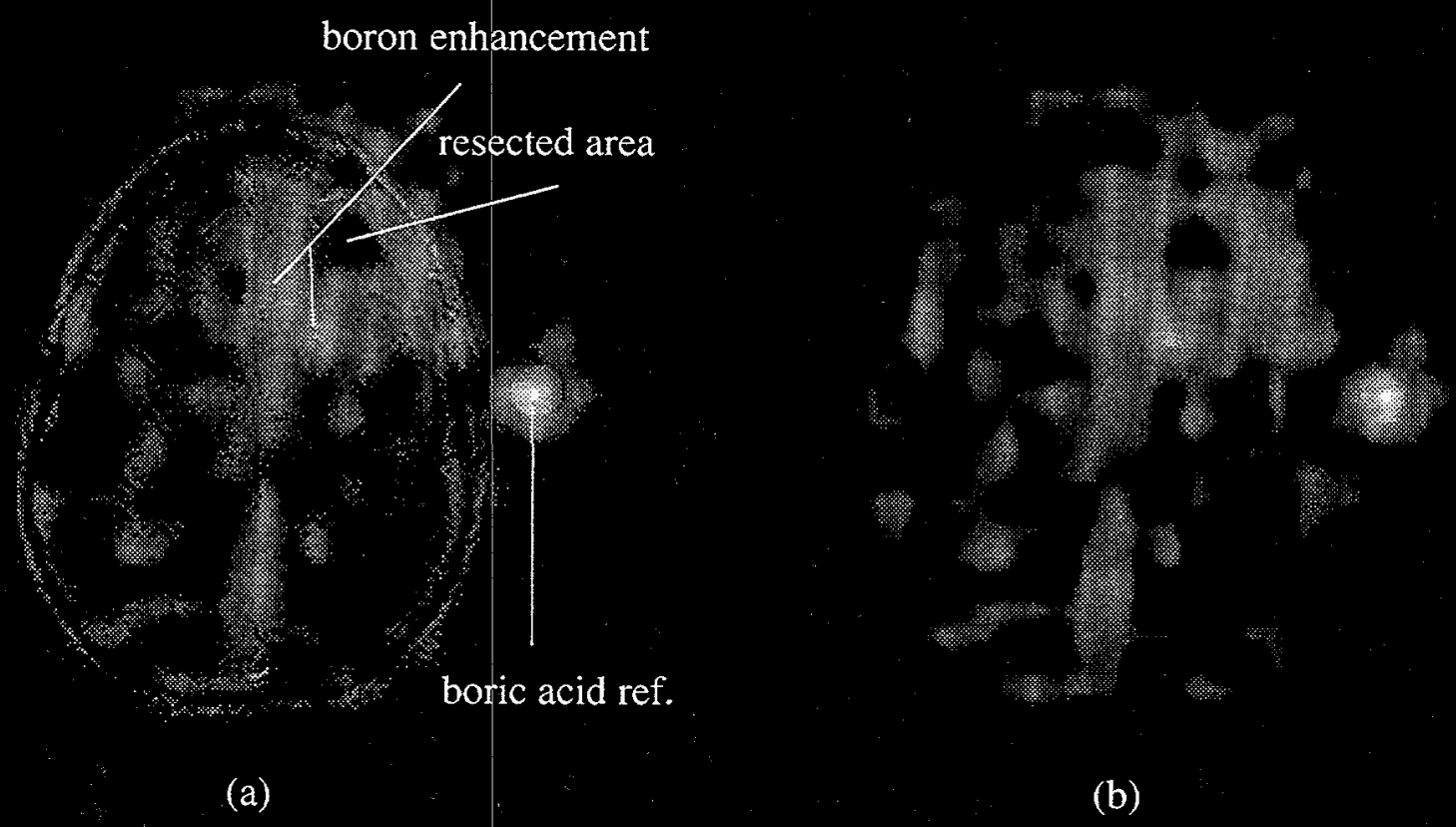

(b)

Figure 9. (Top panel). T1 weighted axial proton images of resected glioblastoma patient, showing gadolinium enhancement of residual tumor pocket (right). (Bottom panel) Boron- 11 image of BSH uptake map (right; in-plane resolution, $7.5 \mathrm{~mm}$ ), as well as superposed boron/proton image (left; BSH dose, $50 \mathrm{mg} / \mathrm{kg}$ boron). Boron- 11 images taken right after end of infusion.

proximity to the other hemisphere. The bottom panel contains the boron-11 image (in-plane resolution is $7.5 \mathrm{~mm}$ ) taken 5 minures post infusion termination (b) as well as this image superimposed on a filtered proton image (a). Higher BSH accumulation is noted in the residual tumor as well as around the periphery of the resection in tissue with surgically damaged blood-brain-barrier (BBB). Other sites of BSH uptake appear to be dura and meningeal membranes as well as sagittal sinus and other vascular areas. BSH subsequently diffused inward away from the resection border.

HPLC analysis of the urine samples revealed mostly non-metabolized BSH.

Figure 10 shows the axial T2 weighed proton image and boron-11 image at the same level for an individual with anaplastic oligodendroglioma in the right frontal lobe. Surgical resection occurred nearly 


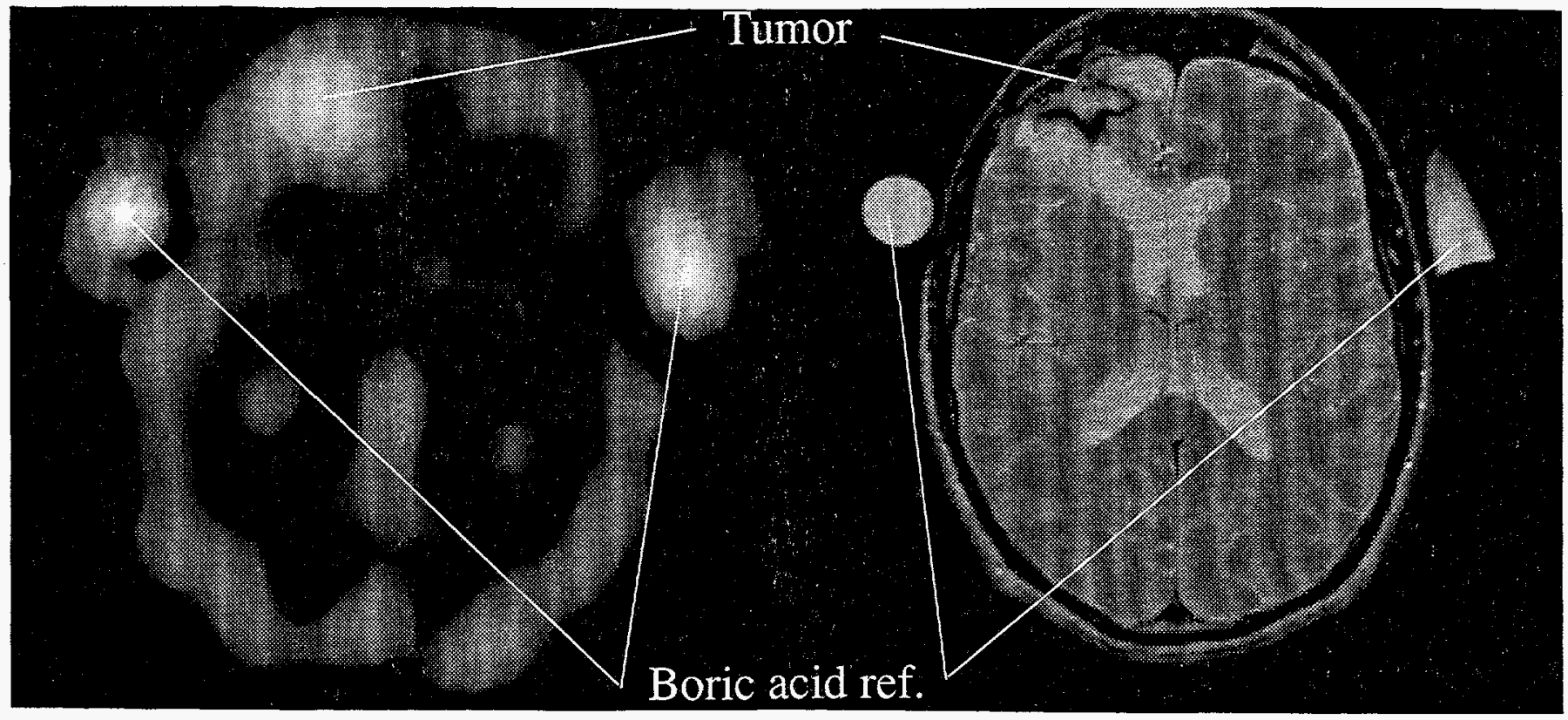

Figure 10. Axial proton and boron-11 (right; in-plane resolution, $15 \mathrm{~mm}$ ) images for resected oligodendroglioma patient receiving $\mathrm{BSH}$. Drug uptake into recurring tumor within resection volume is evident. (Dose: $50 \mathrm{mg} / \mathrm{kg}$ boron, as BSH). Boron-11 images taken right after end of infusion.

one year prior to the boron imaging. Recurring tumor within the resection volume is noted in the proton image. BSH uptake in this tissue is readily apparent in the boron-11 image, taken shortly after the end of the drug infusion. In order to provide greater signal to noise ratio (SNR), the voxel size was increased to $15 \mathrm{~mm}$.
Finally, data is presented from results of a patient with a left frontal glioblastoma who had resection surgery approximately three months prior to the boron imaging study. The resultant cyst is clearly visible in the proton image of Figure 11 (right), as is the large mass of recurring tumor inferior to the original lesion.

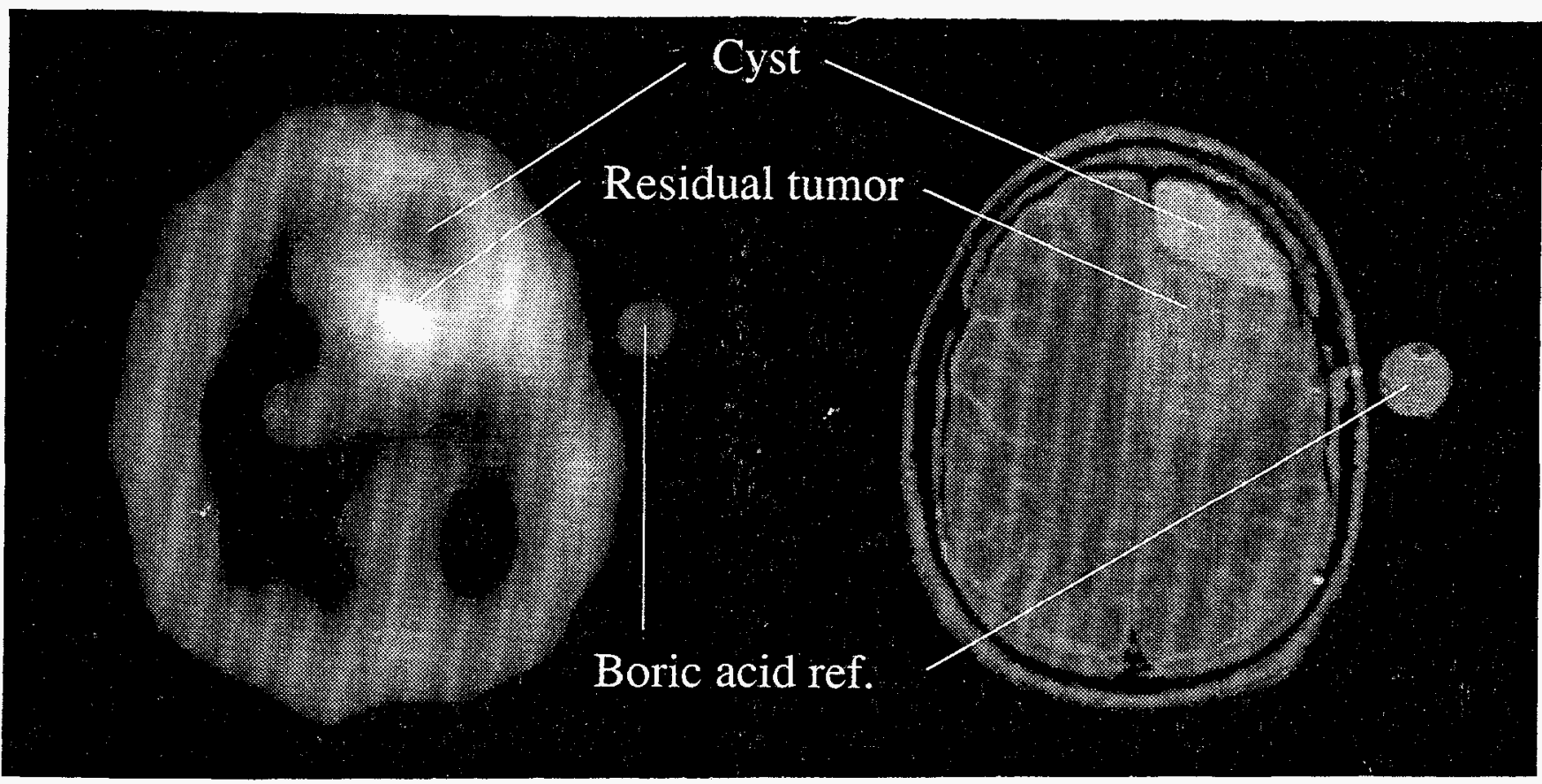

Figure 11. Axial proton and boron-11 (right; in plane resulution, $15 \mathrm{~mm}$ ) images of large recurrent glioblastoma multiforme and BSH uptake into this lesion (Dose: $50 \mathrm{mg} / \mathrm{kg}$ boron (as BSH). Boron-11 images taken right after termination of infusion. 
$\mathrm{BSH}$ absorption into this tissue as well as BBB compromised tissue nearby, meningeal and dural membranes and sagittal sinus is easily visualized. Here voxel size is again $15 \mathrm{~mm}$. In this case the resection cyst was not penetrated by $\mathrm{BSH}$ up to the end of imaging ( $2 \mathrm{hrs}$ post infusion termination).

If $\mathrm{BSH}$ derived boron- 11 image intensity is measured within the recurrent tumor tissue with time, normalizes to boric acid references and further adjustsed for the canine derived $26 \%$ attenuation, a plot of estimated boron content versus time may be created as shown in Figure 12. Here these time dependent values are compared with ICP-AES derived venous blood levels. Peak absorption into tumor lags behind blood by $20-25$ minutes. Hereafter the elimination kinetics are similar. Unfortunately, clinical demands on the MR scanner precluded further extension into the elimination period. If analogizies to the studies of Haselsberger et al. ${ }^{6}$ who used a similar loading dose of BSH (75 $\mathrm{mg} / \mathrm{kg}$ compared with our $87.5 \mathrm{mg} / \mathrm{kg}$ ) are made, the expectation is that at 12 hours post BSH administration boron content in blood was about 30 micrograms $/ \mathrm{mL}$. The expected tumor content would be about $30-40 \mathrm{ppm}$, a prediction modulated by individual physiology and warranting further study. More complete accounts of this research are presented in references 4 and 6.

\section{Human BSH Kinetics for Blood and Tumor}

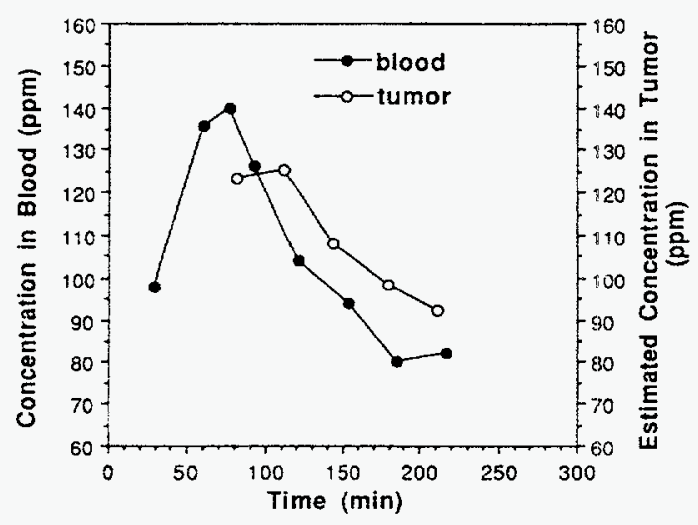

Figure 12. Pharmacokinetics of BSH in the blood (ICP-AES) and recurrent glioblastoma (patient images in Fig. 11), using boron-11 image intensity relative to boric acid reference and adjusting for signal attenuation as found in the canine tumor model. The end of infusion was at $60 \mathrm{~min}$.

\section{Boron-11 MRI of Several BNCT Agents in the Rat Model.}

The evaluation of boron-1 I MRI in the rat model permits evaluation of the newer BNCT candidate compounds which are only available in small quantities. Further positive aspects of this approach include the ability to follow online pharmacokinetics in a variety of organs, including implanted tumors, and better filling factors in terms of small coils (3 inches diameter) snugly accommodated the rat body. Boron-11 MRI has been performed in normal Fischer 344 rats as well as those bearing flank implanted 9L gliosarcomas, using the 3DPR algorithm and the GE clinical MR scanner.

\section{Experimental Potocols}

9L gliosarcoma cells, initially obtained from Dr. John Hilton of The Johns Hopkins University, were grown to confluence in the lab using modified Eagles's medium supplemented with $10 \%$ bovine serum and antibiotics. Approximately one million cells were implanted subcutaneously into the lower flank area of the rats, under ketamine/xylazine anesthesia (50 and $5 \mathrm{mg} / \mathrm{kg}$, respectively). Large tumors, 3 to $5 \mathrm{~cm}$ diameter, grew within $30-35$ days.

The resident knee coil was used to obtain $\mathrm{T} 2$ weighed (fast spin echo) coronal proton images of the rat body. The initial boronated drug evaluated was $\mathrm{BSH}$, at concentrations ranging from $20-60 \mathrm{mg} / \mathrm{kg}$ boron in $1 \mathrm{~mL}$ saline, administered through the lateral tail vein as a slow bolus. Other agents included liposome encapsulated $\mathrm{B}_{20} \mathrm{H}_{17} \mathrm{NH}_{3}$, also administered i.v. at a dose of $10 \mathrm{mg} / \mathrm{kg}$ boron, and l-BPA, whose fructose complex was prepared via exposure of the reactants to $\mathrm{pH} 10$ for a few moments, then neutralized to $\mathrm{pH} 7.4$ prior to delivery either i.v. or i.p. The boron-11 quad birdcage dimensions are $7 \mathrm{~cm}$ diameter, $16 \mathrm{~cm}$ length. The standard 3DPR imaging sequence was used, with a field-of-view (FOV) of $24 \mathrm{~cm}$, yielding cubic voxels of $7.5 \mathrm{~mm}$.

\section{Results}

\section{BSH}

Figure 13 contains coronal proton and corresponding boron-11 images from two adjacent $7.5 \mathrm{~mm}$ thick slices in a rat bearing a large $9 \mathrm{~L}$ gliosarcoma in the right flank. The slice thickness of the proton images at the location corresponding to the boron-11 images, was $3 \mathrm{~mm}$. The boron- 11 data were obtained about ten minutes after i.v. infusion of $60 \mathrm{mg} / \mathrm{kg}$ boron (as BSH). Drug uptake into liver, kidney and bladder is readily observed, as is absorption into the periphery of the tumor. No penetration into the tumor core was noted $60 \mathrm{~min}$ post infusion. Perhaps a combination of poor internal vascularization in this large solid tumor as well as high interstitial pressure may be contributing to this result. 

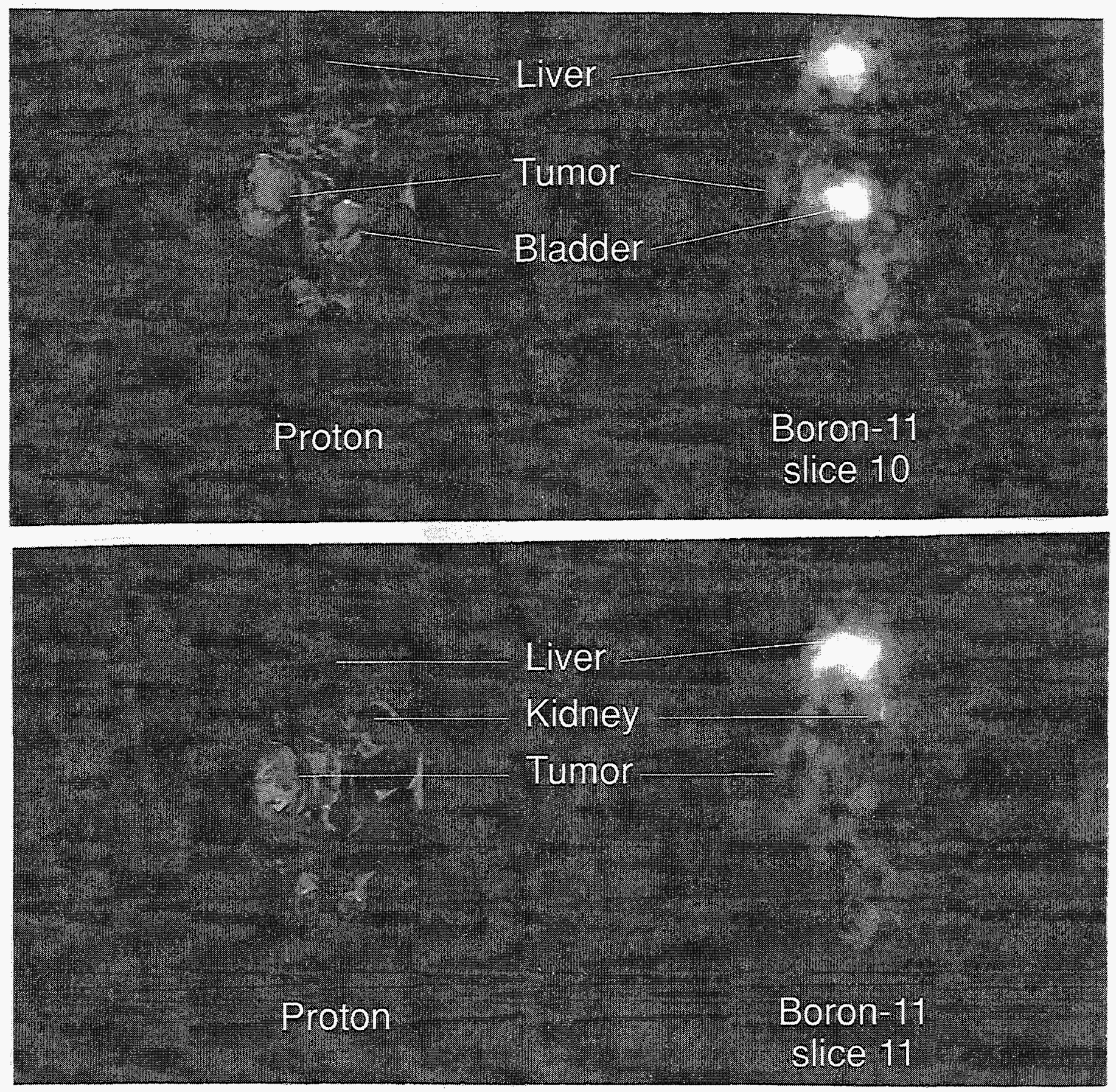

Figure 13. (Top panel). Coronal proton (left) and boron-11 images of a rat bearing a large $9 \mathrm{~L}$ flank tumor, infused with $60 \mathrm{mg} / \mathrm{kg}$ boron (as BSH), i.v.. (Bottom panel, same situation, different tissue level). Boron-11 images taken a few moments post infusion.

The ease with which one can non-invasively follow the time dependence of the image intensities, and therefore pharmacokinetics, may be seen in Figure 14 where the tissue values were scaled to the known concentration of the boric acid standard. Bladder emptying between the last two points accounts for the decrease in signal.

\section{Liposome encapsulated boranes}

Again, using this rat model, newer candidate BNCT agents such as the liposome encapsulated boranes can be evaluated. Some of these have been shown to load mouse tumors with around $3 x$ the boron loading dose as BSH. Figure 15 contains composite data for a rat bearing a large gliosarcoma on the left flank. 


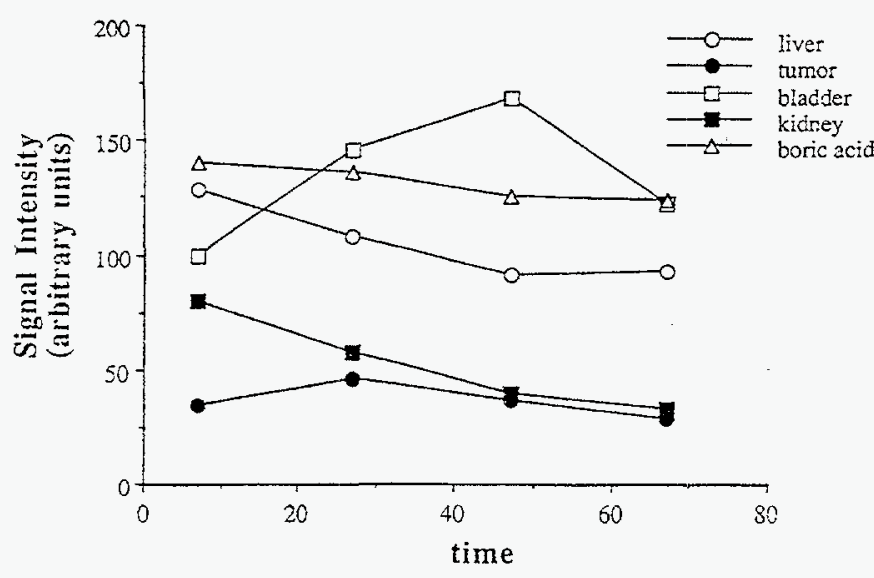

Figure 14. Time dependence of boron-11 image intensities for various tissues post i.v. infusion of 60 $\mathrm{mg} / \mathrm{kg}$ boron (as BSH; see Fig 13). Intensities related to boric acid reference.
Six $\mathrm{mL}$ of a liposome suspension containing 10 $\mathrm{mg} / \mathrm{kg}$ boron (as the amine borane) was infused at about $2 \mathrm{~mL} / \mathrm{min}$. The coronal boron-11 images (the first ever recorded for this borane) taken 1 hour post infusion readily show drug in liver (and (spleen), some in kidney and perhaps some uptake into the heterogeneous tumor. At 23 hrs post-infusion, the drug had decreased notably from liver, spleen and kidney, with the tumor content about the same. ICPAES data, on necropsy tissue taken 24 hrs post infusion, shows tumor content at $28 \mathrm{ppm}$, liver at (52 ppm), kidneys (66 and 72 ppm respectively) and spleen $(185 \mathrm{ppm})$.

\section{I-BPA}

Since 1-BPA is one of the agents being used in BNCT efficacy trials, there was motivation to study its boron-11 MRI characteristics in the rat. The first experiments involved i.p. injection of high doses of the fructose complex (recall that BPA has only about $10 \%$ as much boron as BSH. Long lasting i.p

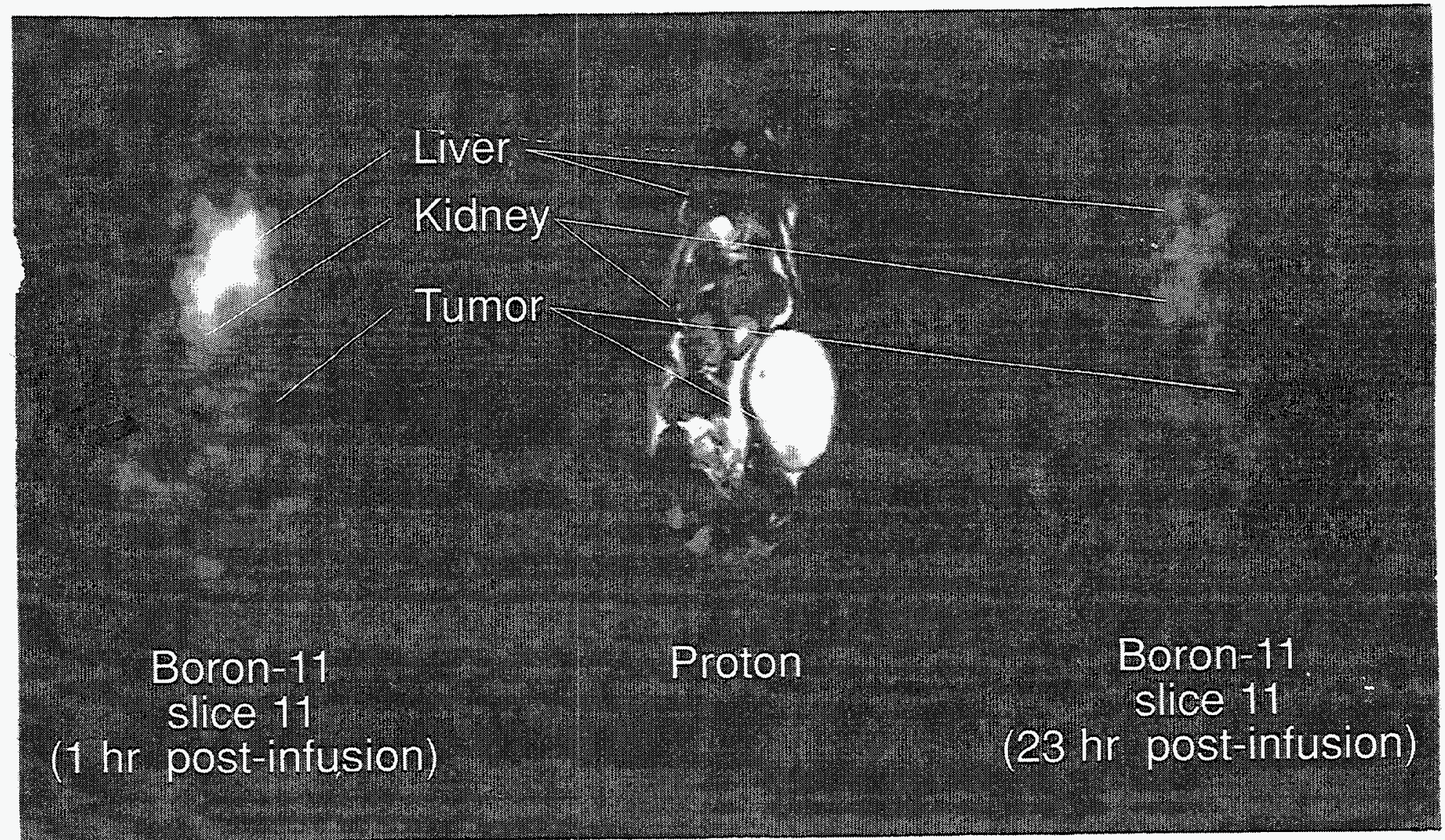

Figure 15. (Center) Coronal proton image of gliosarcoma burdened rat. On the left is a boron-11 image taken a few moments post-i.v. infusion of $10 \mathrm{mg} / \mathrm{kg}$ boron (as amine borane in liposomes). At the right is the boron-11 image at this same level taken 23 hrs post infusion. 
anesthetic, thiobutabarbitol (Inactin) was used which, at $120 \mathrm{mg} / \mathrm{kg}$, will immobilize rats for $8 \mathrm{hrs}$ or more. $1000-1200 \mathrm{mg} / \mathrm{kg} \mathrm{l-BPA}$-fructose (representing 50-60 $\mathrm{mg} / \mathrm{kg}$ boron) in 4.5-5.0 mL water, were administered following the usual proton imaging. The boron-11 spectral line was much broader than from $\mathrm{BSH}$, indicating greater tissue binding (formation of the fructose adduct at the borono hydroxyls causes some line broadening, but not the magnitude seen in vivo). After about 30 minutes the spectral line appeared to narrow and imaging commenced.

Figure 16 contains coronal proton and boron-11 image data about $25 \mathrm{~min}$ post i.p. infusion of 1000 $\mathrm{mg} / \mathrm{kg}$ l-BPA-fructose. Uptake into liver and especially kidney is apparent, as well as other abdominal tissues. These observations are consistent with the ICP-AES results on necropsy tissue, wherein $60-90 \mathrm{ppm}$ boron was found in liver and kidney.

Another animal, carrying a small $(2-3 \mathrm{~mm})$ frontal lesion from intracranial implantation of RG2 glioma cells, was infused with $1200 \mathrm{mg} / \mathrm{kg}$ l-BPA-fructose and imaged as before. Again, uptake was noted in kidney spaces, other peritoneal areas and particularly, in this rat, a high intensity area in the pancreas (the brain lesion was too small for meaningful analysis). ICP-AES data on excised tissues confirmed the high pancreas content (330 ppm) whereas kidney content was about $150 \mathrm{ppm}$.

Since the route of administration in the current Brookhaven trials is i.v., l-BPA-fructose was given via the lateral tail vein. It was suprising to find very little boron signal in tissue until 3-4 hrs postinfusion when small high intensity images in the lower abdomen could be seen. At this point the compound had nearly all been excreted into the bladder as confirmed by ICP-AES analysis ( $\mathrm{Ca} 240$ ppm boron in urine, 20-30 in kidney, 7-18 ppm elsewhere). High-pressure liquid chromatography (HPLC) analysis (NEL) of the urine boron by high resolution boron-11 nuclear magnetic resonance (NMR) revealed 60-70\% free l-BPA, the rest boric acid and "complexed" 1-BPA. The complexed BPA line in this urine sample was no broader than in the uncomplexed molecule, the latter being formed in the low $\mathrm{pH}$ urinary environment.

Speculation is that the binding of 1-BPA-fructose to blood proteins is so great as to broaden the boron- 11 spectral line beyond detection. Further work on this intriguing problem seems warranted.

\section{ACKNOWLEDGEMENTS}

$U$ of $U$ researchers are grateful for the continual support given by Merle Griebenow, and the INEL
(Bill Bauer) for BSH - ICP-AES and other chemical analyses. We also thank the NIH for financial support (R44 NS30746). We are especially grateful to Suzanne Johnson and Scotty McJames, stellar animal techs. Many thanks to Dr. Fred Hawthorne (UCLA) for the liposomes and Dr. Jeff Coderre (BNL) for the l-BPA.

This multidisciplinary work has involved the services of many people at the University:

\section{Department of Radiology}

Ken Bradshaw (Medical Imaging Research Lab (MIRL)

Rock Hadley (MIRL)

Dr. Peng-Peng Tang (MIRL)

Shonn Hendee (MTRL)

Henry Buswell

\section{Department of Neurosurgery}

Dr. M. Peter Heilbrun, Chair

Dr. Rick Tippets

Dr. Dan Fults, III

\section{Department of Neurology}

Dr. Leslie McAllister

\section{REFERENCES}

1. G.H. Glover, J.M. Pauly, K.M. Bradshaw, J. Magn. Reson. Imaging 2:47-52(1992).

2. K.M. Bradshaw, G.H. Glover, J.R. Hadley, M.P. Schweizer, Proc., Society of Magnetic Resonance in Medicine, 12th Annual Meeting, 1993,p 889.

3. K.M. Bradshaw, M.P. Schweizer, G.H. Glover, J.R. Hadley, R. Tippets, P-P. Z. Tang, W.L. Davis, M.P. Heilbrun, S. Johnson and T. Ghanem, Magn. Reson. Med., 34:48-56(1995).

4. K. M. Bradshaw, $\mathrm{PhD}$ Dissertation, University of Utah, 1996.

5. P.-P. Z.Tang, M.P. Schweizer, K.M. Bradshaw, W.F. Bauer, Biochem.Pharm. 49:625-632(1995).

6. K.M. Bradshaw, J.R. Hadley, M.P. Schweizer, M.P.Heilbrun, W.L. Davis, G.H. Glover, Proceedings, Sixth International Conference on BNCT, Kobe, Japan, 1994.

7. K. Haselsberger, H. Radner , G. Pendl, Cancer Res., 54:6318-6320(1994). 
8. $\quad$ S.P. Hendee, K.M. Bradshaw, J.R. Hadley, P.-P. Z. Tang, M.P. Schweizer, Proceedings, Sixth International Conference on BNCT, Kobe, Japan, 1994.
9. R.K. Jain, Scientific American, 271:58-65 (1994)



Figure 16. Coronal proton and boron-11 (right) images of a rat given $50 \mathrm{mg} / \mathrm{kg}$ boron (as l-BPA*fructose, i.p.). Boron-11 image taken about one-half hour post-infusion drug. 


\section{COMPUTATIONAL AND EXPERIMENTAL STUDIES OF AN ELECTRON ACCELERATOR BASED EPITHERMAL PHOTONEUTRON SOURCE FACILITY FOR BORON NEUTRON CAPTURE THERAPY}

\author{
D. W. Nigg, H. E. Mitchell, Y. D. Harker, \\ (INEL), J. F. Harmon, Department of Physics, \\ Idaho State University (ISU)
}

\section{INTRODUCTION}

BNCT is an experimental binary cancer radiotherapy modality involving the administration of a boronated pharmaceutical that preferentially accumulates in malignant tissue, followed by exposure of the treatment volume to a thermal neutron field. This procedure causes the selective destruction of the boron-containing cells by the energetic products of the ${ }^{10} \mathrm{~B}(\mathrm{n}$,alpha) $\mathrm{Li}$ interaction. BNCT research in the United States and Europe has been focused on the use of an epithermal $(0.5 \mathrm{eV}$ to $10 \mathrm{keV})$ neutron beam as the most effective method for generating the necessary thermal neutron field in deep-seated treatment volumes. Epithermal-neutron beams can be generated by small nuclear reactors ${ }^{1-5}$ and by accelerator-based neutron sources ${ }^{6-8}$. So far, however, only reactors have actually been used to produce therapeutically-useful epithermal-neutron beams for BNCT. Some low-intensity prototypes of accelerator-based sources, generally featuring the use of proton or deuteron beams and beryllium or lithium targets have been constructed. Scaling of these devices to output levels suitable for clinical application will in many cases require additional developments in the relevant accelerator technology, as well as the resolution of some rather difficult issues associated with target cooling. This report describes an alternate approach to the realization of a clinically-useful accelerator-based source of epithermal neutrons for BNCT that reconciles the often-conflicting objectives of target cooling, neutron beam intensity, and neutron beam spectral purity via a two-stage photoneutron production process driven by an electron linear accelerator rather than by a heavy-particle accelerator. A description of the basic concept is provided and the results of initial proof-ofprincipal experiments using a low-current benchtop model of the proposed device are presented.

\section{CONCEPTUAL DESIGN FOR A CLINICAL FACILITY}

A conceptual design for a device to produce photoneutrons having a spectral distribution appropriate for epithermal-neutron BNCT is shown in Figure 17. In this device, which was inspired by a related idea first described in Reference 9, electron beams at an energy of approximately $6 \mathrm{MeV}$ impinge inward upon tungsten targets located at the outer radius of a small cylindrical tank of heavy water $\left(\mathrm{D}_{2} \mathrm{O}\right)$. This tank may also contain beryllium to enhance the neutron yield. A fraction of the energy of the electrons is converted in the tungsten targets into radially-inward-directed bremsstrahlung radiation. Photoneutrons are subsequently generated in the $\mathrm{D}_{2} \mathrm{O}$ (and beryllium) region within the tank. The photoneutron yield per incident electron (about $10^{-4}$ at the incident electron beam energy of interest) from this arrangement is comparable to the neutron yield attainable ${ }^{5}$ with published accelerator-based epithermal-neutron sources for BNCT that use lowenergy protons impinging on a lithium target. Photoneutrons produced in the central region enter a surrounding cylindrical moderating and filtering region composed, in this particular design, of $90 \%$ aluminum fluoride $\left(\mathrm{AlF}_{3}\right)$ and $10 \%$ lithiated aluminum, by volume, with $1 \%$ by weight of natural lithium fluoride added to suppress the thermal neutron flux. Mixtures of $\mathrm{AlF}_{3}$ and $\mathrm{Al}$ have been shown ${ }^{5}$ to be extremely effective for production of epithermal neutrons in reactor-based systems. The filter/moderator region is followed by a bismuth-lead gamma shield and a lithiated-polyethylene neutron beam delimiter. The geometry of the device provides for two horizontally-opposed treatment beams, as shown.

It may be noted that an electron energy of $6 \mathrm{MeV}$ is estimated to be near the optimum operating energy for this system concept. Use of a significantly higher electron beam energy would increase the photoneutron yield per incident electron but it would also produce disproportionately larger, potentially unmanageable, levels of photon contamination in the neutron source. On the other hand, reducing the electron beam energy below the estimated optimum. 


\section{Side View Through Section B-B}

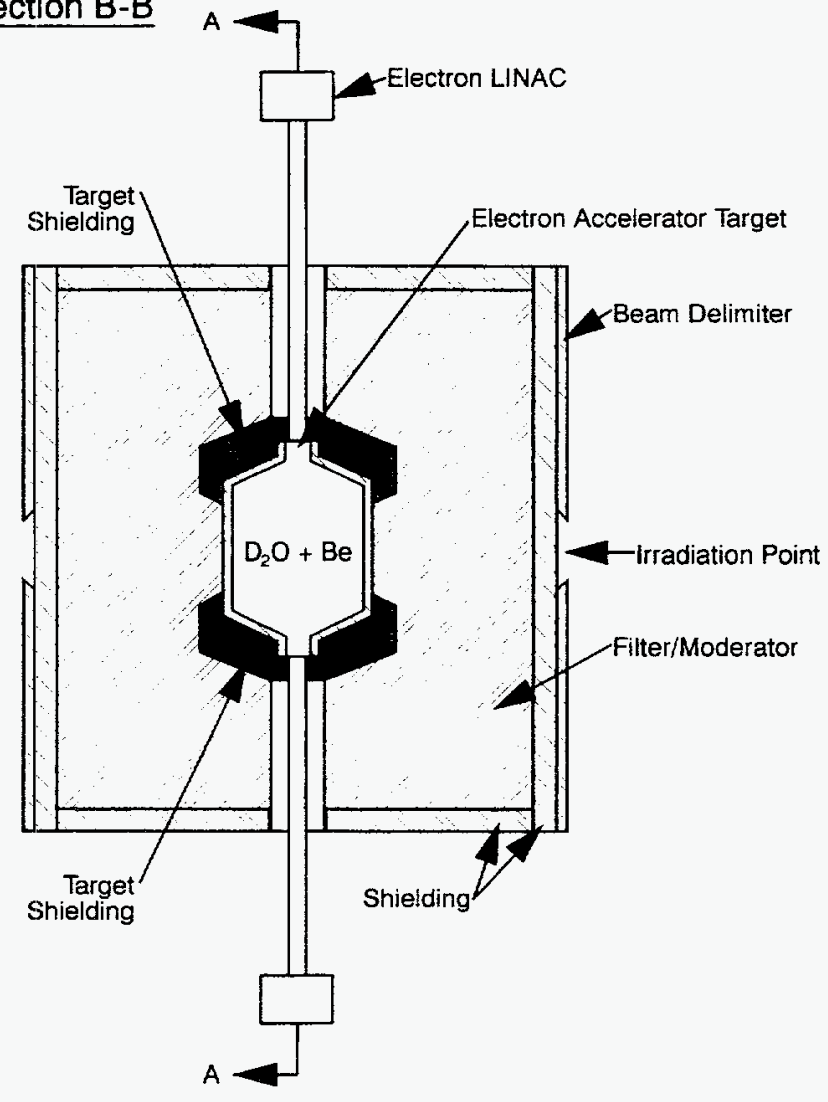

\section{End View Through Section A-A}

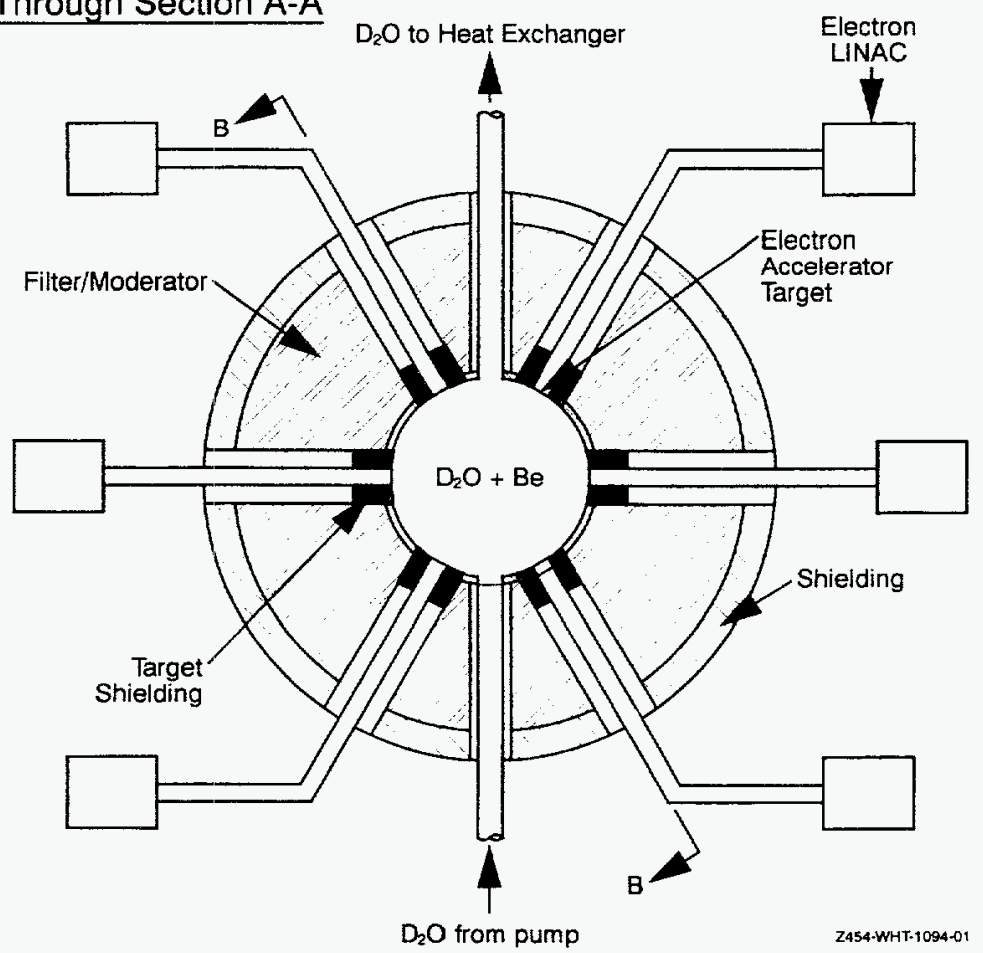

Figure 17. Epithermal photoneutron source. (Patent pending) 
reduces the photon flux in absolute terms, but the photoneutron yield is reduced to a greater degree, thus the relative photon content of the neutron source would tend to increase Calculations to estimate the performance of the proposed photoneutron device were performed using the $\mathrm{ACCEPT}^{10}$ threedimensional electron-photon coupled transport code to compute the bremsstrahlung flux throughout the code (with the BUGLE- $80^{12}$ cross section library) to compute the transport of photoneutrons (and neutroncapture gammas) to the irradiation position. These two codes were coupled using photoneutron production data developed and validated as described in Reference 13. Confirmatory neutron and capturegamma transport calculations were performed using the MCNP $^{14}$ Monte-Carlo neutron and photon transport code. The geometric model used for the calculations is shown in Figure 18. A flow chart for the basic computational sequence is shown in Figure 19.

The DORT results for the calculated scalar neutron flux spectrum at the irradiation point for the clinical concept illustrated in Figure 17 are presented in Figure 20. These results are for the case of $100 \%$ $\mathrm{D}_{2} \mathrm{O}$ in the central conversion region with an incident $6 \mathrm{MeV}, 1 \mathrm{~mA}$ electron beam configuration. Similar calculated results are obtained using MCNP. Scaling the electron beam current to $100 \mathrm{~mA}$ and integrating the computed neutron spectrum shown in Figure 20 over the appropriate lethargy range yields a therapeutically-useful total epithermal flux intensity at the irradiation point of approximately $1 \times 10^{9}$ $\mathrm{n} / \mathrm{cm}^{2} / \mathrm{s}$. The calculated nonselective neutron-induced proton recoil dose in hydrogenous tissue per unit useful epithermal neutron flux at the irradiation point for this case is $1.6 \times 10^{-11} \mathrm{cGy} / \mathrm{n} / \mathrm{cm}^{2}$, which is below what is believed to be the radiobiologicallyacceptable maximum. The incident gamma dose at the irradiation point due to neutron capture gammas originating within the device is approximately $1.5 \mathrm{x}$ $10^{-11}$ in the same units. The incident gamma dose at the irradiation point due to direct source bremsstrahlung is controllable to approximately the same level (or less, as needed) by appropriate shielding placed at various strategic locations within the device as shown in Figure 17. Waste heat from the entire process may be removed using standard heat transfer techniques by flowing the $\mathrm{D}_{2} \mathrm{O}$ through the central tank to an external heat exchanger and thence back into the central tank. Modest (10-20 liters/second) $\mathrm{D}_{2} \mathrm{O}$ flow rates appear to be sufficient to remove the expected waste heat without exceeding reasonable temperature levels within the system.

\section{BENCHMARK EXPERIMENTS}

Experimental proof-of-principle testing for a lowcurrent benchtop prototype of the epithermal photoneutron source concept has been initiated and significant preliminary results have been produced. The primary objective of these first experiments has been to validate the computational methods used as described above to estimate the performance of the full-scale conceptual device. The experimental program has included measurements of the unfiltered photoneutron source as well as measurements of filtered epithermal-neutron spectra produced using two different advanced neutron filtering assemblies. The first of these filtering assemblies is based on the use of an $\mathrm{Al} / \mathrm{AlF}_{3} / \mathrm{LiF}$ composite material developed by the Technical Research Centre of Finland. The second features a novel Aluminum/Teflon $\left(\mathrm{Al} / \mathrm{CF}_{2}\right)$ design developed at the INEL. Some preliminary measurements of the photon contamination of the filtered neutron source have also been completed and the results are presented herein.

\section{METHODS AND MATERIALS}

An initial series of experiments was performed to measure the neutron production rate in a small volume of $\mathrm{D}_{2} \mathrm{O}$ driven by a bremsstrahlung source and to obtain information concerning the variation of the photoneutron source strength with incident electron energy within the energy range of interest. A tunable electron linear accelerator (LINAC) manufactured by the Varian Corporation, shown in Figure 21, was used. The accelerating cavity is driven by a magnetron radio frequency (RF) power supply and is contained within a rectangular enclosure with an electron drift tube extending out from the enclosure. The average energy of the electron beam can be tuned over the range of approximately $4-9 \mathrm{MeV}$ by varying the electron injection current and the magnetron power in various combinations, and thereby varying the loading of the radiofrequency field within the accelerating cavity. Typical effective direct current (DC) electron beam current levels in this device are on the order of a few microamperes, producing a bremsstrahlung radiation field at the target that is on the order of several Grays per minute (several hundred rads per minute). Figure 22 shows a closer view of the main electron drift tube, which is terminated by a water-cooled tungsten target for converting the electron beam energy into bremsstrahlung radiation. As shown in Figures 23 and 24 , the foreward-peaked bremstrahlung radiation emanating from the accelerator target is further collimated by a cylindrical tungsten shield and is subsequently directed into a sealed cylindrical lucite 
Schematic Detail of

Drift-Tube and Tank Interface

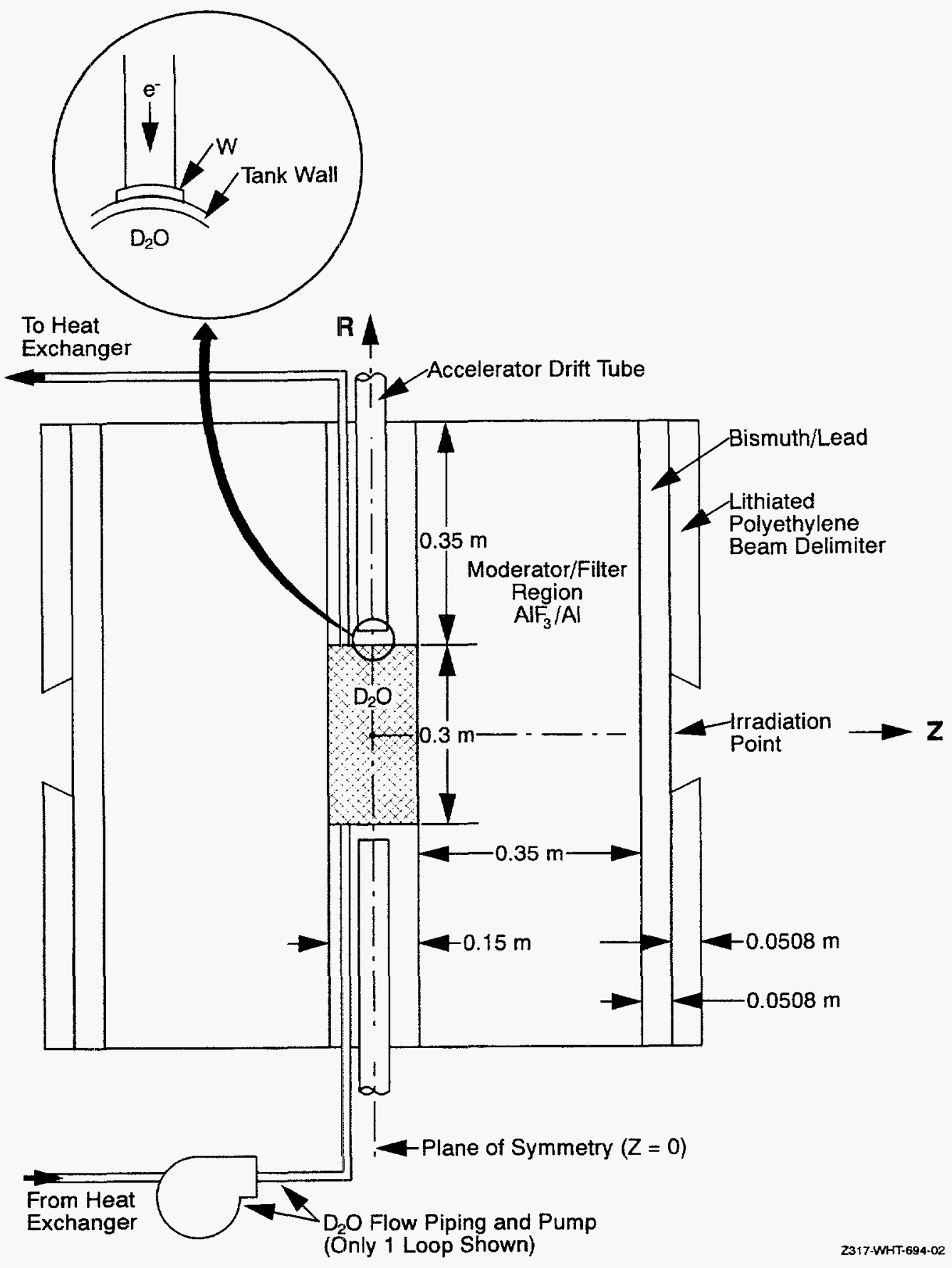

Figure 18. Calculational model for initial clinical epithermal photoneutron source concept. 


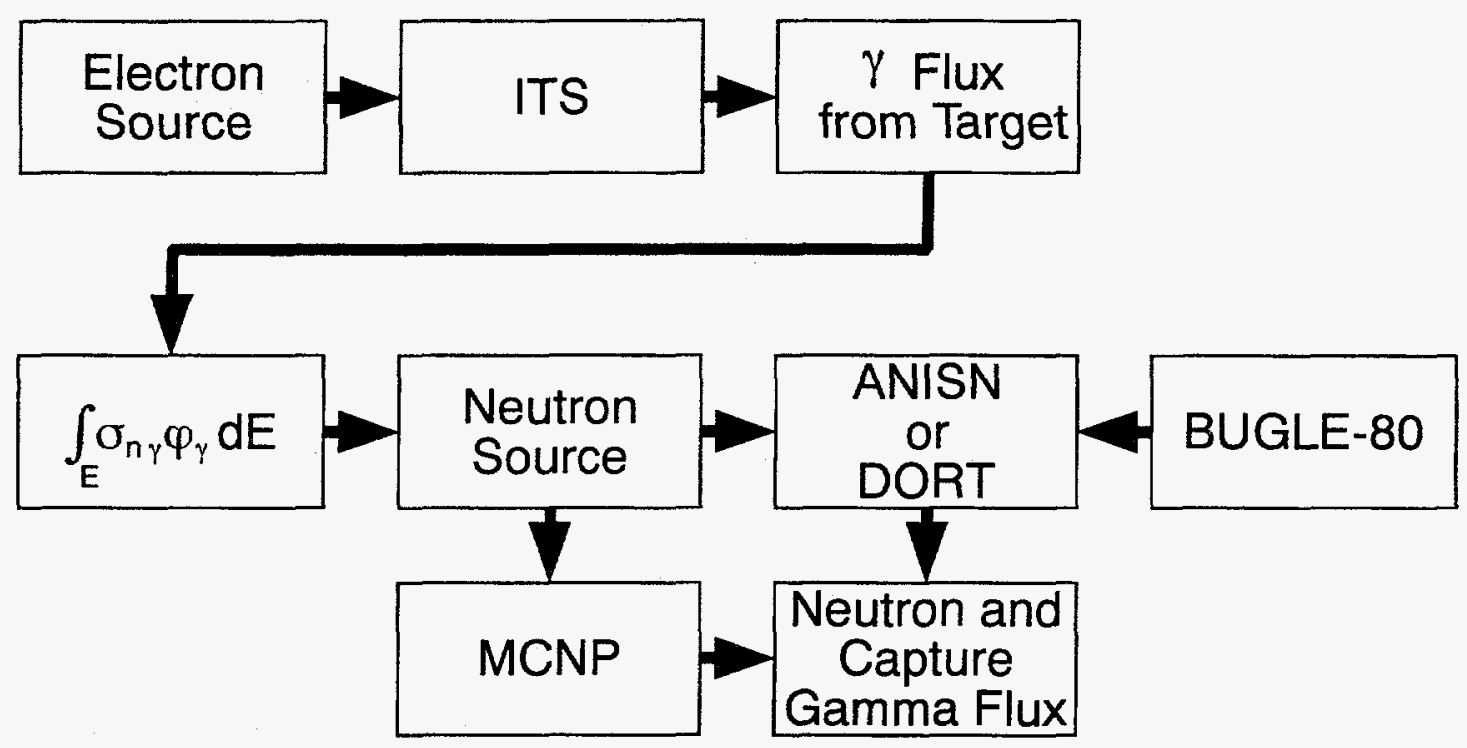

2454-WHT-1094-03

Figure 19. Computational sequence for epithermal photoneutron source evaluations.

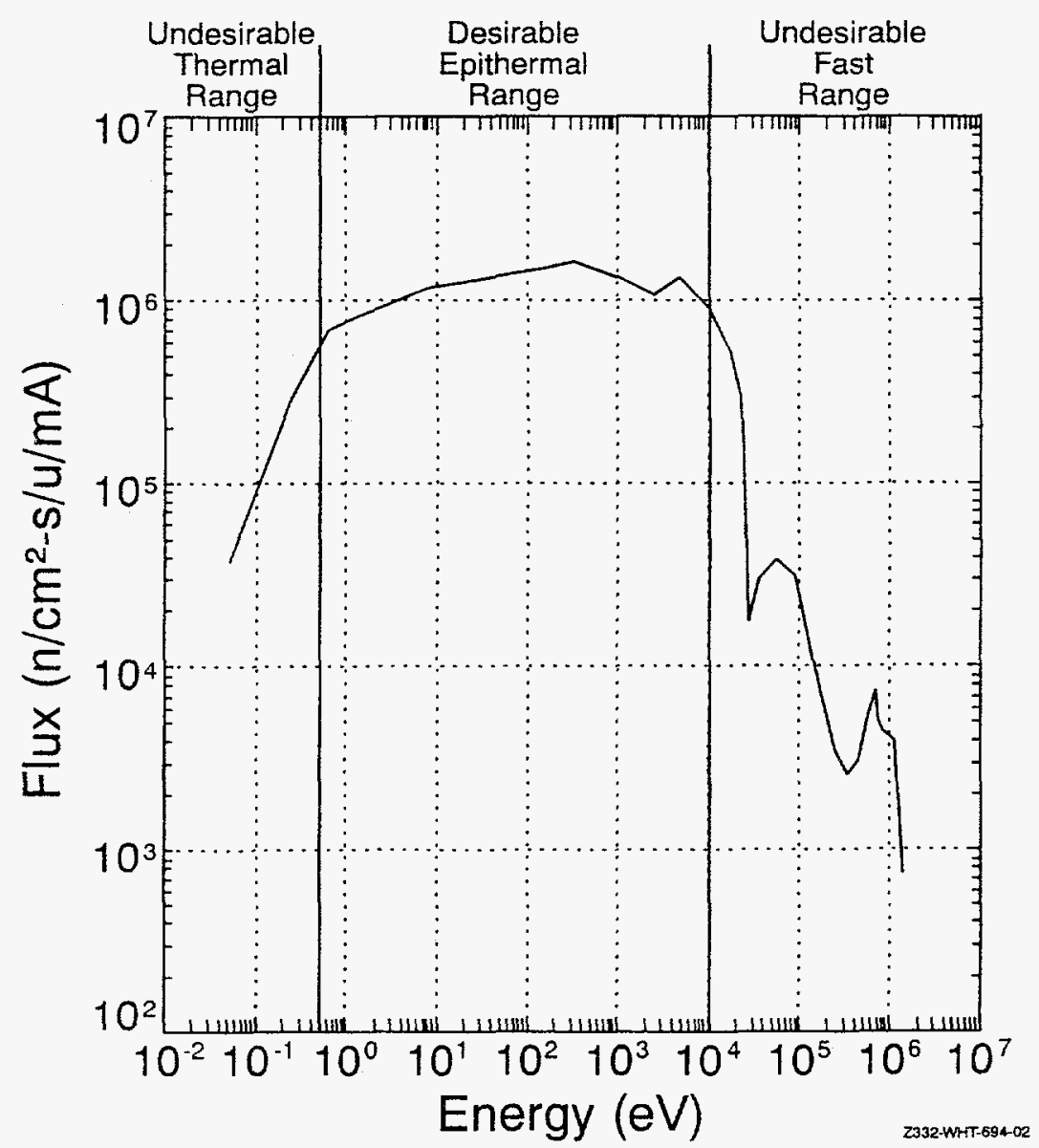

Figure 20. Free field flux spectrum for the conceptual BNCT epithermal neutron source design $\left(E_{e}=6 \mathrm{MeV}\right)$. 


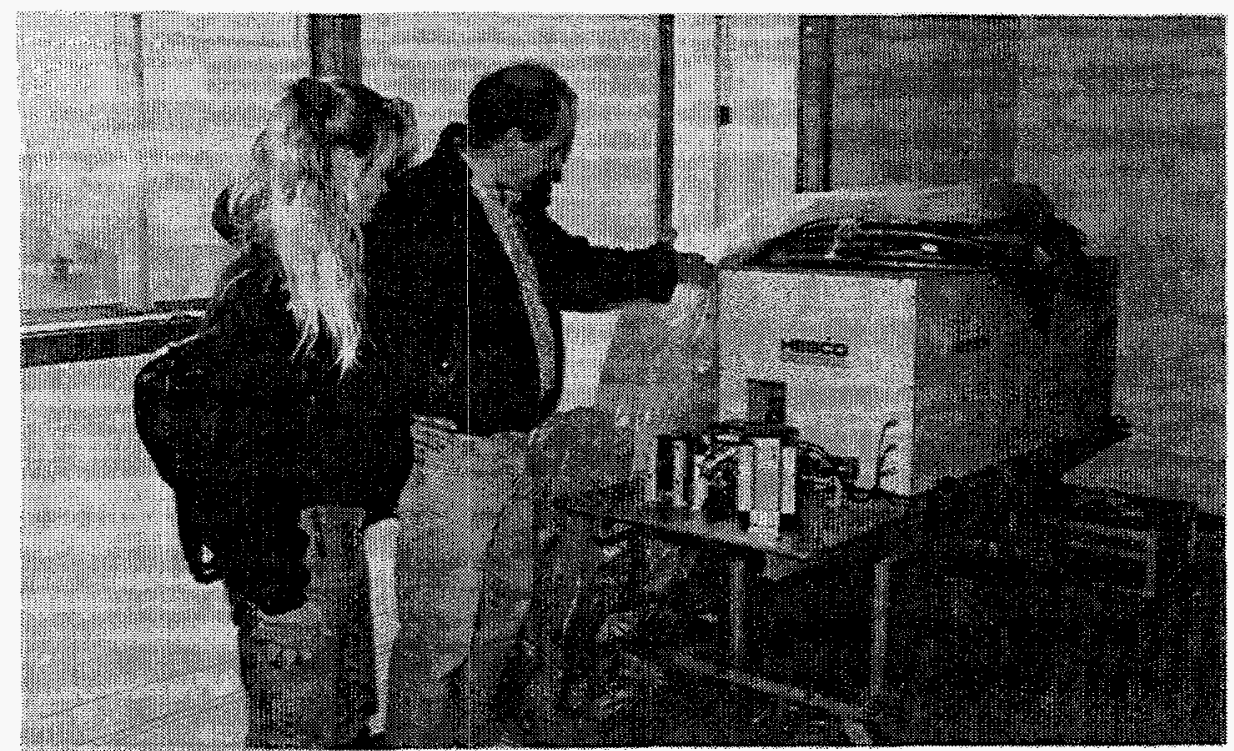

Figure 21. Varian electron linear accelerator.

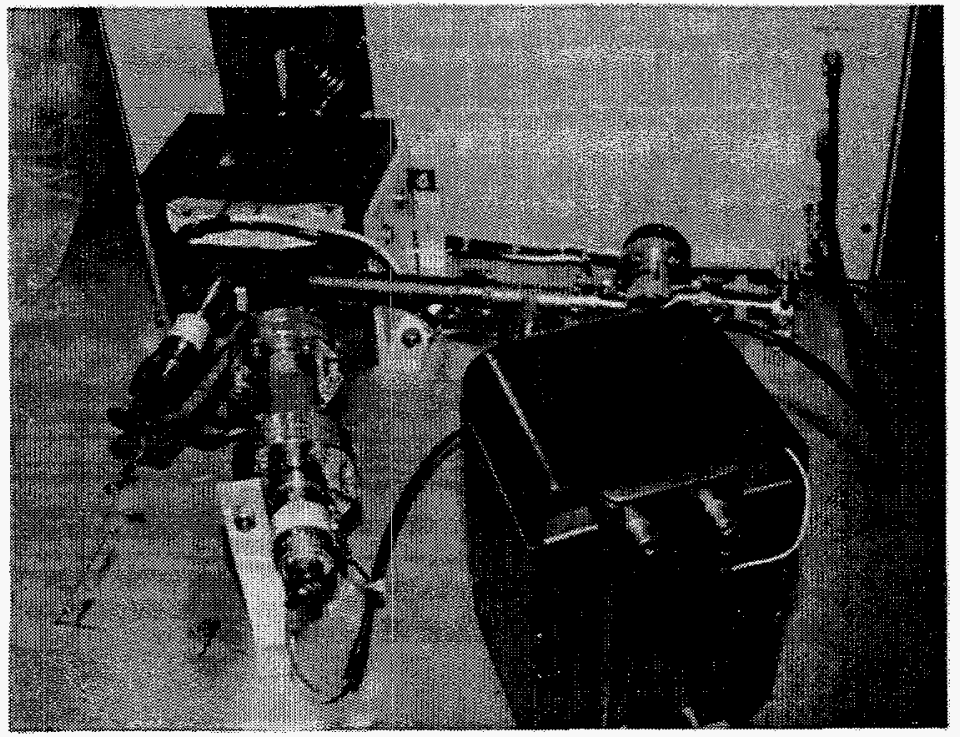

Figure 22. Varian electron linear accelerator - detail of the beam tube and target assemblies. 


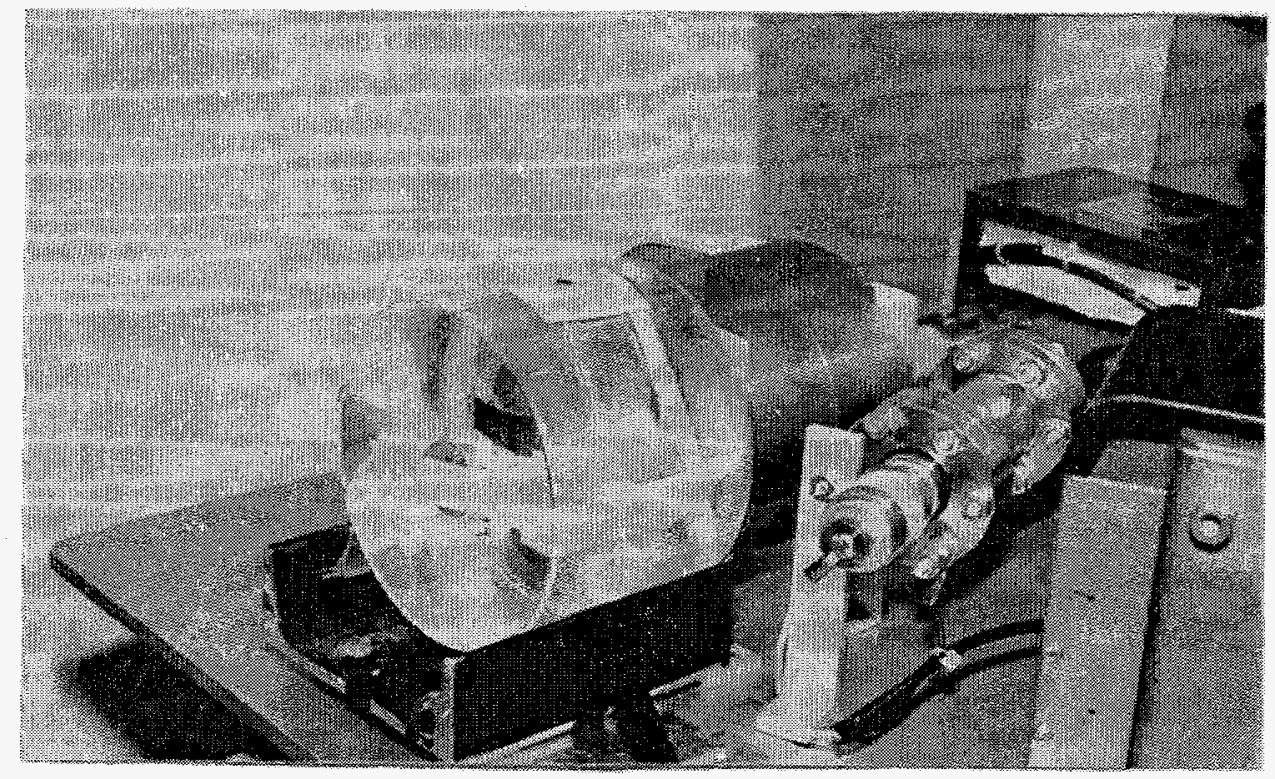

Figure 23. Varian electron linear accelerator with the collimator and photoneutron production module in place. Activation foil positions are also shown.

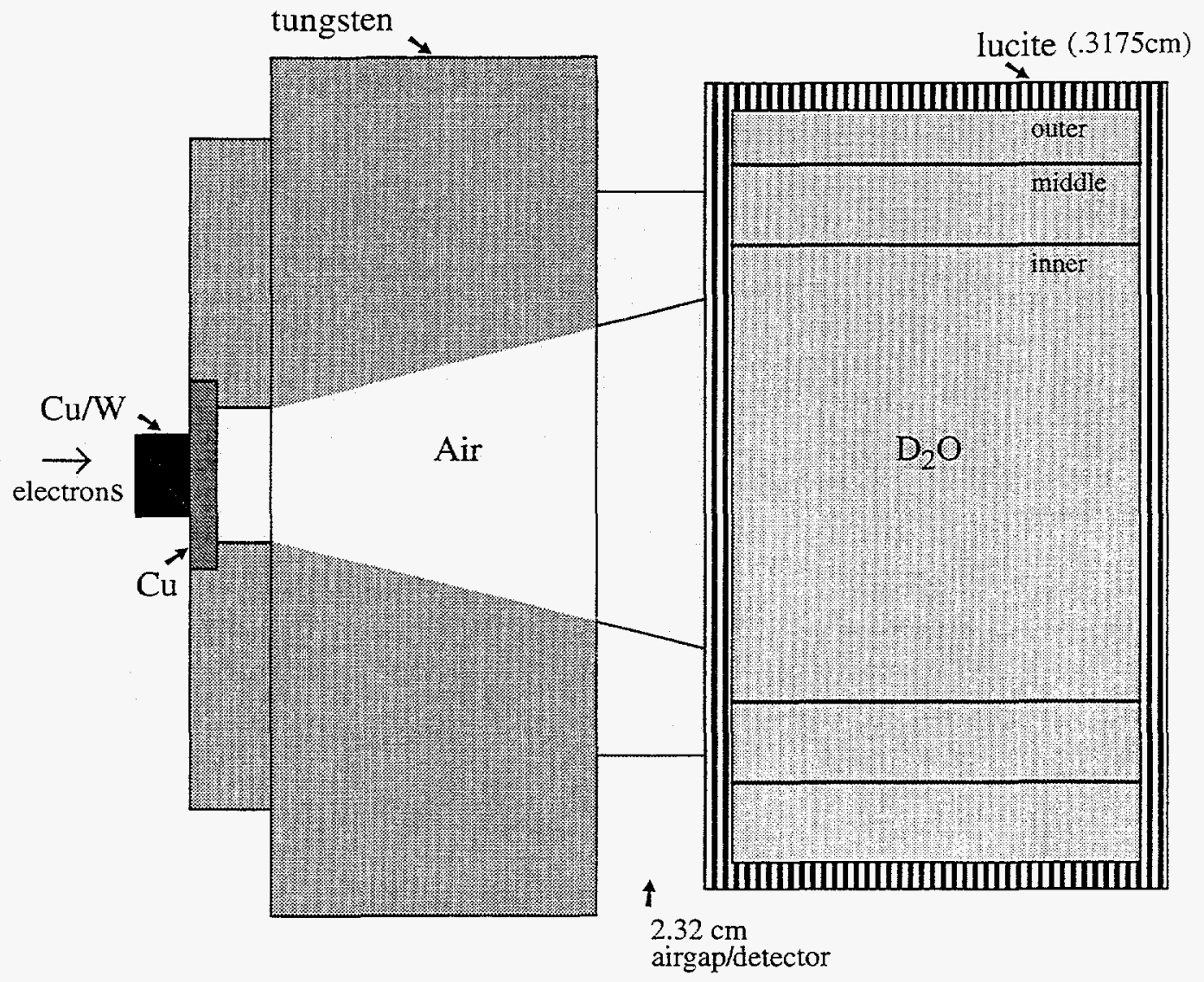

Figure 24. Schematic detail of the photoneutron production apparatus. 
container of $\mathrm{D}_{2} \mathrm{O}$ having an outer radius of approximately $76 \mathrm{~mm}$ and a height of approximately $100 \mathrm{~mm}$, and a wall thickness of approximately 3.2 $\mathrm{mm}$.

The measured activation of indium foils placed at the outer radius and on the outer face of the $D_{2} \mathrm{O}$ container was used to infer a measured photoneutron production rate within the container. This was done with the aid of a fine-mesh, 27-group, twodimensional, DORT discrete-ordinates neutron transport calculation of the foil activation per photoneutron produced within the container, assuming a theoretical photoneutron source spectrum for each nominal electron beam energy. The DORT model included the lucite container, the heavy water inside the container, and the indium foils. Cross section sets for all materials in this model were computed using the COMBINE ${ }^{15}$ code. The measured photoneutron source intensity in each case was obtained by dividing the measured foil activation rate by the calculated foil activation rate per source neutron produced in the $\mathrm{D}_{2} \mathrm{O}$ container.

The measured photoneutron production rate within the container, obtained as described above, was compared with the theoretical absolute photoneutron production rate within the container, calculated from first principles using the computational sequence previously illustrated in Figure 19. The theoretical calculation was normalized to the measured bremsstrahlung radiation field at a known location in the geometric setup (just downstream of the $\mathrm{D}_{2} \mathrm{O}$ container, on the beam axis, one meter from the tungsten accelerator target). This normalization procedure also yielded an estimate of the electron beam current produced by the accelerator for this particular experiment. A direct measurement of the electron current impinging on the accelerator target was also obtained by magnetically diverting the electron beam from the tungsten target into a second drift tube terminated by a Faraday cup. This second drift tube can be seen to the right of the main drift tube in Figures 22 and 23. The average energy and spectral distribution of the electron beam can also be directly estimated by varying the magnetic field used to divert the electron beam into the second drift tube and correlating the measured beam current with the strength of the magnetic field, which is, in turn, proportional to the energy of the beam. Thus, two independent methods for normalizing the theoretical calculation of the photoneutron source strength were available (the direct electron beam current measurement, and the normalization to the bremsstrahlung radiation flux at a known location).
Upon completion of the initial series of unfiltered photoneutron source experiments, a series of filtered neutron source experiments was conducted using the experimental arrangements illustrated in Figures 2529. For these experiments, the $D_{2} \mathrm{O}$ photoneutron source was set up as before, but a filtering region was added, downstream of the heavy water photoneutron source region, centered on the electron beam axis. Two different neutron filtering assemblies were used, both of which were designed to moderate and filter the photoneutron source emanating from the heavy water in a manner that produces a neutron spectrum suitable for epithermal-neutron BNCT at the irradiation point. The first neutron filter (Figures 2527) was constructed of a composite material ( $69 \%$ by weight $\mathrm{AIF}_{3}, 30 \%$ by weight $\mathrm{Al}$, and $1 \%$ by weight natural LiF), developed by the Technical Research Center of Finland (VTT-Finland). Four blocks of this patented material with a total mass of approximately $107 \mathrm{~kg}$ were provided to the INEL by VTT Finland for this work. This particular material was specifically developed by VTT as an epithermalneutron filter material for $\mathrm{BNCT}^{5}$. The dimensions of the filter region were $30 \times 30 \times 40 \mathrm{~cm}$, with an orientation such that the filter thickness along the beam axis for the data reported here was $30 \mathrm{~cm}$. The measured average density of the VTT filtering material was $3.01 \mathrm{~g} / \mathrm{cm}^{3}$. The entire filter was surrounded by $2.54 \mathrm{~cm}$ of borated polyethylene as shown in Figures 26 and 27, serving to isolate the filtering region from neutrons that are backscattered from the walls of the laboratory.

A second filtering arrangement composed of laminated $0.635-\mathrm{cm}$ Teflon $\left(\mathrm{CF}_{2}\right)$ and aluminum sheets was also tested, as shown in Figures 28 and 29. This concept was developed at the INEL as an alternate, high-efficiency, fluorine-based filter for epithermal neutron production. Teflon, which has a significantly greater resistance to radiation damage than one might first think ${ }^{16}$, is an inexpensive, readily available, chemically-stable fluorinecontaining material, which, in combination with aluminum, was postulated to be an effective neutron filtering material, provided that there is not an unacceptable level of spectral degradation by elastic scattering from carbon. Preliminary theoretical calculations using the DORT program indicated that this was indeed the case, hence a Teflon/Aluminum filter was constructed for testing and for comparison of its performance with that of the VTT material. The Teflon/Aluminum filtering region had a cubic configuration, $30.5 \mathrm{~cm}$ on a side, and once again, the entire filter region was surrounded by borated polyethylene for isolation from room return of neutrons. 


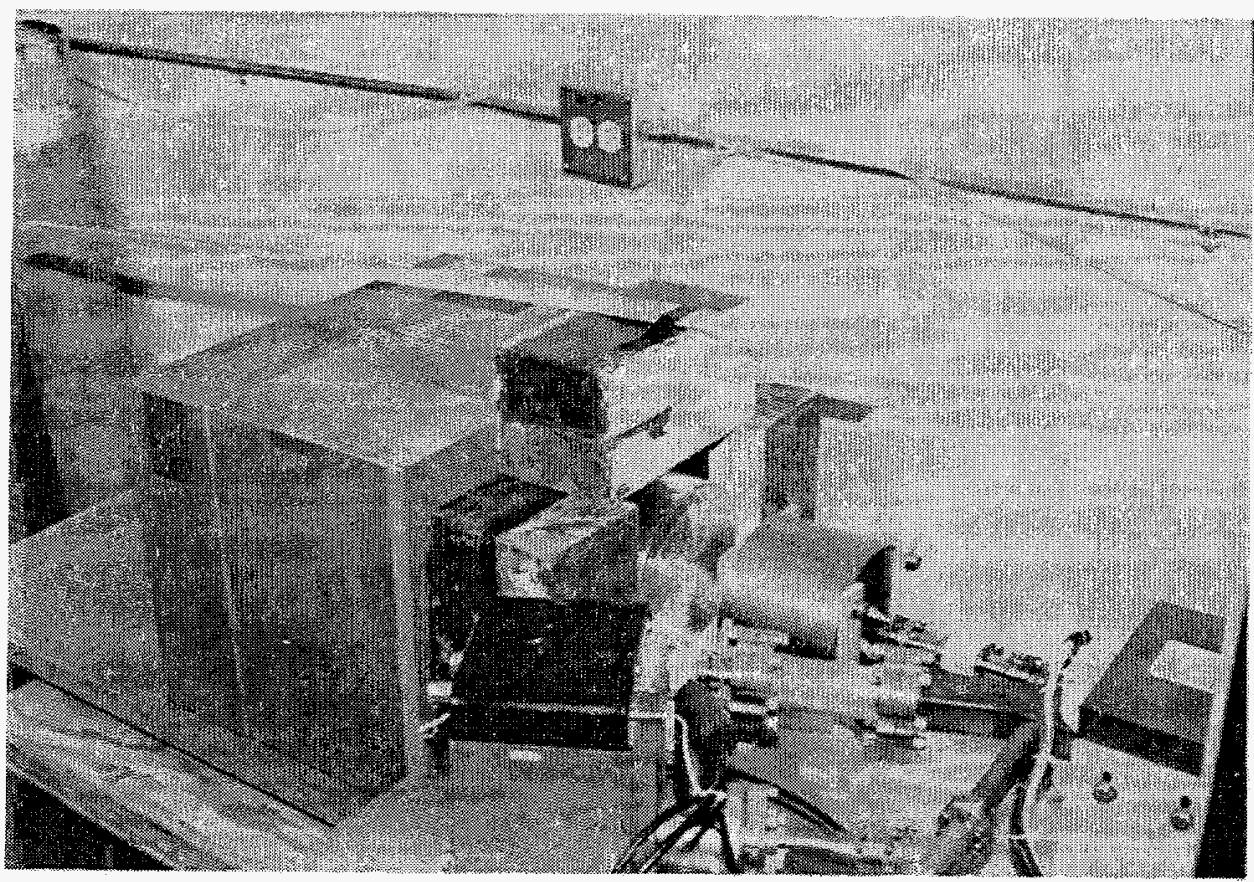

Figure 25. Photoneutron production and filtering apparatus, showing the VTT Aluminum Fluoride composite filtering blocks in place.

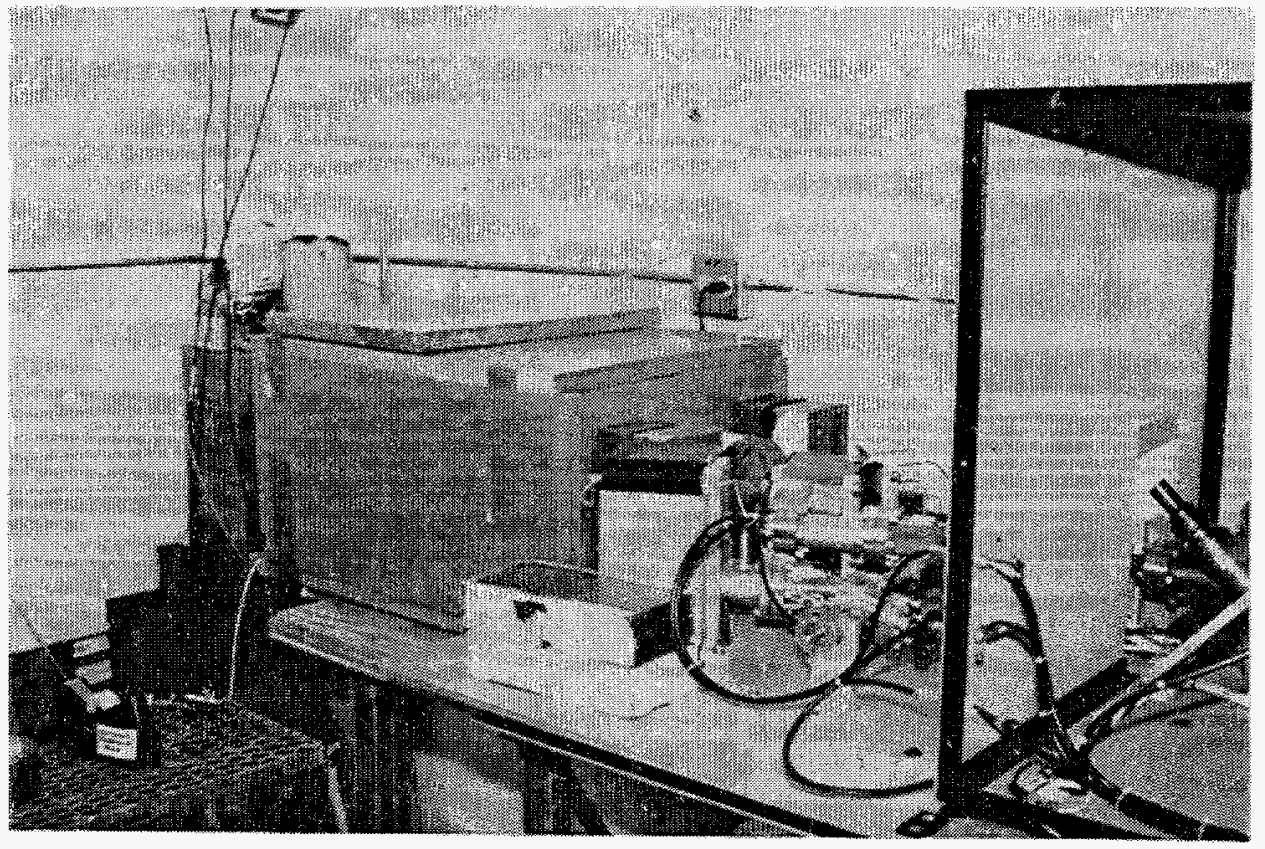

Figure 26. Photoneutron production and filtering apparatus, showing the VTT filtering material with the surrounding borated polyethylene isolation shield. 


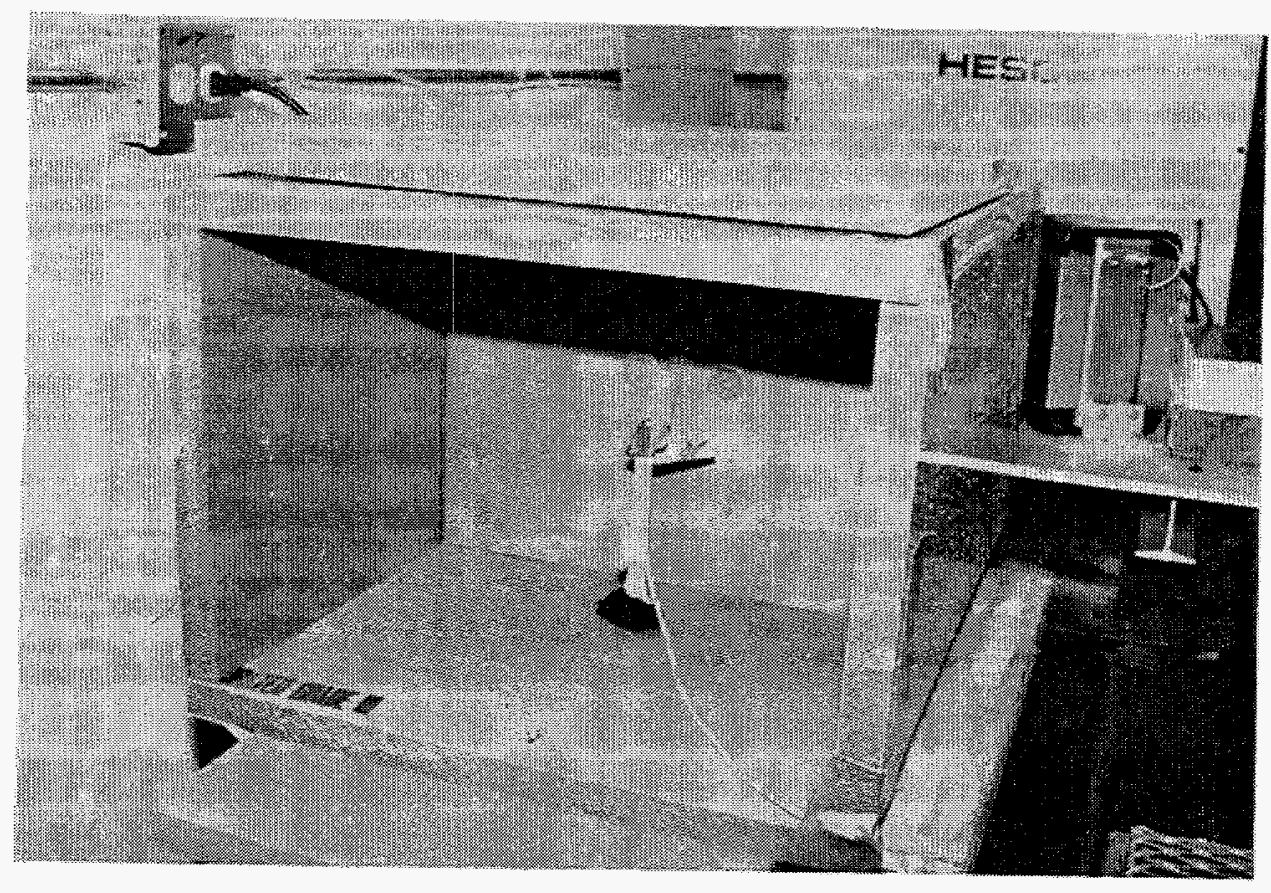

Figure 27. Downstream face of the VTT epithermal-neutron filter, showing activation foil and ion chamber placement. The end cover has been removed for clarity.

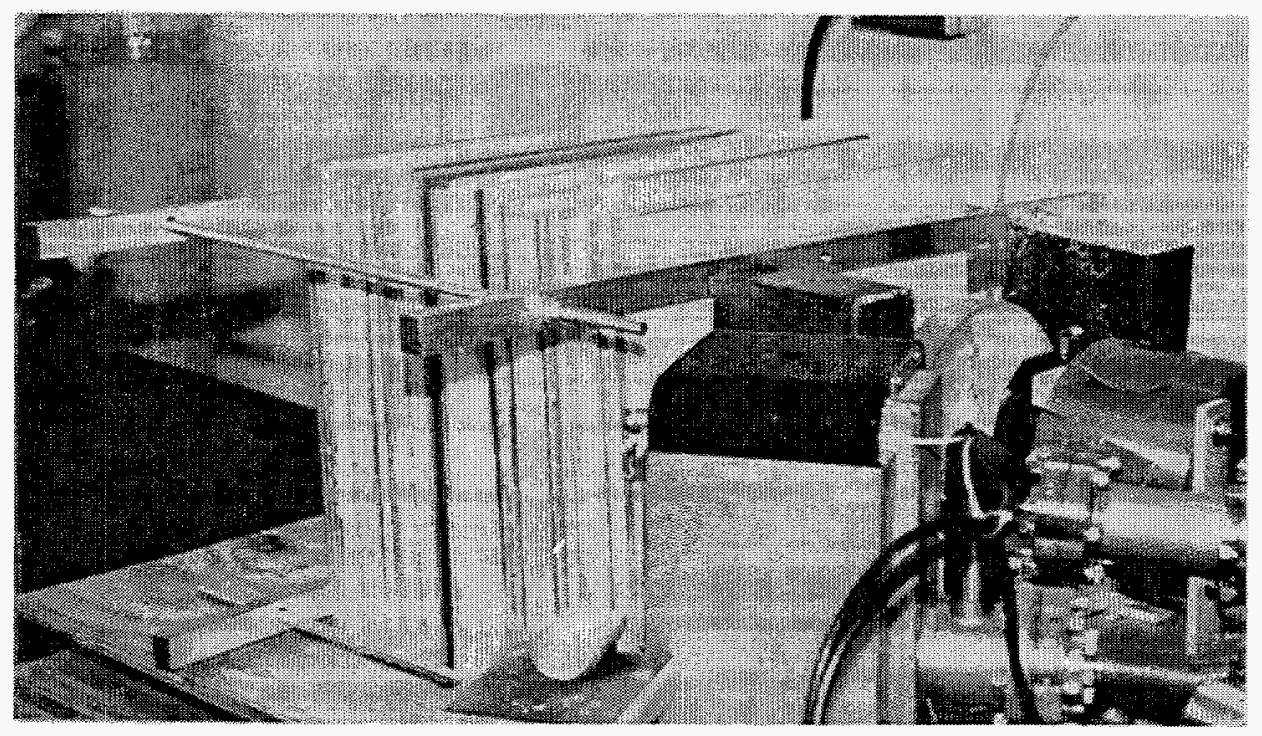

Figure 28. Photoneutron production and filtering apparatus, showing the Teflon/Aluminum filtering module in place. 


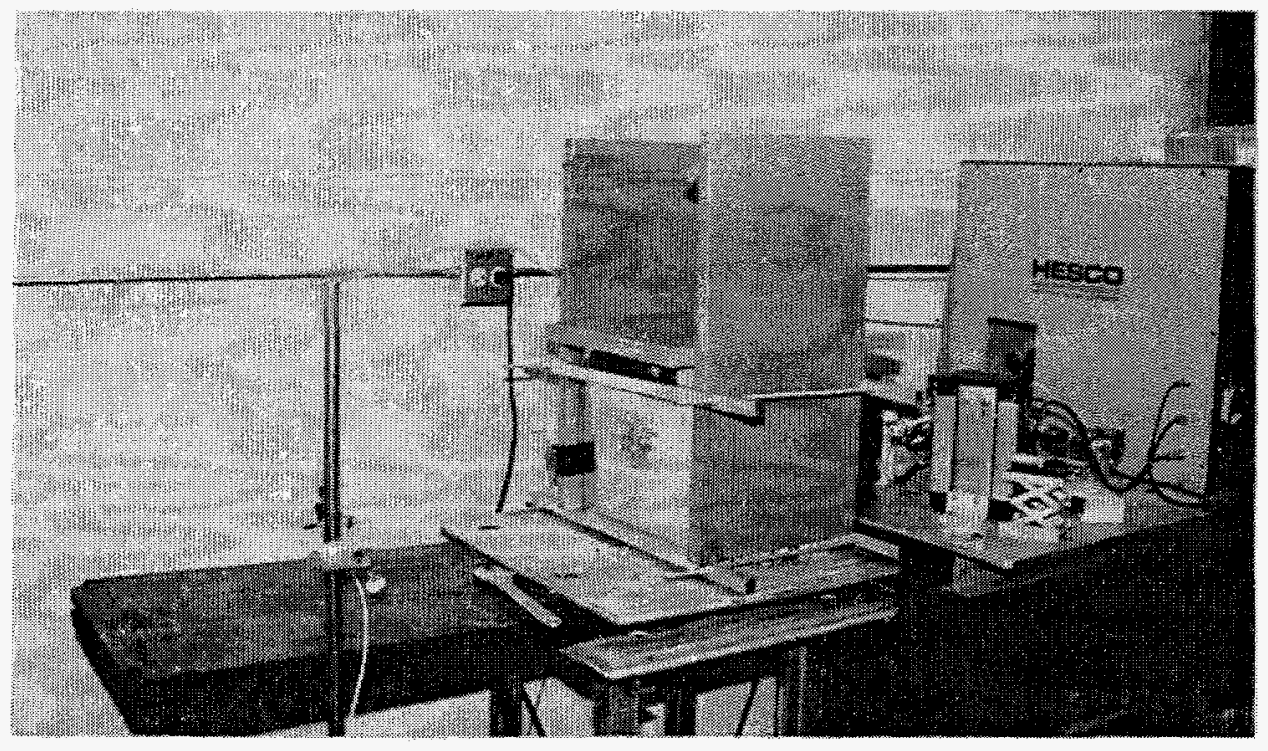

Figure 29. Downstream face of the Teflon/Aluminum epithermal-neutron filter, showing activation foil placement as well as the placement of the borated polyethylene isolation shield. (The downstream polyethylene cover has been removed.)

The electron beam energy used for the filtered neutron source measurements was established at a nominal average value of $6 \mathrm{MeV}$, although there is believed to have been a significant spread of electron energy around this nominal value due to the performance characteristics of the Varian electron LINAC. In particular the data indicated that there was a significant fraction of high-energy $(7-8 \mathrm{MeV})$ electrons in the electron beam. Since the accelerator is nominally designed to operate at approximately 9 $\mathrm{MeV}$ under ideal loading conditions, this was not an unexpected phenomenon.

Measurements of the filtered neutron source intensity and spectral characteristics produced by each of the two filtering arrangements were performed using standard resonance and threshold activation foil techniques. The foil materials and interactions that were employed in various combinations for the measurements are shown in Table 2 . With one exception, the activation interactions used for the measurements were insensitive to the gamma component of the neutron field. In the case of the Indium-115 inelastic scattering interaction, it was necessary to experimentally correct for photoninduced activation by repeating all measurements using light water rather than heavy water in the photoneutron production region. This provided a measurement of the purely photon-induced component of the total reaction rate for this interaction, all other factors being equal. The copper and gold foils were cadmium-covered, to eliminate their response to the thermal neutron component of the flux field. Indium foils were used both with and without cadmium covers. After irradiation, the induced activity of each foil was counted using standard calibrated germanium gamma detectors and PC-based gamma spectrum analysis software.

Neutron intensity and spectral measurements were taken at two locations in the experimental apparatus: 1) on the electron beam axis, between the $D_{2} \mathrm{O}$ photoneutron source region and the filter region (the "upstream" side of the filter) and, 2) on the opposite, "downstream", side of the filter, again on the beam axis, as shown, for example, in Figure 27. Thus, a direct comparison of the neutron flux intensity and spectral characteristics on opposing sides of the filter, on the beam axis, could be obtained. Once again, an ion chamber was placed on the downstream side of the filter for calibration and normalization purposes, as shown in Figure 27, although a direct measurement of the electron current from the accelerator target to ground was used as the primary means for normalization of the filtered neutron source experiments.

Directly-unfolded neutron spectral data for sets of coarse neutron energy intervals over the entire energy range of interest (from thermal energy up to approximately $2.5 \mathrm{MeV}$ ) were obtained for each experiment. In the case of the experiments involving the VTT filtering material, indium foils with and without cadmium covers, as well as cadmiumcovered gold and copper foils were placed at separate azimuthatly-symmetric locations about the beam axis 
Table 2. Activation foil interactions used in the epithermal photoneutron source experiments.

\begin{tabular}{lll}
\hline Interaction & \multicolumn{1}{c}{$\begin{array}{c}\text { Energy Range of Maximum } \\
\text { Cross Section }\end{array}$} & $\begin{array}{c}\text { Activation Gamma Energies } \\
\text { of Interest (keV) }\end{array}$ \\
\hline In-115 (n,gamma) & Thermal and $1 \mathrm{eV}$ Resonance & $1293,1097,416$ \\
In-115 (n,n') & Threshold at $430 \mathrm{keV}$ & 336 \\
$\mathrm{Au}-197(\mathrm{n}$, gamma) & Resonance at $5 \mathrm{eV}$ & 411 \\
$\mathrm{Cu}-63(\mathrm{n}$, gamma) & Resonance at $1 \mathrm{keV}$ & 511 (Positron) \\
\hline
\end{tabular}

on the downstream side of the filter. Indium foils alone, again with and without cadmium covers, were placed on the upstream side of the filter. This provided three linearly-independent foil response functions (i.e. effective foil cross sections as a function of neutron energy) on the upstream side of the filter and five linearly-independent response functions on the downstream side. These were: neutron capture in indium with and without cadmium as well as inelastic scatter in indium (experimentally corrected as described previously for photon activation of the $336 \mathrm{keV}$ indium-115 isomer), for the upstream side of the filter, and the same three indium response functions along with neutron capture in gold and copper for the downstream side. The foil arrangement described above thus permitted measured spectral information to be generated for a maximum of three coarse neutron energy groups over the energy range of interest on the upstream side of the VTT filter and for a maximum of five coarse energy groups on the downstream side of the filter. Effective shielded cross sections for each foil were computed for use in the spectral unfolding process using a $27-$ group DORT model of the entire apparatus, including the foils. Detailed, 27-group cross section data for all materials in the DORT model were generated using the COMBINE code. Coarse-group selfshielded foil cross sections for unfolding were then prepared by averaging the 27 -group detailed foil cross sections over the calculated a-priori 27 -group neutron fluxes within each coarse group, at each foil location.

In the case of the Teflon/Aluminum filter experiments, a slightly different spectral characterization procedure was used. A single cadmium-covered indium foil was placed on the upstream side of the filter for normalization. Five indium foils, followed by one copper foil, were stacked in a single cadmium-covered package that was placed on the beam axis on the downstream side of the filter, with the copper foil located on the downstream side of the foil package. With this arrangement the interior indium foils in the downstream package were thus shielded from resonance neutrons, forcing them to have linearlyindependent spectral responses relative to that of the first indium foil in the stack, which was directly adjacent to the downstream face of the filter, unshielded from resonance neutrons. Also, the copper foil was heavily-shielded from neutrons below about $100 \mathrm{eV}$ by the intervening indium foils, forcing its spectral response more toward the energy range of the primary resonance for this particular foil material. The measured inelastic scatter reaction rates of all five indium foils were added together to provide more sensitivity in the energy range above the threshold for this interaction.

Four spectral response functions having a useful degree of linear independence were thus available from the downstream foil package used for the Teflon/Aluminum filter measurements. These were: inelastic scatter in indium (once again experimentally corrected for photon activation of the $336 \mathrm{keV}$ indium-115 isomer), neutron capture in the first indium foil, neutron capture in one of the interior indium foils (the center foil in the package of five was used), and finally, neutron capture in copper, shielded by indium. Effective shielded cross sections used in the spectral unfolding process for all foils in the stack were computed in this case using an MCNP model of the filter and foil package, since the COMBINE resonance model would not be appropriate for multiple foils.

Finally, it may be noted that all of the unfiltered and filtered neutron source experiments described above were designed to have a simple geometry that could be easily modeled in theoretical a-priori calculations using the DORT code in cylindrical geometry. All components in the neutron production and filtering apparatus were arranged in a coaxial relationship along the extended electron beam axis, with a high degree of azimuthal symmetry about this axis. This 
arrangement also served to maximize the photon component of the filtered neutron source at the measurement locations, as an aid in calibration and normalization of the absolute neutron intensity measurements.

As can be seen from Figure 17, the coaxial geometric arrangement used for the proof-of-principal experiments would not be appropriate for an actual clinical device. At the relativistic electron energies of interest in this concept, the bremsstrahlung radiation produced in the electron LINAC target is highlypeaked in the foreward direction and is approximately an order of magnitude smaller in the direction at right angles to the electron beam axis. Hence in a clinical device, one would desire to locate the patient irradiation point as shown in Figure 17, on an axis perpendicular to the electron beam axis, in order to minimize the photon contamination of the clinical neutron source at the irradiation point. Accordingly, an additional experiment was performed using the arrangement shown in Figures 30-32, where the VTT filtering material was stacked vertically above the $\mathrm{D}_{2} \mathrm{O}$ photoneutron production module, at right angles to the beam axis. The filtering thickness was again $30 \mathrm{~cm}$ and the cylindrical $\mathrm{D}_{2} \mathrm{O}$ container was turned on its side, with the bremsstrahlung source from the accelerator impinging radially rather than axially onto the container.

The vertical filter configuration allowed an initial experimental confirmation of the postulate that a suitable neutron source could be produced with the apparatus aligned with the neutron and electron beam axes oriented at right angles. This measurement also provided a preliminary indication of the photon content of the filtered neutron source at right angles to the electron beam axis. Only the total neutron fluxes on the upstream and downstream sides of the neutron filter were measured. This was done using cadmium-covered indium foils. No spectral data were taken. The photon dose rate at the irradiation point was measured using a calibrated ion chamber. Lead shielding was placed around the ion chamber as shown in Figure 31 in order to exclude stray photons scattered from behind the accelerator target region by the surrounding air, so that the ion chamber reading would include only photons passing directly through the filter assembly to the measurement point from the photoneutron production region.

\section{RESULTS}

The results of the unfiltered photoneutron source strength experiments are shown in Figure 33 for three different average electron beam energies. The theoretical calculations of the photoneutron source produced within the container, normalized to the downstream bremsstrahlung flux measurements for each electron beam energy, are also shown for comparison. (Normalization of the theoretical calculations to the directly-measured electron beam current for each beam energy produces essentially the same results). Agreement between theory and experiment is well within a factor of two over the electron energy range considered, validating that the computational methods used to estimate the performance of the conceptual clinical device described earlier do indeed produce realistic results for the absolute intensity of the photoneutron source that can be generated.

The results of the on-axis filtered photoneutron experiments are shown in Figures 34 and 35 . Apriori calculated (27-group DORT) neutron spectra for on the upstream and downstream measurement locations are shown along with the measured neutron flux data, unfolded from the foil activation rates using a direct inversion of the matrix equation describing the relationship between the foil activation rates and the corresponding neutron fluxes in each coarse energy group over the range of interest. In these figures, the spectral data are plotted at the lethargy midpoint of each coarse energy group defined in the unfolding process. The calculated spectra are normalized in each case to the measured activation rates of the upstream indium foils, which, in turn, bear a known relationship to the electron LINAC beam current and photoneutron production rate, as demonstrated by the unfiltered neutron source experiments described previously. This allows a direct comparison of the measured and calculated downstream neutron fluxes, with the calculation normalized to the measured upstream flux. The measured neutron flux data shown in the figures are simply the unfolded absolute fluxes per unit lethargy at each energy.

As can be seen from Figures 34 and 35 , both the VTT filtering material and the Teflon/Aluminum filter produce neutron spectra that are in general agreement with expectations, with the VTT material being somewhat more effective in reducing the fast neutron component of the spectrum for a given filter thickness, although the experimental uncertainty is somewhat large, due to the low intensity of this component relative to the desirable epithermal component. It is of interest that the measured intensities of the downstream neutron sources produced by both of the filtering arrangements were actually somewhat higher than expected, relative to the upstream photoneutron source intensities used for normalization. 


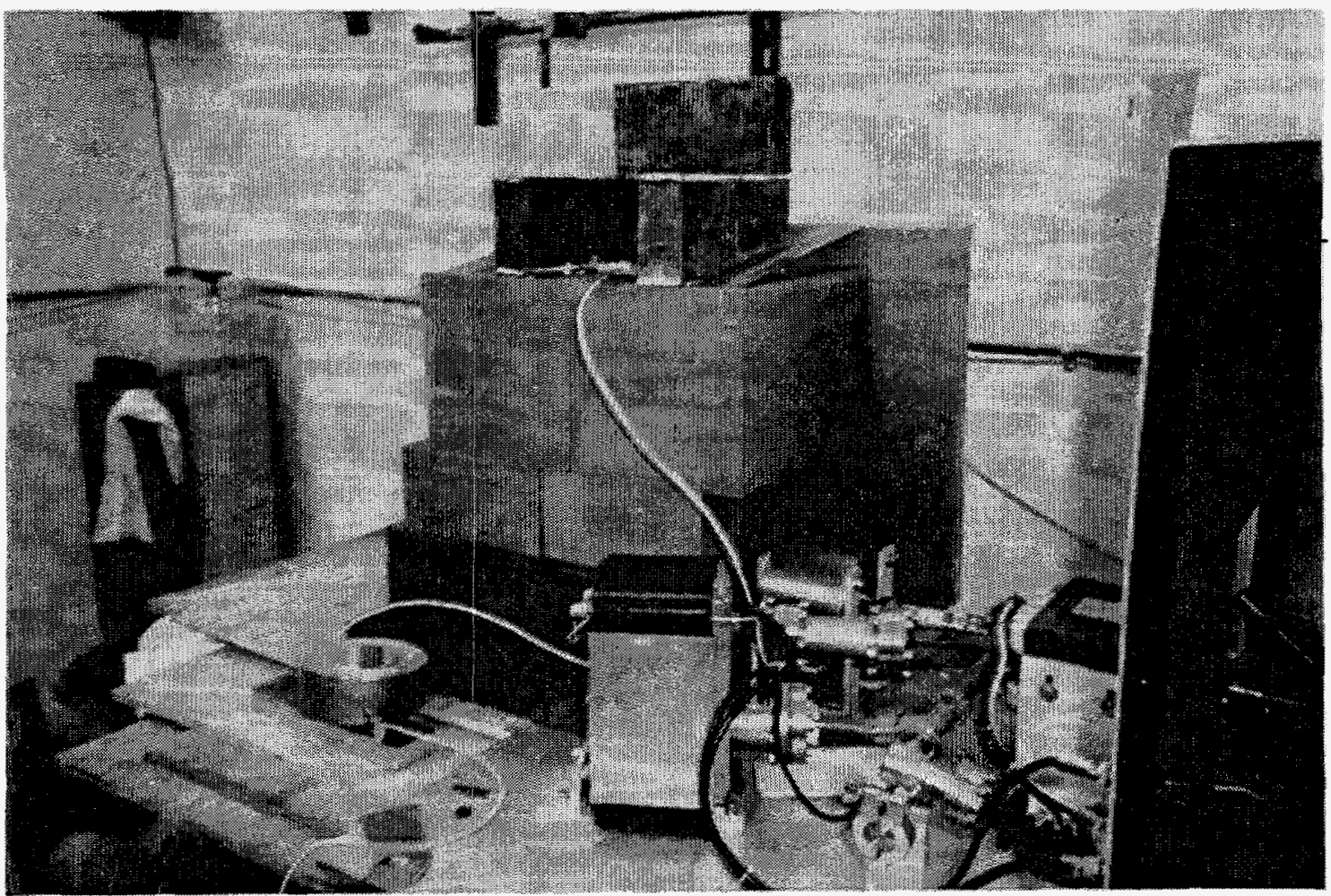

Figure 30. Photoneutron production and filtering apparatus, with the VTT filtering material oriented such that the neutron source axis of symmetry is at right angles to the electron beam axis.

Measurement of the total neutron flux on the downstream side (i.e. the top) of the VTT filtering material for the off-axis configuration illustrated in Figures $30-32$ yielded a value of of $8.7 \times 10^{4}$ neutrons $/ \mathrm{cm}^{2}-\mathrm{s}$ at an electron beam current of approximately 5 microamperes. This is comparable to the total downstream neutron flux produced with the coaxial arrangement using the same filter, obtained by integrating under the downstream spectrum curve in Figure 34. When sufficient shielding from air scatter of photons emanating from the accelerator target region was provided, the photon dose rate from radiation passing directly through the filter to the measurement point was below the published detection limit of the instrumentation (approximately $1 \mathrm{mR}$ per minute, or $1.67 \times 10^{-5} \mathrm{cGy}$ per second). Combining the photon and neutron measurements thus yields a maximum photon dose at the measurement point of approximately $2.0 \times 10^{-10}$ cGy per unit neutron fluence. This could easily be reduced by an order of magnitude, to below the radiobiologically-acceptable maximum, by inclusion of gamma shielding on the downstream face of the filter, as was specified in the clinical concept described previously. It should be emphasized, however, that although the results of these measurements for an irradiation point located on an axis at right angles to the electron beam axis are highly-encouraging, the results are quite preliminary in nature and are subject to a rather high level of exerimental uncertainty due to the ad hoc nature of the experimental setup that was used. Additional proof-of-principal measurements with more prototypical, properly-shielded, geometry will be necessary as described below.

\section{DISCUSSION AND CONCLUSIONS}

Theoretical computations as well as the initial experimental neutron source intensity and spectral data presented in this work indicate that, with some careful engineering, the proposed photoneutron device could offer a promising alternate approach to the production of epithermal neutrons for BNCT. Clinically-useful neutron source intensity and spectral purity levels appear to be attainable by straightforeward scaling using existing electron accelerator technology ${ }^{8}$. Heat transfer studies performed to date ${ }^{18}$ indicate that the accelerator target and photoneutron production components of the proposed device can be designed in such a manner that waste heat from the entire process is effectively removed, although once again, careful engineering and prototype testing will be required. In addition, measurements indicate that photon contamination of the neutron source at the patient location appears to 


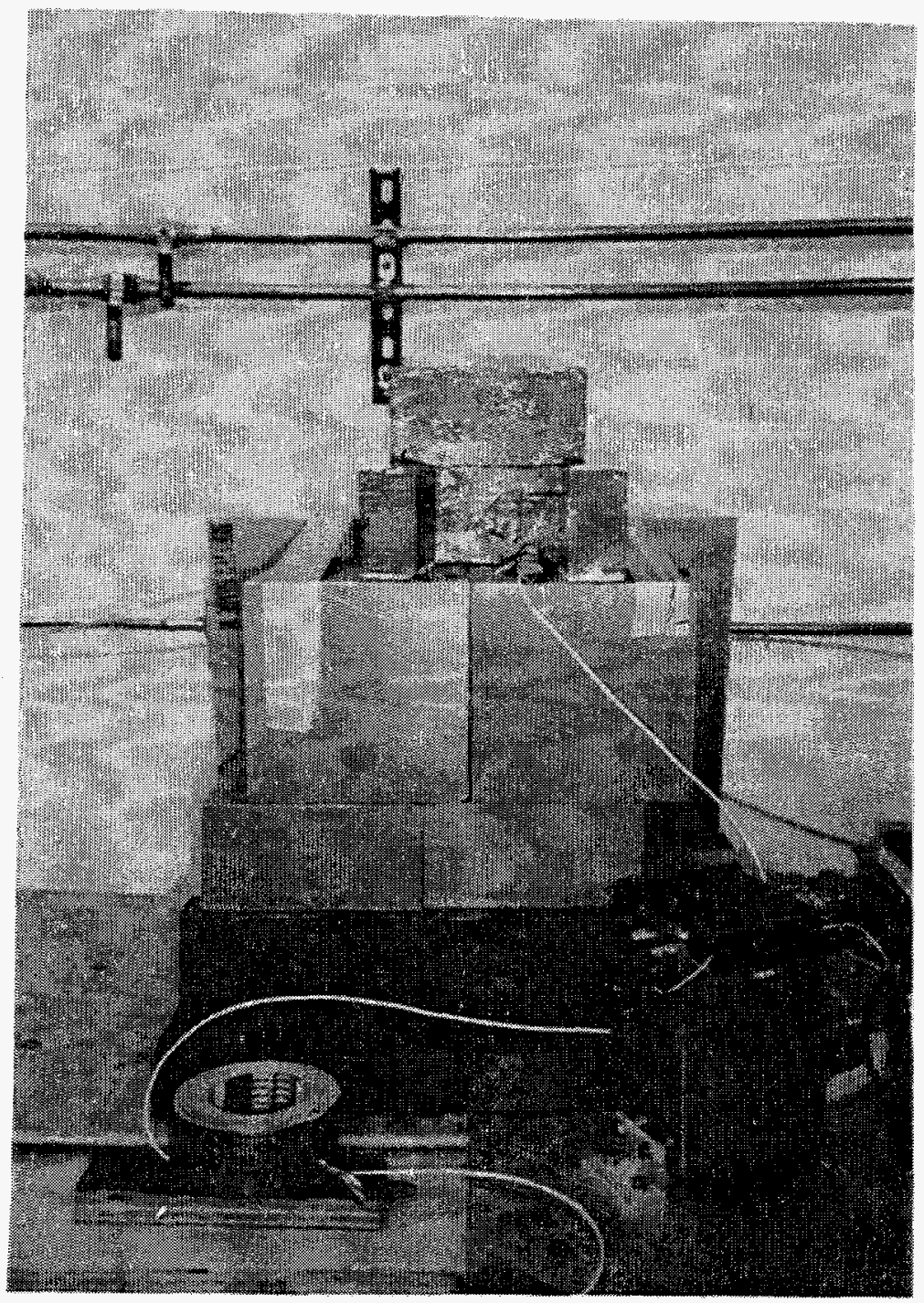

Figure 31. Side view of the vertical filter apparatus, showing the placement of the ion chamber and shielding on the downstream (top) face.

be controllable to acceptable levels. In summary, the data show that reconciliation of the conflicting objectives of target cooling, neutron beam intensity, and neutron beam spectral purity that are inherent in the design of essentially all proposed accelerator neutron sources for BNCT may very well be achievable in a practical clinical device based on the photoneutron concept. Figure 36 shows an artist's concept of such a clinical device.

Near-term future work on this concept will be focused in two areas. First, the electron beam drift tube of the electron LINAC will be extended in length by about $60 \mathrm{~cm}$. This will allow construction of an experimental arrangement that allows the irradiation point to be on an axis at right angles to the electron beam axis, with both axes in a horizontal plane rather than in a vertical plane. This will in turn allow the construction of more prototypical shielding to eliminate stray photons from various components of the system, permitting a more realistic measurement of the photon content of the neutron source at the irradiation point. Control of photon contamination of the neutron source to acceptable levels at the irradiation point is crucial to the succcess of the overall concept developed in this work. Second, it is anticipated that an L-Band electron LINAC having the capability to produce an electron beam with an effective DC current that is approximately two orders of magnitude greater than is the case with the Varian electron LINNAC used in the work presented here will be available to the investigators within the next two years. This will allow improved proof-ofprincipal measurements of the type discussed here to 


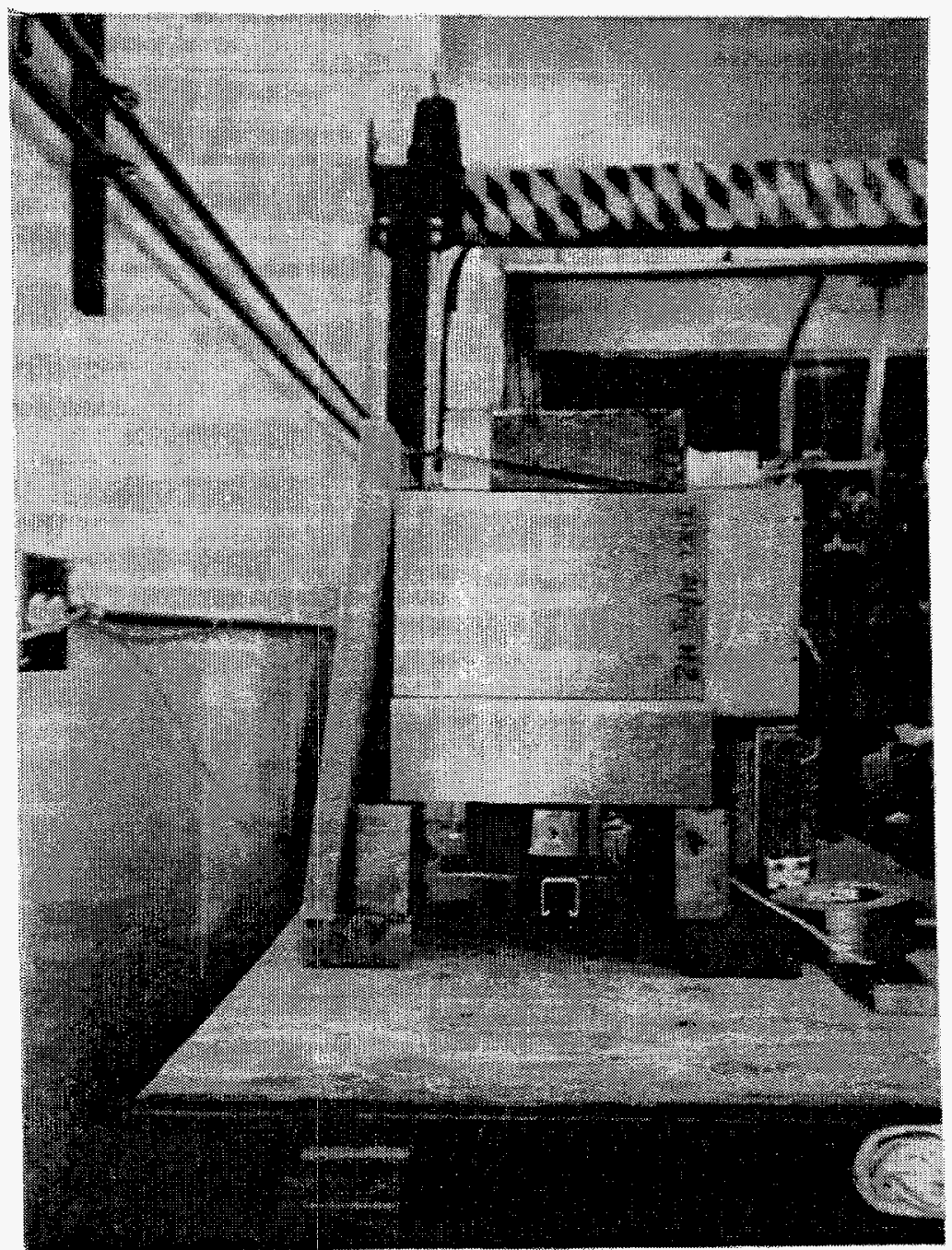

Figure 32. View underneath the vertical filter apparatus, looking up the electron beam axis, showing the heavywater container orientation.

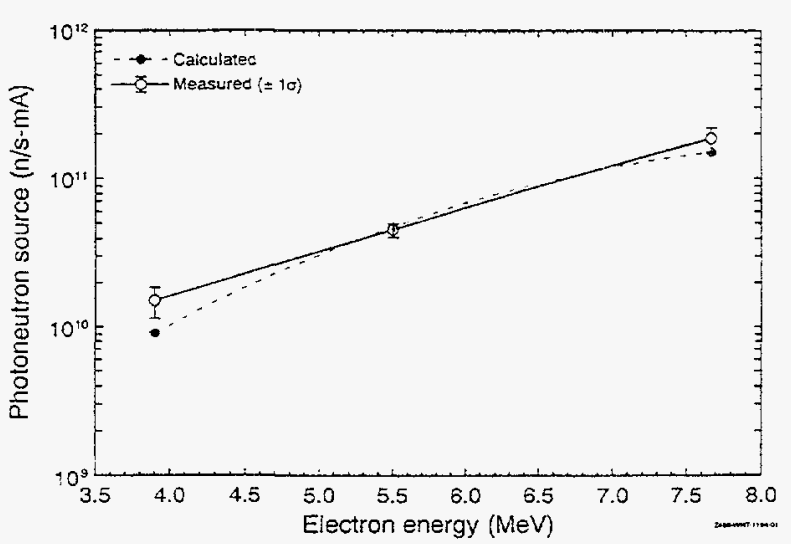

Figure 33. Calculated and Measured Total Photoneutron Sources for the Varian Photoneutron Experiment. be performed in a manner that allows much greater spectral detail as well as a significantly-reduced level of experimental uncertainty. In addition, experimental optimization studies leading to the design of a full-scale device will be greatly facilitated.

\section{ACKNOWLEDGEMENTS}

The Technical Research Centre of Finland (VTTFinland) provided, essentially at cost, four blocks of the specialized $\mathrm{AlF}_{3} / \mathrm{Al} / \mathrm{LiF}$ epithermal-neutron filtering and moderating material used for part of this work. The assistance of Iiro Auterinen, of VTTFinland, in this matter is gratefully acknowledged. Also the efforts of the investigators were greatly facilitated by the assistance of Idaho State University Environmental Monitoring Laboratory, which 


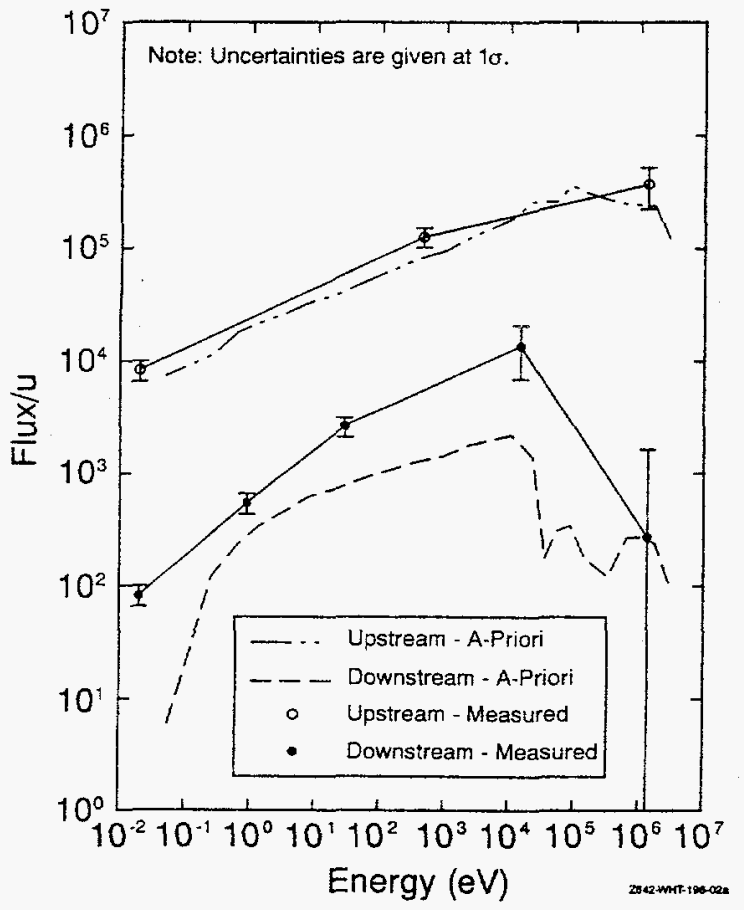

Figure 34. A-Priori and Measured Photoneutron Spectra for the $30-\mathrm{cm}$ Aluminum-Aluminum Fluoride Lithium Fluoride Filtering Assembly. (Electron Current $=3.7$ microamperes)

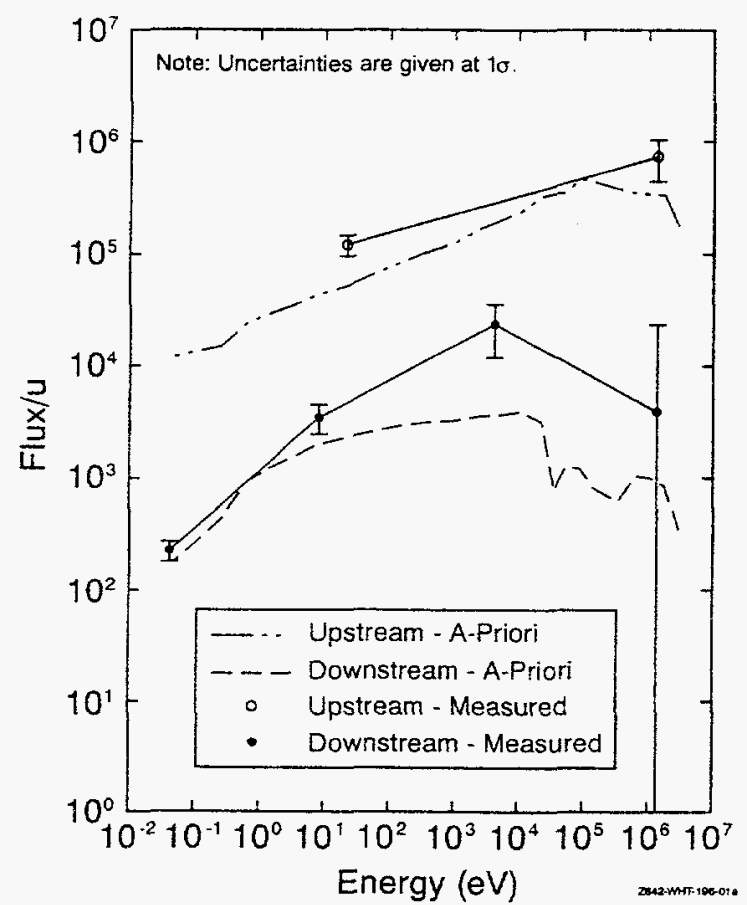

Figure 35. A-Priori and Measured Photoneutron Spectra for the $30-\mathrm{cm}$ Aluminum-Teflon Filtering Assembly. (Electron Current $=6.2$ microamperes) provided access to the gamma spectroscopy equipment used for the foil measurements. The investigators also gratefully acknowledge the participation of Idaho State University students Lane Tramell, Jim Seamans, and Jim Lewanctowski, who provided general assistance with operation of the electron LINAC, setup of experiments, etc. Chuck Wemple (INEL) performed MCNP computations to obtain effective shielded neutron cross sections for some of the activation foils. Finally, it may be noted that one of the investigators (HEM) performed much of this work in partial fullfillment of the requirements for her Ph.D. degree from the Georgia Institute of Technology, via an Associated Western Universities (AWU) student internship sponsored by the INEL.

\section{REFERENCES}

1. Wheeler, et. al., "Epithermal Neutron Beam Design for Neutron Capture Therapy at the PBF and BMRR Reactor Facilities", Nuclear Technology, 92:106-117 (1990).

2. Harling, et. al., "Boron Neutron Capture Therapy and Radiation Synovectomy Research at the Massachusetts Institute of Technology Research Reactor", Nuclear Science and Engineering, 110:330 (1992).

3. Nigg and F.J. Wheeler, "Conceptual Physics Design for an Epithermal-Neutron Beam at the Georgia Institute of Technology Research Reactor", Transactions of the ANS, 65:146 (1992).

4. Moss, "Progress Towards Boron Neutron Capture Therapy at the High-Flux Reactor Petten", Neutron Beam Design. Development, and Performance for Neutron Capture Therapy, O.K. Harling, et. al., Editors, Plenum Press, New York, 1990.

5. Auterinen and P. Hiismaki, "Epithermal BNCT Neutron Beam Design for a TRIGA II Reactor", Advances in Neutron Capture Therapy, R. Barth and A. Soloway, Editors, Plenum Press, New York, 1993, pp 81-84.

6. Wang, et. al., "A Neutronic Study of an Accelerator-Based Neutron Irradiation Facility for Boron Neutron Capture Therapy", Nuclear Technology, 84:93 (1989)

7. Yanch, et. al., "Accelerator-Based Epithermal Neutron Beams for Neutron Capture Therapy", 
Advances in Neutron Capture Therapv, R. Barth and A. Soloway, Editors, Plenum Press, New York, 1993, pp 95-98.

8. Crawford, et. al., "Neutrons for Capture Therapy Produced by $72 \mathrm{MeV}$ Protons," Progress in Neutron Capture Therapy for Cancer, B.J. Allen, et. al., editors, Plenum Press, New York, 1992.

9. Jones and W.Y. Yoon, "Feasibility Study of the Application of a Linear Electron Accelerator to BNCT", Proceedings of the 12th International Conference on the Application of Accelerators in Research and Industry, University of North Texas, Denton TX, November, 1992.

10. Hablieb and T.A. Mehlhorn, "ITS - The Integrated TIGER Series of Coupled Electron/Photon Monte Carlo Transport Codes", SAND84-05873, Sandia National Laboratory, November, 1984.

11. Rhoades and R.L. Childs, "An Updated Version of the DOT-4 One- and Two-Dimensional Neutron/Photon Transport Code, ORNL-5851, Oak Ridge National Laboratory (1982).

12. Roussin, "BUGLE-80 Coupled 47-Neutron, 20 Gamma-Ray $P_{3}$ Cross Section for LWR Shielding Calculations", DLC-75, Radiation Shielding Information Center, Oak Ridge National Laboratory (1980).

13. Jones, et. al., "Material Identification Technology (MIT) - Concept Feasibility Study",
WINCO-1147, Idaho National Engineering Laboratory (1993).

14. Briesmeister, editor, "MCNP - A General Monte Carlo Code for Neutron and Photon Transport", LA-7396 (Rev 2), Los Alamos National Laboratory, September 1986.

15. Grimesey, D.W. Nigg, R.L. Curtis, "COMBINE/PC - A Portable ENDF/B Version 5 Neutron Spectrum and Cross-Section Generation Program", EGG-2589 (Rev 1), Idaho National Engineering Laboratory, February, 1991.

16. DeGraff, "Electrons by the Bucketful - An Industrial Irradiation Service Center", IEEE Transactions on Nuclear Science, 26:1, February, 1979, pp 1793-4.

17. Drewell, C.B. Lawrence, J. McKeown, D.W Nigg, and J. Ungrin, "600 kW Electron Beam Power for Boron Neutron Capture Therapy (BNCT) with IMPELLA", In: J.R. Venhuizen and D.W. Nigg (eds), Proceedings of the First International Workshop on Accelerator-Based Neutron Sources for Boron Neutron Capture Therapy, CONF-940976, September, 1994, pp 67-78.

18. McEligot, "Accelerator Target Cooling for the BNCT Epithermal Source", In: J.R. Venhuizen (ed), 1995 INEL BNCT Program Annual Report (this document). 


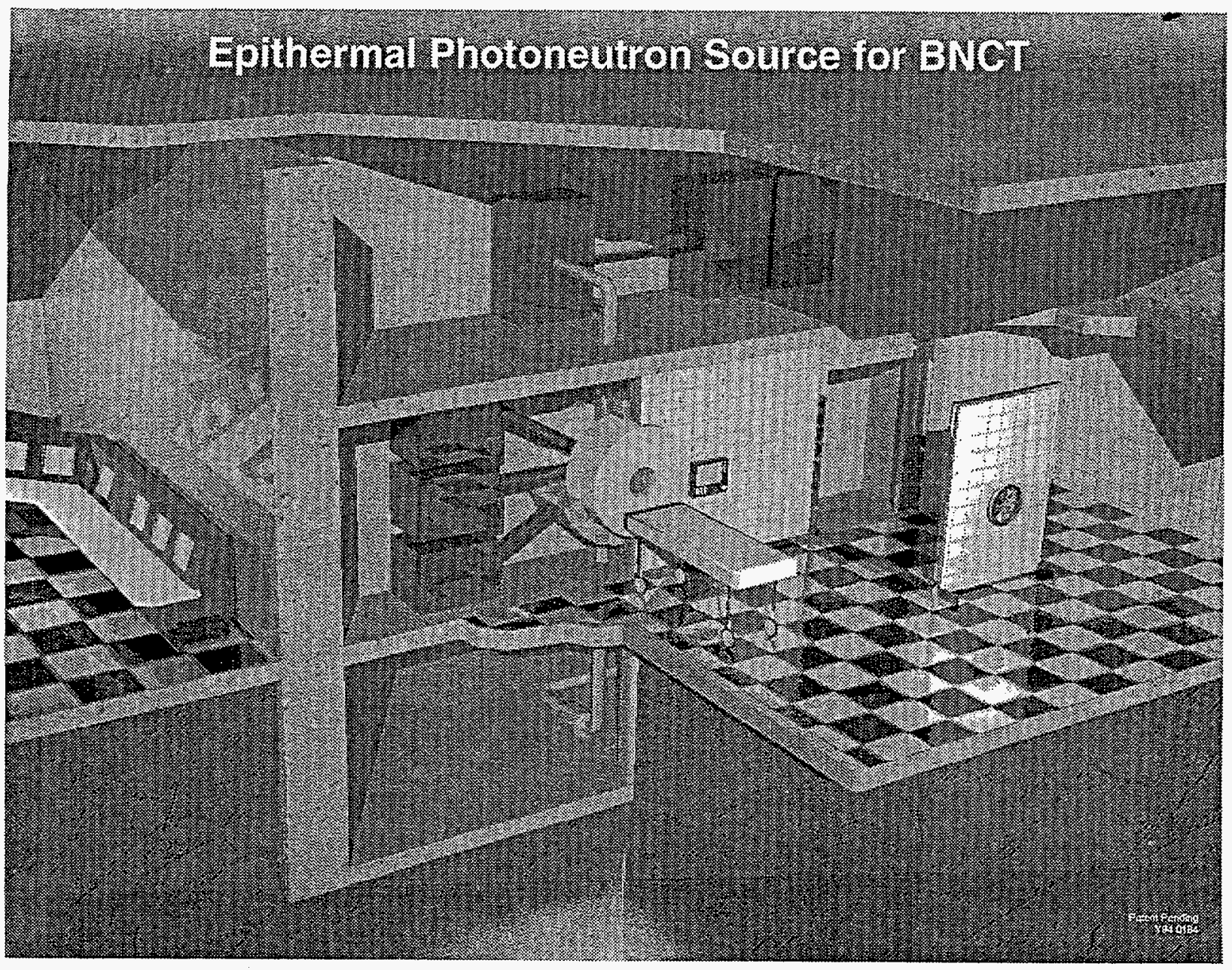

Figure 36. Epithermal Photoneutron Source for BNCT. 


\section{CONCEPTUAL STUDIES OF TARGET COOLING FOR AN EPITHERMAL PHOTONEUTRON ACCELERATOR FOR BORON NEUTRON CAPTURE THERAPY}

\section{M. McEligot, (INEL)}

\section{INTRODUCTION}

BNCT is an experimental binary cancer radiotherapy modality involving the administration of a boronated pharmaceutical that preferentially accumulates in malignant tissue, followed by exposure of the treatment volume to a thermal neutron field. Nigg summarized the neutron source requirements and options for the procedure. $\mathrm{He}$ concluded that accelerator-based epithermal-neutron sources may constitute the basis for a more deployable technology than reactor-based sources in the long term. Accordingly, a preconceptual design $^{2}$ for a clinical scale device utilizing an electronlinear-accelerator has been completd for this purpose. As a consequence of scoping calculations and the results of initial benchtop-scale experiments, further exploration of the concept is in process at the INEL.

However, target cooling may be the Achilles heel of this accelerator-based concept. Current estimates are that the target cooling system must remove energy at a rate of about $12 \mathrm{Mw} / \mathrm{m}^{2}$ or more to be successful. This flux is of the same order-of-magnitude as those expected in the cooling of plasma facing components (PFC) in proposed fusion devices and reactors, and is an order-of-magnitude above the typical CHF in saturated pool boiling of water. The heat flux to be dissipated is still two to three times greater than CHF in subcooled pool boiling.

Accordingly, the purpose of this study is to examine the question whether it is possible to provide adequate cooling of the accelerator targets in the concept of Nigg and, if so, how it might be accomplished.

The conceptual design of the BNCT accelerator-based epithermal-neutron source is presented in Figures 37 and 38. Patient treatments are expected to take about thirty minutes to an hour. Figure 37 schematically demonstrates the overall configuration and the inset in Figure 38 shows the initial arrangement proposed for the tungsten target. The source region is (approximately) a short cylinder with heavy water providing (1) photoneutrons from the incident photon field from the tungsten targets and (2) cooling of the targets. The comers of the cylinder are chamfered slightly. Six electron-linear-accelerators and their targets are distributed around the circumference of the cylinder to yield the desired reaction rate. These electron beams are expected to be about $20 \mathrm{~mA}$ at 6 $\mathrm{MeV}$, depositing a $120 \mathrm{~kW}$ (maximum) heat load in each target. The water inflow may be from the top or bottom of the configuration with the exit on the opposite side; this geometry should induce a recirculating flow field as in the aneurysm model experiments of Budwig ${ }^{3}$.

The approximate dimensions of the BNCT source vessel are $30 \mathrm{~cm}(1 \mathrm{ft})$ diameter and $15 \mathrm{~cm}(6 \mathrm{in})$ along the axis. The inlet and outlet piping for the flowing water is estimated to be about eight $\mathrm{cm}$ ( 3 in) inside diameter. In this preliminary design the aluminum wall of the vessel (tank) is assumed to be about six mm (1/4 in) thick, with the tungsten target being one to three $\mathrm{mm}(1 / 8 \mathrm{in})$ thick. The target area has been chosen as about $100 \mathrm{~cm}^{2}$, which corresponds to a diameter of about $11 \mathrm{~cm}$ (4.4 in) if circular.

Several assumptions and approximations have been made to lead to "worst case" thermal analyses for the target cooling problem, with the result that the suggested design would be expected to be conservative. These assumptions and approximations include:

- The asymptotic steady-state condition is treated. Thus, no additional energy storage terms appear in the analyses (except as specifically noted).

- All incident electrons are considered to interact in the tungsten target rather than passing through to the heavy water.

- The energy of the photoneutron interaction in the $\mathrm{D}_{2} \mathrm{O}$ is neglected.

- The energy of the resulting photon flux is neglected, so it is assumed that the energy of the incident electrons becomes a thermal energy source in the target.

- Penetration depth of the electron beam is taken as negligible, i.e., the electrons interact and generate thermal energy at the immediate surface.

- The major heat sources, such as the klystrons and accelerator structures, are assumed to be cooled independently from the $\mathrm{D}_{2} \mathrm{O}$ circuit. (This separate total source is about $2 \mathrm{Mw}^{4}$.)

- Thermal conduction around the periphery of the aluminum vessel is neglected. Therefore no assistance from this extended surface is considered and the conduction problem becomes onedimensional.

- The $\mathrm{D}_{2} \mathrm{O}$ flow rate through the vessel is taken as 10 $\mathrm{L} / \mathrm{sec}$ as a lower limit ${ }^{2}$. 

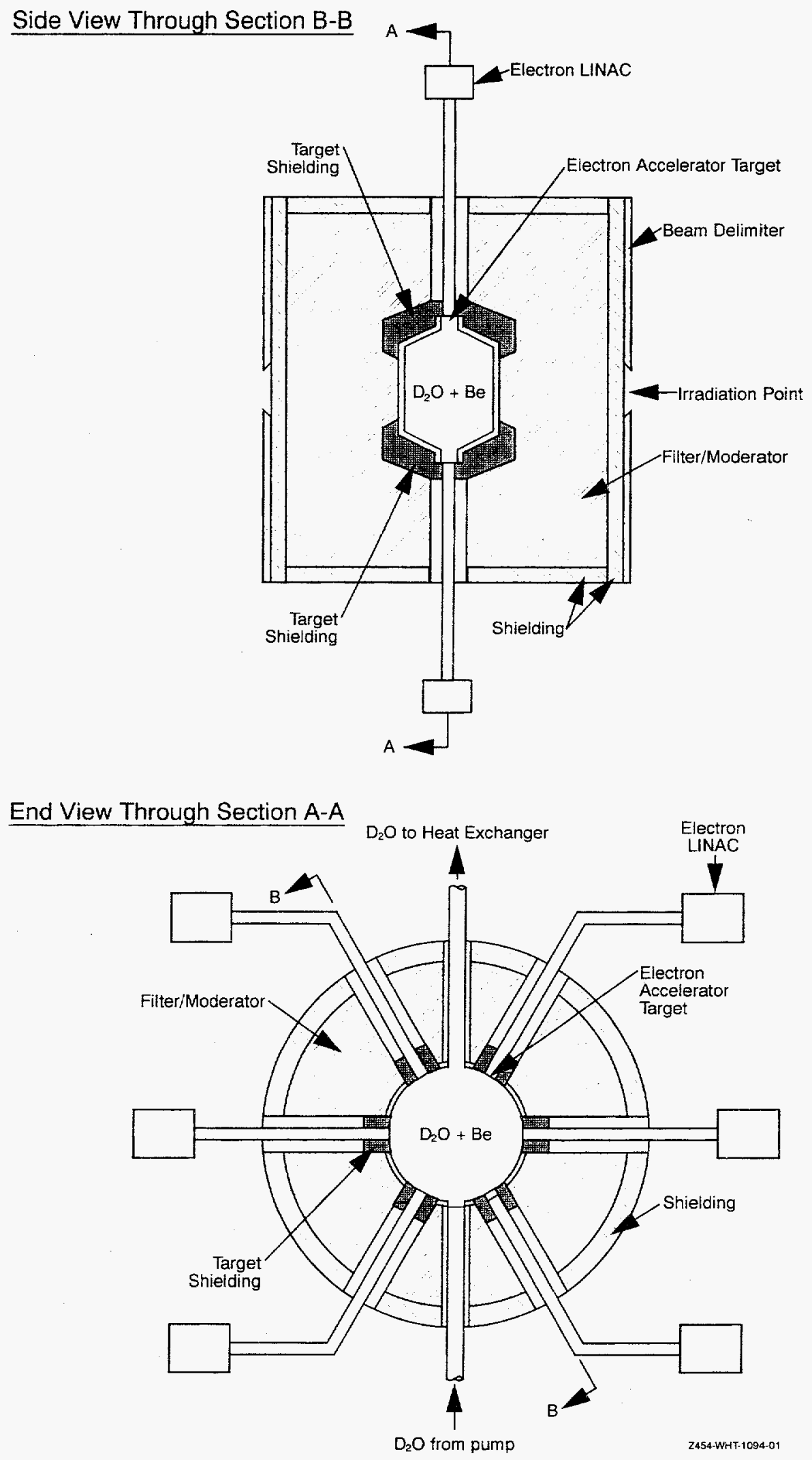

Figure 37. Epithermal photoneutron source (patent pending) ${ }^{2}$. 


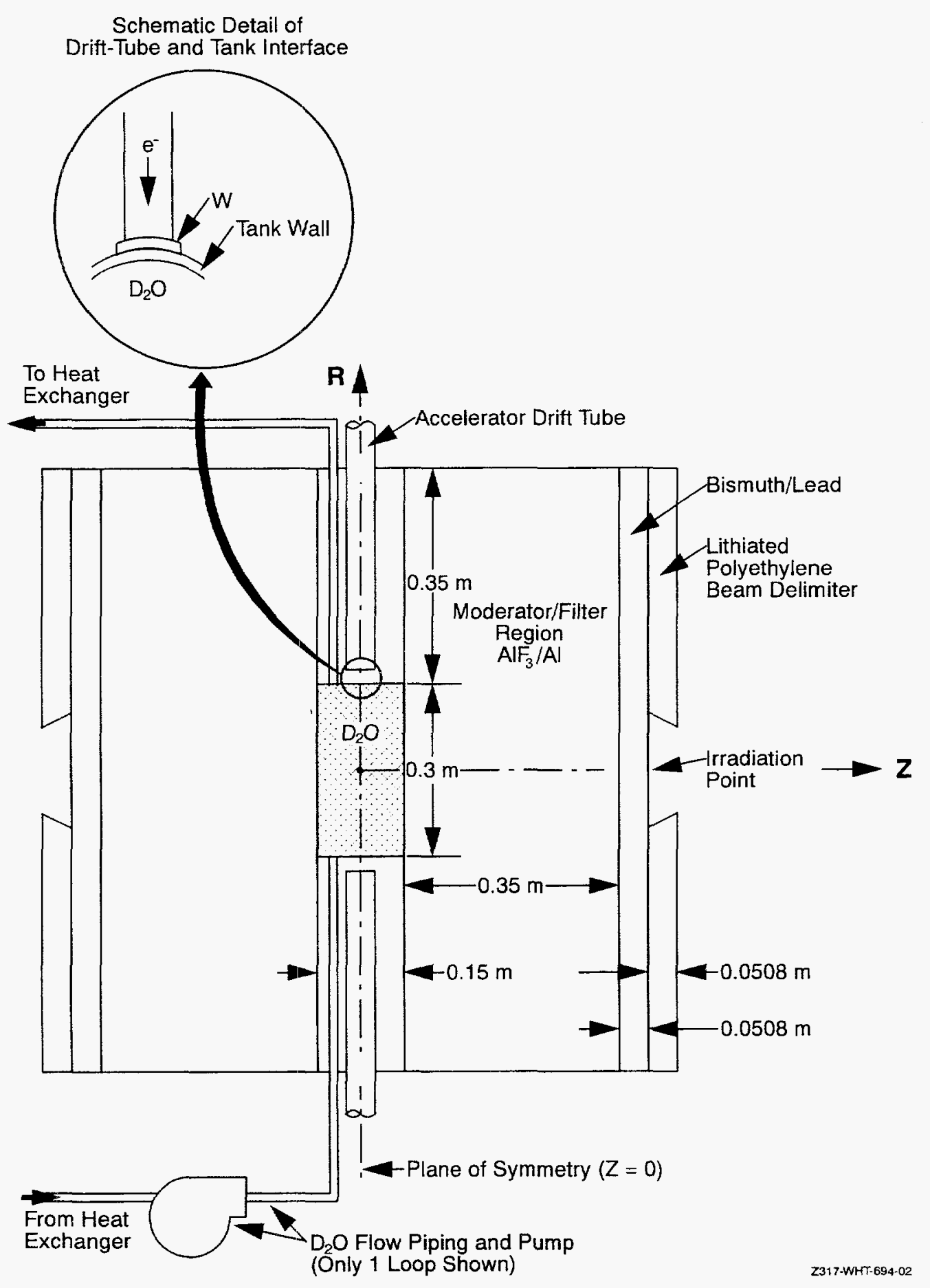

Figure 38. Approximate geometry of calculational model for initial clinical epithermal photoneutron source concept ${ }^{2}$. 
- Pressure of the $\mathrm{D}_{2} \mathrm{O}$ in the vessel is approximately one atmosphere.

Consequences of the above assumptions are that the total power to be dissipated from the tungsten targets to the cooling water is about $720 \mathrm{Kw}$, and the heat flux is about $12 \mathrm{Mw} / \mathrm{m}^{2}$ The temperature rise of the $\mathrm{D}_{2} \mathrm{O}$ would be about $15^{\circ} \mathrm{C}\left(28^{\circ} \mathrm{F}\right)$ in passing through the vessel. Saturation temperature is $374.2^{\circ} \mathrm{K}(\approx 101.1$ ${ }^{\circ} \mathrm{C} \approx 213.9^{\circ} \mathrm{F}$ ) at $100 \mathrm{kPa}$ (Appendix). If the inlet temperature is held to $30^{\circ} \mathrm{C}\left(86^{\circ} \mathrm{F}\right)$ or less, the minimum subcooling would be about $55^{\circ} \mathrm{C}$.

With thermodynamic and transport properties evaluated at $30^{\circ} \mathrm{C}$ (Appendix), the inlet Reynolds number may be estimated to be about $1.9 \times 10^{5}$ at the flow rate of 10 $\mathrm{L} / \mathrm{sec},(11 \mathrm{~kg} / \mathrm{sec}, 24 \mathrm{lbm} / \mathrm{sec})$. The inlet flow thereby would become a turbulent jet, inducing a recirculating flow in the opposite direction near the periphery of the vessel. If Reynolds numbers are calculated based on the diameter of the vessel, it would still be about $5 \mathrm{x}$ $10^{4}$; so the recirculating flow can be expected to remain turbulent.

At $10 \mathrm{~L} / \mathrm{sec}$, the inlet velocity of a jet from a $8 \mathrm{~cm}(3$ in) tube would be about $2 \mathrm{~m} / \mathrm{sec}(7 \mathrm{ft} / \mathrm{sec})$. The velocity field in the recirculating flow of this unusual geometry is unknown. In order to estimate a very approximate, duct-equivalent velocity for the reversed flow along the wall, the assumption is made that it covers about half the vessel radius at the widest spot, and that the induced flow rate is approximately the same as the inlet flow rate. These assumptions may provide an upper limit for this reference velocity; they give an estimate of about $0.8 \mathrm{~m} / \mathrm{sec}(3 \mathrm{ft} / \mathrm{sec})$ for a ductequivalent bulk velocity in the reversed flow.

With this background, the design challenge will be to dissipate about $12 \mathrm{Mw} / \mathrm{m}^{2}$ into the flowing water reliably without causing a failure of the vessel or target. As shown in the treatment below, accomplishment of this goal is unlikely without utilizing some enhanced techniques with subcooled nucleate boiling.

\section{THERMAL ANALYSES}

The initial question is: will cooling be necessary during patient treatment? That is, does the tungsten target have sufficient thermal capacity that it would not exceed its failure temperature during the period of patient treatment? The properties of tungsten and aluminum are listed in the Appendix. It the assumption is made that there are no heat losses from the target during the treatment period and that the material temperature is spatially uniform at all instants (high thermal diffusivity), the rate of temperature rise would be

$$
\frac{d T}{d \theta}=\frac{q^{\prime \prime}{ }_{\text {in }}}{\rho C_{p} \Delta x}
$$

where $\theta$ is the time variable. For a $2 \mathrm{~mm}$ target thickness and the assumed tungsten properties, at $\mathrm{q}^{\mathrm{in}}=$ $12 \mathrm{Mw} / \mathrm{m}^{2}$ the temperature would rise at the order of $10^{7} \mathrm{C} / \mathrm{hr}$. With $6 \mathrm{~mm}$ of aluminum in perfect contact, this rate would be reduced approximately one-fourth and the aluminum would reach its melting temperature in about one second. Effective cooling is thus necessary. This crude calculation also indicates that it may be necessary to exercise care when initially starting the linear accelerator(s).

Thermal conduction through original target geometry

If the $\mathrm{D}_{2} \mathrm{O}$ flow is effective in removing the energy from the aluminum backing of the target (Figure 38), one wonders whether the temperatures in the aluminum or tungsten would exceed their allowable temperatures.

Under the assumptions above, the governing energy equation reduces to Fourier's law of conduction ${ }^{s}$ which can be solved to

$$
\left[\frac{\left(t_{h}-t_{c}\right)}{\Delta x}\right]_{i}=\frac{q^{\prime \prime}}{k_{i}}
$$

for the $i^{\text {th }}$ material. For tungsten, the temperature gradient would be about $80^{\circ} \mathrm{C} / \mathrm{mm}$ at $12 \mathrm{Mw} / \mathrm{m}^{2}$ and for aluminum about $55^{\circ} \mathrm{C} / \mathrm{mm}$. A six mm (1/4 in.) wall of aluminum would have a temperature difference of about $330{ }^{\circ} \mathrm{C}$ across its thickness and probably would not exceed its melting temperature of about 600 ${ }^{\circ} \mathrm{C}\left(\sim 1100^{\circ} \mathrm{F}\right)$ - provided the surface temperature is kept near $100^{\circ} \mathrm{C}$ via nucleate boiling. A thicker wall may have a problem.

\section{Thermal contact resistance / thermal radiation}

With a melting point of about $3660^{\circ} \mathrm{K}^{6}$, tungsten would not have a problem if there was perfect contact between it and the aluminum wall. However, a worst case treatment of the thermal contact resistance between the two materials would assume that their differential thermal expansion could cause a bowing of one material, so that there would be sections with no contact. In this case the dominant mode of heat transfer would become thermal radiation across the evacuated region.

The thermal emissivity of tungsten ranges from about 0.03 to 0.6 , and for aluminum from 0.02 to 0.8 (anodized) ${ }^{6,7}$. Approximating the situation as radiation 
between two gray parallel plates and taking pessimistic values, the overall radiation factor $F_{12}^{5}$ in the relation

$$
q_{\text {rad }}^{\prime \prime}=F_{12} \sigma\left(T_{w}^{4}-T_{A l}^{4}\right)
$$

is about 0.019 . The value becomes about 0.03 if the aluminum is anodized. If both surfaces are treated to become essentially "black" surfaces (perfect absorbers and perfect emitters), $F_{32}$ is unity.

In Figure 39 the predicted radiant heat flux is plotted versus target temperature for optimistic and pessimistic choices of $F_{12}$; the melting temperature of tungsten is indicated on the abscissa. Even with perfectly black surfaces a radiant flux of $12 \mathrm{Mw} / \mathrm{m}^{2}$ could not be sustained without failure to the target. However, if effectively uncooled, the other side of the target would exchange radiant energy with the accelerator structure in view and the heat flux to the aluminum would be reduced. For a distribution of fifty per cent to the structure and fifty per cent to the aluminum, an overall radiation factor $F_{12}>0.7$ would be required to avoid melting. This value could be difficult to insure and still would not accommodate excursions above the nominal power level.

These estimates of thermal radiation demonstrate that for a conservative design the possibility of a gap opening between the aluminum and tungsten should be avoided.

It is recommended that an alternate configuration be designed for target mounting. One possibility would be to deposit the tungsten onto the aluminum by a plasma spray process, forming an integral bond between the two materials ${ }^{8}$. Alternatively, the target/accelerator installation into the source vessel could be designed so that there is direct contact between the tungsten and the flowing $\mathrm{D}_{2} \mathrm{O}$ - or the entire vessel could be fabricated of tungsten. One conceptual approach is shown as Figure 40 ; this idea will be used as the basis of the remainder of this study.

\section{Pool boiling}

For forced convection of light liquids, such as heavy water, White ${ }^{9}$ suggests that typical convective heat transfer coefficients fall in the range 100 to $20,000 \mathrm{w} / \mathrm{m}^{2}-{ }^{\circ} \mathrm{K}$. Taking the optimistic value, a predicted temperature difference between the solid surface and the bulk water of about $600^{\circ}{ }^{\circ} \mathrm{C}$ is found at $12 \mathrm{Mw} / \mathrm{m}^{2}$. This temperature difference is sufficient to expect that nucleate boiling, and maybe film boiling, would be initiated.

While there will be forced flow through the BNCT assembly, consideration of pool or natural convective boiling normally provides a lower bound on heat transfer by boiling processes. And as heat fluxes increase, results for nucleate boiling merge indicating that the nucleate boiling dominates over the forced flow [White, Fig. 9.11'], but CHF increases with flow velocity and subcooling. Unfortunately, the effective velocity in the BNCT assembly in the vicinity of the targets is not known. Accordingly, the first estimates will be for pool boiling.

It should be noted that in pool boiling the vapor removal away from the surface is via buoyant forces. Therefore, it seems desirable that in the BNCT assembly, the flow direction be chosen to augment, rather than hinder, the induced flow. Since the inlet jet should cause a recirculating (reversed) flow near the walls, it may be best to construct the inlet plumbing so that the jet is directed downward so the direction near the targets is upward. (Ruan, Bartsch and Yang ${ }^{10}$ have found that with downflow near the surface the CHF may vary from extremely unstable flow with low CHF to stable flow $\mathrm{CHF}$ as high as in upflow.)

For a useful general treatment of boiling, the reader is referred to the text of Carey ${ }^{\text {II }}$. Recent surveys of the key problem of CHF have been published by Lienhard $^{12}$, Celata $^{13}$ and Katto ${ }^{14}$.

The approximate orientation of the target surfaces relative to vertical would be 30,90 and 150 degrees (Figure 37). Nishikawa ${ }^{15}$ measured effects of surface orientation in pool boiling. Some dependence on angle was found at low heat fluxes, but their nucleate boiling curves merged as the heat flux was increased. At low velocities in a channel, Gersey and Mudawar ${ }^{16}$ [their Fig. 4] found a dependence of $\mathrm{CHF}$ with orientation, but no significant variation with upflow for the range of angles of the BNCT targets.

CHF for an infinite horizontal flat plate, facing upward in a pool at saturation temperature, is about $1 \mathrm{Mw} / \mathrm{m}^{2}$ according to the correlation of Zuber ${ }^{17}$ and Carey ${ }^{11}$ (eqn. 7.64). Subcooling increases CHF. According to a correlation by Kutateladze ${ }^{12}$, accounting for subcooling, CHF for $\mathrm{H}_{2} \mathrm{O}$ at one atmosphere would be about 2 $\mathrm{Mw} / \mathrm{m}^{2}$ with $10{ }^{\circ} \mathrm{C}$ subcooling, and about $4 \mathrm{Mw} / \mathrm{m}^{2}$ with subcooling of $50{ }^{\circ} \mathrm{C}$ as in the BNCT vessel [Carey ${ }^{11}$ example 8.1]. These values are not sufficient for the accelerator targets; if the targets could not survive at the temperatures resulting in film boiling, some "enhanced" cooling technique(s) must be applied.

While the properties of $\mathrm{D}_{2} \mathrm{O}$ and $\mathrm{H}_{2} \mathrm{O}$ are similar, there is still uncertainty in the trends of CHF between them. Data from comparative studies differ in direction. Knoebel ${ }^{19}$ found CHF to be 16 per cent greater with heavy water than with light water at the same velocity 
Thermal radiation across a gap

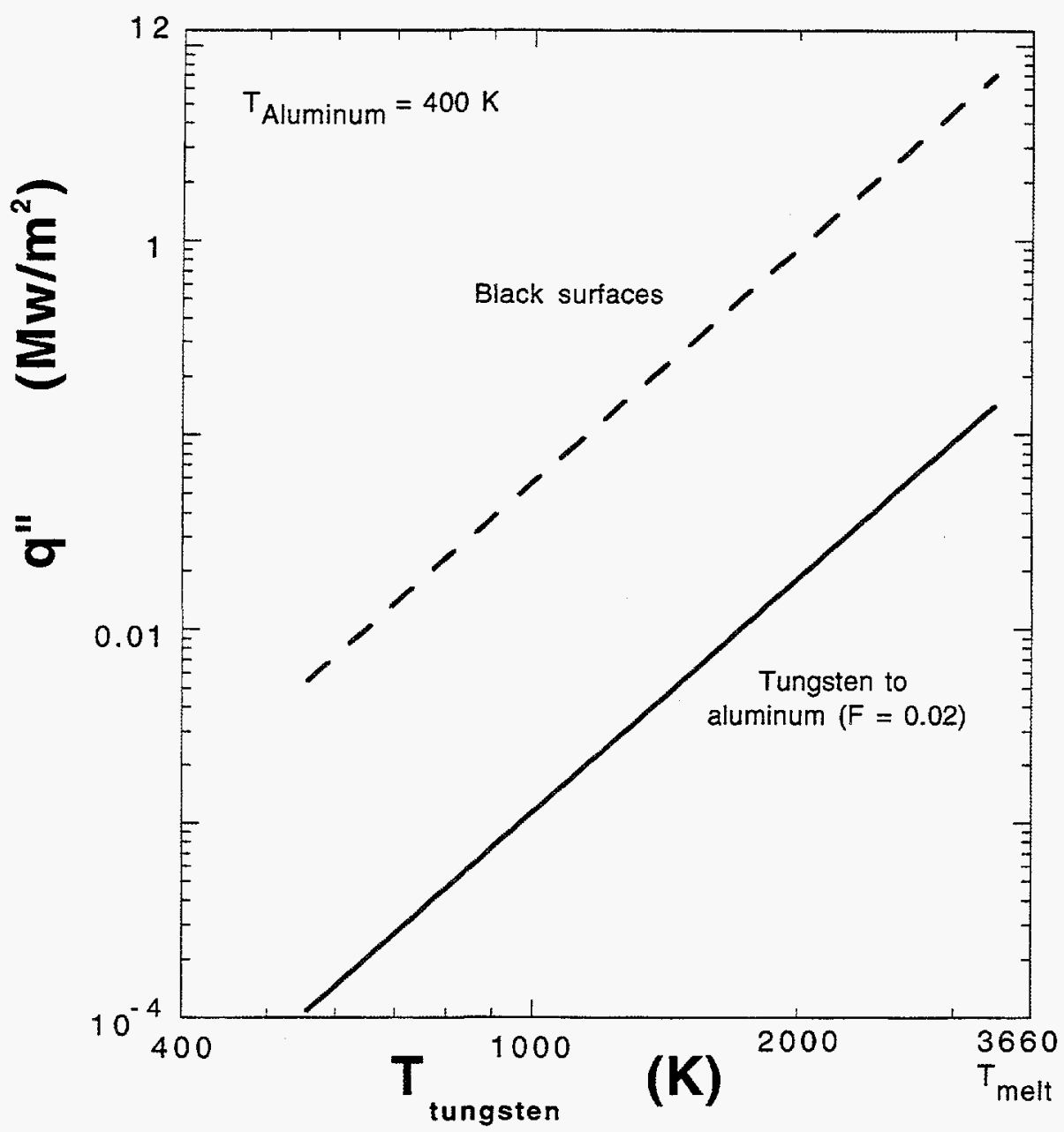

Figure 39. Thermal radiation flux between parallel surfaces of tungsten and aluminum.

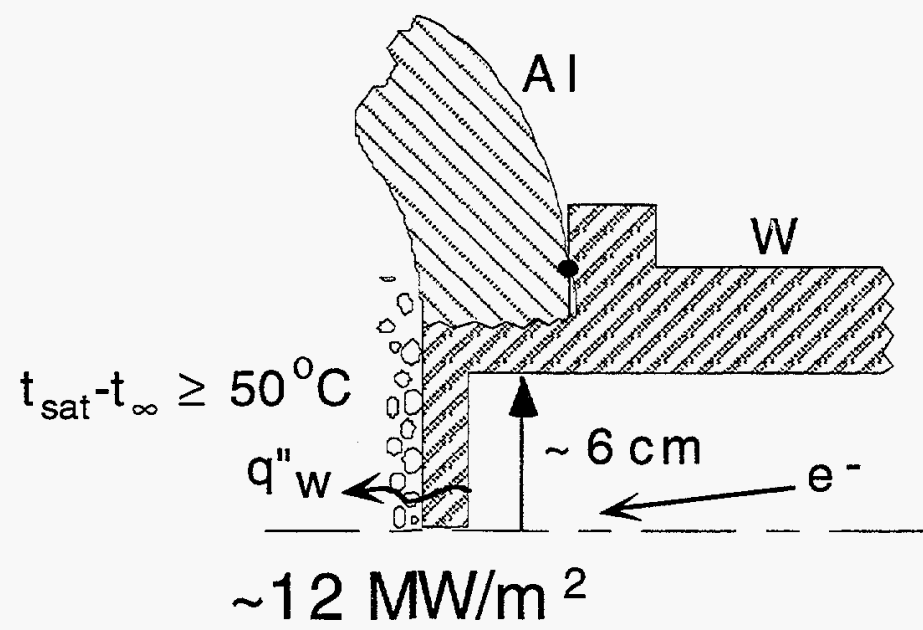

Figure 40. Schematic diagram of revised conceptual target geometry and thermal conditions. 
and subcooling. On the other hand, Williams and Beus $^{20}$ found light water to be better. Therefore, it is likely that the cooling technique selected ultimately will need to be tested with $\mathrm{D}_{2} \mathrm{O}$.

Bui and Dhir $^{21}$ measured natural convective film boiling of saturated water on a vertical surface of about $10.3 \mathrm{~cm}$ height (comparable to the accelerator targets). Their observed heat transfer coefficients were of the order of $200 \mathrm{w} / \mathrm{m}^{2}-{ }^{\circ} \mathrm{K}$. At $12 \mathrm{Mw} / \mathrm{m}^{2}$, the resulting temperature difference would be $t_{\text {wall }}-t_{\text {sat }} \approx 6 \times 10^{4}{ }^{\circ} \mathrm{C}$. Even if there were perfect conduction to the entire vessel surface, making the average heat flux an order-ofmagnitude lower, the resulting surface temperature would be over $6000{ }^{\circ} \mathrm{C}$, greater than the melting temperature of tungsten. Thus, film boiling must be avoided.

As demonstrated for an array of heating elements in series by McGillis, Carey and Strom ${ }^{22}$, increasing subcooling and increasing liquid velocities increase $\mathrm{CHF}$ as shown in Figure 41. (This experiment had some features in common with the configuration of targets around the circumference of the BNCT source.) Therefore, related schemes for this purpose will be examined in the next section.

\section{Enhanced cooling techniques}

Enhanced or augmented cooling techniques ${ }^{23}$ are often envisioned as complex surface modifications. One such approach will be considered: the "Hypervapotron"24,25,26 However, a number of other simpler techniques may also increase $\mathrm{CHF}$.

The heated surface area in contact with the coolant may be effectively increased by thermal conduction along the walls. The present assumptions have purposely

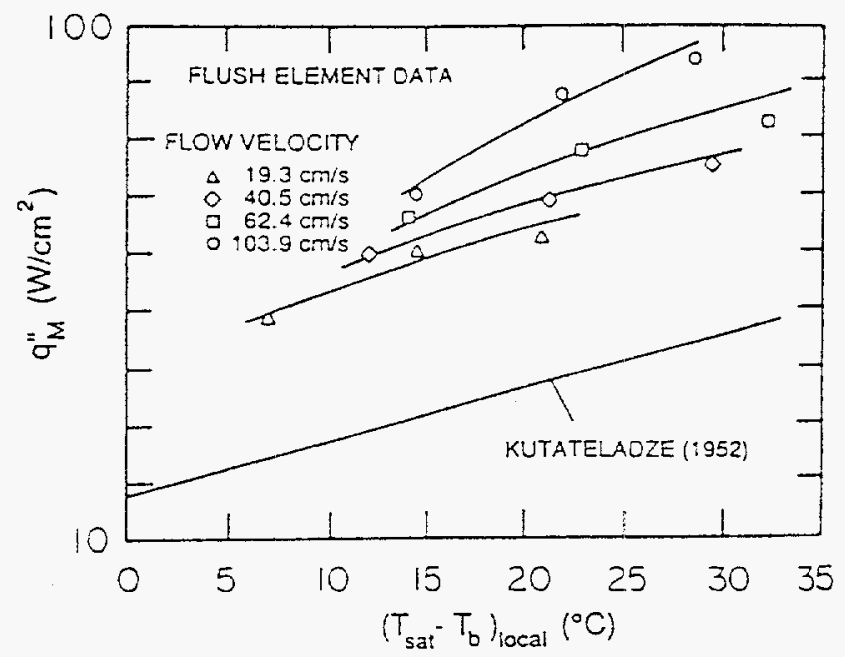

Figure 41. Effects of velocity and subcooling on critical heat flux data for the last flush heater element in an array [McGillis, Carey and Strom ${ }^{22}$, their Fig. 7]. neglected this mechanism in order to present a "worst case" scenario for conservative design. The benefits might be estimated by applying an extended surface analysis ${ }^{5}$ with a spatially-variable convective heat transfer coefficient. However, the appropriate value of $h\{\Phi\}$ is not well known, with the location of the single-phase to nucleate-boiling transition particularly uncertain. With the conceptual design of Figure 40, this thermal conduction would be inhibited by the thermal contact resistance between the plug-shaped tungsten target and the surrounding aluminum wall. Direct plasma spray deposition of tungsten onto the aluminum wall could reduce or eliminate this contact resistance. Typical thermal conductivities are about $240 \mathrm{w} / \mathrm{m}^{\circ}-\mathrm{K}$ for pure aluminum, $160-180 \mathrm{w} / \mathrm{m}^{\circ}-\mathrm{K}$ for aluminum alloys and $150 \mathrm{w} / \mathrm{m}^{\circ}-\mathrm{K}$ for tungsten, so a pure aluminum wall is preferable to a tungsten vessel in this sense.

Another means of increasing the heat transfer surface area is to revise the conceptual accelerator design by increasing the size of the target around the periphery of the vessel for the same accelerator power, thereby reducing the resulting heat flux. In the "current design" about 65 percent of the peripheral area is occupied by the targets plus inlet and outlet tubes, so it might be possible to reduce the heat flux by about thirty percent. This value can be improved by increasing the diameter and/or width of the BNCT source vessel.

By increasing the $\mathrm{D}_{2} \mathrm{O}$ system pressure, the saturation temperature will increase, increasing the subcooling and, in turn, CHF. For saturated pool boiling Carey ${ }^{7}$ presents an example of the variation of CHF with pressure: by increasing pressure to about 85 atmospheres, CHF can be raised to about $3.5 \mathrm{Mw} / \mathrm{m}^{2}$. Subcooling of $50^{\circ} \mathrm{C}$ may increase this value by a factor of two to four (subcooling can be increased by refrigerating the inflow). Intuition indicates that these modifications in operating conditions would be expensive, but they may warrant investigation due to their apparent "simplicity."

Several techniques which involve modifications of the internal flow geometry in the BNCT source vessel are indicated schematically in Figure 42.

Many studies in the last couple decades have examined nucleate boiling from small heated elements in channels for electronic cooling or for plasma facing components in fusion devices. The investigations of $\mathrm{Baker}^{27}$, Samant and Simon ${ }^{28}$, Lee and Simon ${ }^{29}$, Mudawar and Maddox $^{30}$,McGillis, Carey and Strom ${ }^{22}$, Galloway and Mudawar ${ }^{31}$, Willingham and Mudawar ${ }^{32}$, Leland and Chow ${ }^{33}$, Gersey and Mudawar ${ }^{16}$, Galloway and Mudawar ${ }^{34}$, Wu and Simon $^{35}$ and Desta and Simon ${ }^{36}$ provide examples. These experiments have generally used refrigerants or other liquids rather than water as the working fluid. 
Channel flow

(Mudawar and Maddox, 1989)

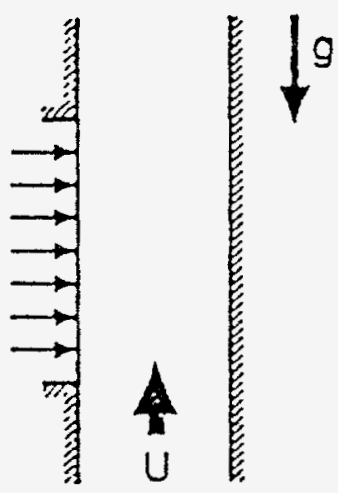

\title{
$30 \mathrm{~m} / \mathrm{s}, 50 \mathrm{C}$ subcooled $\sim 15 \mathrm{Mw} / \mathrm{m}^{2}$
}

Plane wall jet. liquid ambient (Katto and Kurata, 1980)

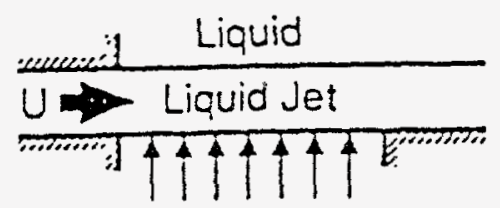

Combined plane impinging jet / channel flow

(Mudawar and Wadsworth)

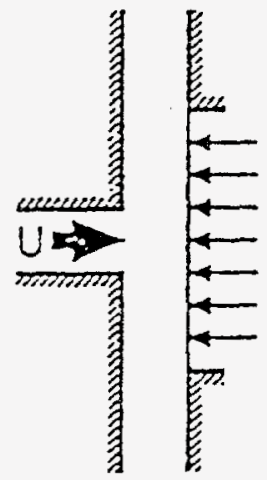

\author{
$9 \mathrm{~m} / \mathrm{s}, 50 \mathrm{C}$ subcooled, \\ $6 \mathrm{~mm}$ jet \\ $\sim 10 \mathrm{Mw} / \mathrm{m}^{2}$
}

\section{$5 \mathrm{~m} / \mathrm{s}, 50 \mathrm{C}$ subcooled, \\ $2 \mathrm{~mm}$ jet}

$\sim 15 \mathrm{Mw} / \mathrm{m}^{2}$

Heat fux

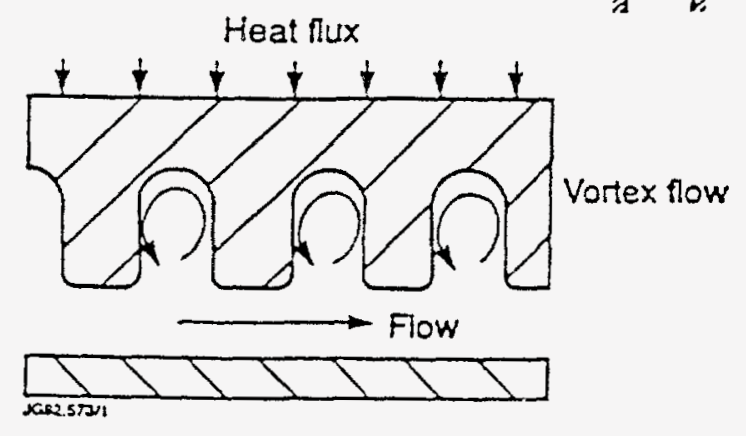

Hypervapotron

\section{$4 \mathrm{~m} / \mathrm{s},>$ ? C subcooled, 6 $\mathrm{mm}$ channel [Falter et al., 1992] \\ $>16 \mathrm{Mw} / \mathrm{m}^{2}$}

Figure 42. Schematic diagrams of types of enhanced cooling techniques considered for application to BNCT target cooling. 
Mudawar and Maddox $^{30}$ measured CHF during subcooled flow boiling of a dielectric fluorocarbon (FC72) on a smooth $1.3 \times 1.3 \mathrm{~cm}^{2}$ simulated electronic chip inside a vertical rectangular channel. They correlated their results in terms of a dimensionless $\mathrm{CHF}$, the Weber number and the Jakob number [Carey, eqn. $8.13^{11}$ ].

If their correlation is applied with the recirculating flow estimate of $0.8 \mathrm{~m} / \mathrm{sec}$ and subcooling of $50^{\circ} \mathrm{C}, \mathrm{CHF}$ is predicated to be about $5 \mathrm{Mw} / \mathrm{m}^{2}$ (however, the Weber number in the BNCT application is outside their data range, so this estimate must be used with caution). In this correlation the effect of duct velocity is about $\mathrm{q}^{\prime \prime} \mathrm{CHF}$ $\sim \mathrm{V}^{7 / 23}$. This observation implies that, if the $\mathrm{D}_{2} \mathrm{O}$ flow is constrained into a channel formed adjacent to the heated wall enroute to the central source region, then CHF might be increased to a level above the heat flux from the target. For example, from this power law approximation, a channel velocity of about $30 \mathrm{~m} / \mathrm{sec}$ would be required for a CHF of about $15 \mathrm{Mw} / \mathrm{m}^{2}$. This required velocity might be reduced by the effects of surface curvature $\left[\mathrm{Wu}\right.$ and $\left.\mathrm{Simon}^{35}\right]$ or it might be increased, depending on the level of subcooling.

In 1980 Katto and $\mathrm{Kurata}^{37}$ reported CHF measurements for saturated water issuing from a wall jet along a small heated surface in a saturated pool of water. Heated surfaces were $1,1.5$ and $2 \mathrm{~cm}$ long, and the range of wall jet velocities was 1.5 to $10 \mathrm{~m} / \mathrm{sec}$. At $9 \mathrm{~m} / \mathrm{sec}$ they achieved $\mathrm{CHF} \approx 3.8 \mathrm{Mw} / \mathrm{m}^{2}$. No data were obtained with a subcooled jet in a subcooled pool. $\mathrm{Katto}^{38}$ feels that this boiling system is subject to a rather complicated situation with respect to the velocity distribution at the upstream end of the heater, so he has not continued study of this boiling system. For the BNCT assembly, distributing the inlet flow equally to wall jets at the six individual targets would give velocities about $14 \mathrm{~m} / \mathrm{sec}$ at each location. This fifty per cent increase in velocity should counter the 35 per cent reduction of $\mathrm{q}^{\prime \prime} \mathrm{CrF}$ due to the longer target surface (according to the correlation of Katto and Kurata ${ }^{37}$ ). If the effect is the same as in the channel by Gersey and Mudawar ${ }^{16}$, subcooling of $50^{\circ} \mathrm{C}$ would increase $\mathrm{CHF}$ to about $11 \mathrm{Mw} / \mathrm{m}^{2}$. Thus, it appears that a wall jet manifold would be a possible solution. with slightly higher velocity and/or subcooling.

Mudawar and Wadsworth ${ }^{39}$ performed experiments to investigate boiling heat transfer from a smooth 12.7 $\mathrm{mm}$ by $12.7 \mathrm{~mm}$ (one-half inch) heat source to a jet of dielectric Fluorinert FC-72 liquid issued from a thin rectangular orifice into a channel confined between the surfaces of the heat source and the nozzle. The geometry is shown schematically in Figure 42. This configuration for a impinging jet could be fabricated opposite each target in the BNCT vessel and be connected to a manifold.
As a first approximation to a conceptual design, consider the dimensions of $\mathrm{L} / \mathrm{W} \approx 50$ and $\mathrm{H} / \mathrm{W} \approx 2$ for the 10 by $10 \mathrm{~cm}^{2}$ target with channel spacing $W$. This yields a value $\mathrm{W} \approx 2 \mathrm{~mm}$. Using equation 12 of Mudawar and Wadsworth ${ }^{39}, 1 \mathrm{~m} / \mathrm{sec}$ and $50{ }^{\circ} \mathrm{C}$ subcooling, one predicts $\mathrm{CHF} \approx 5.1 \mathrm{Mw} / \mathrm{m}^{2}$ for $\mathrm{H}_{2} \mathrm{O}$. With CHF varying as $\mathrm{V}^{0.7}$, a velocity of about $5 \mathrm{~m} / \mathrm{sec}$ would give about $15 \mathrm{Mw} / \mathrm{m}^{2}$.

Falter $^{24}$, et al. has noted that the divertor plates in the Joint European Torus fusion device will require cooling of about $12 \mathrm{Mw} / \mathrm{m}^{2}$. Their approach is the "Hypervapotron" surface [Beuthert ${ }^{40}$; Falter ${ }^{41}$; Cattadori $\left.{ }^{26}\right]$ shown in the lower subfigure of Figure 42. The surface typically consists of "fins" over which subcooled coolant flows in a perpendicular direction; grooves between the fins are curved at their roots. The classical vapotron effect, where steam forms in the grooves and its ejection provides the driving force for heat transfer, occurs at low velocities. At higher velocities, turbulence induced by the flow over the fins appears to dominate the heat exchange. Critical heat fluxes are high. With $3 \mathrm{~m} / \mathrm{sec}$ Falter ${ }^{41}$ had an apparent $\mathrm{CHF}$ at about $14 \mathrm{Mw} / \mathrm{m}^{2}$. Baxi and Falter ${ }^{42}$ achieved over $15 \mathrm{Mw} / \mathrm{m}^{2}$ at $4 \mathrm{~m} / \mathrm{sec}$ in a $6 \mathrm{~mm}$ channel at a pressure of 6.4 bar and inlet temperature of about 15-20 ${ }^{\circ} \mathrm{C}$; thus, the subcooling was about $140^{\circ} \mathrm{C}$. Falter $^{43}$ notes that they have data up to $30 \mathrm{Mw} / \mathrm{m}^{2}$, but assumes that they exceeded CHF locally because they had high frequency noise spikes in the water pressure measurements.

With a Hypervapotron flow cross section of $10.5 \mathrm{~cm}$ width and $3 \mathrm{~mm}$ gap, a $4 \mathrm{~m} / \mathrm{sec}$ flow rate (as by Baxi and Falter ${ }^{42}$ ) would be provided by about $1.3 \mathrm{~L} / \mathrm{sec}$ (or less than $10 \mathrm{~L} / \mathrm{sec}$ total for six). Provided the surface does not cause unacceptable difficulties for the photon optics of the BNCT source, the Hypervapotron should also provide an adequate cooling technique, but it would require appropriate testing and further analysis. The temperature rise through the solid material is substantial at high heat fluxes [Baxi and Falter ${ }^{42}$, so some additional thermal protection might be necessary for the adjacent aluminum wall of the vessel.

\section{Concluding remarks}

The design challenge for the BNCT target cooling will be to dissipate about $12 \mathrm{Mw} / \mathrm{m}^{2}$ into the flowing heavy water reliably without causing a failure of the vessel or target. This current study has examined the orders-ofmagnitude of heat fluxes attainable via some possible approaches. It is anticipated that the thermal energy transfer from the target to the water must be by subcooled nucleate boiling in order for the target to survive. Therefore, the critical heat flux of the technique chosen must exceed $12 \mathrm{Mw} / \mathrm{m}^{2}$ by a safe margin. 
At a flow rate of $10 \mathrm{~L} / \mathrm{sec}$ and one atmosphere pressure, subcooling required in the $\mathrm{BNCT}$ assembly would be about $50^{\circ} \mathrm{C}$ or more.

Estimated values of $\mathrm{CHF}$ for some typical situations are shown in Table 3 . Since the influence of orientation is small at high heat fluxes, these estimates indicate that more aggressive approaches are necessary.

Cooling techniques considered for application to the BNCT accelerator targets are listed in Table 4 with order-of-magnitude estimates of the CHF for the conditions indicated.

Other versions of extended surface ("fins") approaches may be useful along with combinations of the above techniques.
The estimates above are primarily based on experiments with fluids other than $\mathrm{D}_{2} \mathrm{O}$. An uncertainty of about \pm 20 per cent probably should be added when extending these results to heavy water for the BNCT source.

From this review, it appears that it should be possible to cool the targets adequately but that it will not be an easy task. The target must be configured so that no gaps can occur between the tungsten and the cooled surface; the resulting thermal contact resistance would be too large.

Table 3. Estimated values of critical heat flux for some typical situations.

\begin{tabular}{llll} 
Horizontal plate & saturated pool boiling & $1 \mathrm{~atm}$ & $1 \mathrm{Mw} / \mathrm{m}^{2}$ \\
Horizontal plate & saturated pool boiling & $85 \mathrm{~atm}$ & $3.5 \mathrm{Mw} / \mathrm{m}^{2}$ \\
Horizontal plate & $50^{\circ} \mathrm{C}$ subcooling & $1 \mathrm{~atm}$ & $4 \mathrm{Mw} / \mathrm{m}^{2}$ \\
Recirculating flow boiling at $0.8 \mathrm{~m} / \mathrm{sec}$ & $50^{\circ} \mathrm{C}$ subcooling & $1 \mathrm{~atm}$ & $5 \mathrm{Mw} / \mathrm{m}^{2}$ \\
\hline
\end{tabular}

Table 4. Cooling techniques for BNCT accelerator target source cooling with estimated CHF attainable.

\begin{tabular}{llll} 
Flow & Conditions & Subcooling & CHF \\
Pressurized & $85 \mathrm{~atm}$ & $50{ }^{\circ} \mathrm{C}$ & $10 \mathrm{Mw} / \mathrm{m}^{2}$ \\
Wall jet & $14 \mathrm{~m} / \mathrm{sec}$ & $50{ }^{\circ} \mathrm{C}$ & $11 \mathrm{Mw} / \mathrm{m}^{2}$ \\
Flow channel & $30 \mathrm{~m} / \mathrm{sec}$ & $50{ }^{\circ} \mathrm{C}$ & $15 \mathrm{Mw} / \mathrm{m}^{2}$ \\
Impinging jet & $5 \mathrm{~m} / \mathrm{sec}$ & $50{ }^{\circ} \mathrm{C}$ & $15 \mathrm{Mw} / \mathrm{m}^{2}$ \\
Modified Hypervapotron & $4 \mathrm{~m} / \mathrm{sec}$ & $140{ }^{\circ} \mathrm{C}$ & $>15 \mathrm{Mw} / \mathrm{m}^{2}$ \\
\hline
\end{tabular}




\section{Appendix. Material Property Estimates}

Heavy water $\left(\mathrm{D}_{2} \mathrm{O}\right)$ and light water $\left(\mathrm{H}_{2} \mathrm{O}\right)$ properties are compared below at approximately one atmosphere and saturation temperature. Tabulations of the heavy water properties were provided by Cliff Davis ${ }^{44}$; these tables had been calculated by Roy Shaw ${ }^{45}$ with a small post processing program applied to the output from the
STG2XG code of Tolli ${ }^{46}$. The light water properties were taken from the compilation by Reynolds ${ }^{47}$ with the exception of the surface tension, which came from the text by Incropera and deWitt. For other conditions, an Apple Macintosh program for both $\mathrm{D}_{2} \mathrm{O}$ and $\mathrm{H}_{2} \mathrm{O}$ properties is available from Shaw.

Pressure, $\mathrm{p}(\mathrm{kPa})$

$\underline{\mathrm{D}_{2} \mathrm{O}}$

100

0.05838

4158.4

1062.5

0.65381

0.002369

$\sim 2.37$

374.2

$2.0714 \times 10^{6}$

$2.4808 \times 10^{6}$

$4.0938 \times 10^{5}$

1.089
$\underline{\mathrm{H}_{2} \mathrm{O}}$

101.3

0.0589

4217

958.77

0.59031

0.0025066

$\sim 2.51$

372.78

$2.257 \times 10^{6}$

$2.675 \times 10^{6}$

$4.180 \times 10^{5}$

1.102 [Carey, eqn. $7.64^{11}$ ]

The following properties for liquid heavy water were taken from the tabulation of Ulrych ${ }^{48}$ at $30{ }^{\circ} \mathrm{C}$ with the exception of the surface tension which was obtained from tables produced by the code of Tolli ${ }^{46}$ :

Density, $\rho\left(\mathrm{Kg} / \mathrm{m}^{3}\right)$

Specific heat at constant pressure, $\mathrm{c}_{\mathrm{p}}\left(\mathrm{KJ} / \mathrm{Kg}-{ }^{\circ} \mathrm{K}\right)$

Volumetric coefficient of thermal expansion, $\beta(1 / \mathrm{K})$

Thermal conductivity, $\mathrm{k}\left(\mathrm{w} / \mathrm{m}-{ }^{\circ} \mathrm{K}\right)$

Absolute viscosity, $\mu(\mathrm{Kg} / \mathrm{m}-\mathrm{s})$

Kinematic viscosity, $v\left(\mathrm{~m}^{2} / \mathrm{sec}\right)$

Thermal diffusivity, $\alpha\left(\mathrm{m}^{2} / \mathrm{sec}\right)$

Prandtl number, $\operatorname{Pr}=c_{p} \mu / k$
1103.3

$0.242 \times 10^{-3}$

0.589

$972 \times 10^{-6}$

$0.881 \times 10^{-6}$

$0.126 \times 10^{-6}$

7.0 
The following properties of the solid metals were approximated from the tabulations in the text by Incropera and deWitt ${ }^{6}$ :

$\begin{array}{lccc}\text { Temperature }=300 \mathrm{~K} & \text { Tungsten } & \frac{\text { Aluminum }}{\text { Pure }} & \text { Aluminum } \\ \text { Density, } \rho\left(\mathrm{Kg} / \mathrm{m}^{3}\right) & 19,300 & 2702 & 2770 \\ \begin{array}{l}\text { Specific heat at constant pressure } \\ \quad \mathrm{c}_{\mathrm{p}}\left(\mathrm{KJ} / \mathrm{Kg}-^{\circ} \mathrm{K}\right)\end{array} & 132 & 9024-\mathrm{T} 6 \\ \text { Thermal conductivity, } \mathrm{k}\left(\mathrm{w} / \mathrm{m}-{ }^{-} \mathrm{K}\right) & 174 & 237 & 875 \\ \text { Thermal diffusivity, } \alpha\left(\mathrm{m}^{2} / \mathrm{sec}\right) & 68.3 \times 10^{-6} & 97.1 \times 10^{-6} & 177\end{array}$

\section{ACKNOWLEDGMENTS}

The study reported was supported through the Laboratory Directed Research and Development Program of Lockheed Idaho Technologies Company under DOE Idaho Field Office Contract DE-AC0794ID13223.

\section{REFERENCES}

1. Nigg, D. W., $1994 . \quad$ Neutron source requirements and options for BNCT. Proc., First Int. Workshop on Accelerator-based Neutron Sources for Boron Neutron Capture Therapy, CONF-940976, Vol. I, pp. 3-9, Jackson, Wyo., 11-14 September.

2. Nigg, D. W., H. E. Mitchell, Y. D. Harker, W. Y.Yoon, J. L. Jones and J. F. Harmon, 1994. Epithermal photoneutron source studies for BNCT. Proc., First Int. Workshop on Accelerator-based Neutron Sources for Boron Neutron Capture Therapy, CONF-940976, Vol. II, pp. 373-386, Jackson, Wyo., 11-14 September.

3. Budwig, R., D. Elger, H. Hooper and J. Slippy, 1993. Steady flow in abdominal aortic aneurysm models. J. Biomedical Engr., $\underline{115}$, pp 418-423.

4. Drewell, N. H., C. B. Lawrence, J. McKeown, D. W. Nigg and J. Ungrin, $1994.600 \mathrm{~kW}$ electron-beam power for Boron Neutron Capture Therapy (BNCT) with IMPELA. Proc., First Int. Workshop on Accelerator-based Neutron Sources for Boron Neutron Capture Therapy, CONF-940976, Vol. I, pp. 67-77, Jackson, Wyo., 11-14 September.

5. Kreith, F., 1973. Principles of heat transfer, 3rd ed. Scranton: Intext

6. Incropera, F. P., and D. P. deWitt, 1981. Fundamentals of heat transfer. New York: Wiley.

7. Touloukian, Y. S., and D. P. deWitt, 1970. Thermal radiative properties. Thermophysical properties of matter, Vol. 7, New York: IFI/Plenum.

8. Lundberg, L. B., $1995 . \quad$ Personal communication, Idaho National Engineering Laboratory,

9. White, F. M., 1984. Heat transfer. Reading: Addison-Wesley.

10. Ruan, S. W., G. Bartsch and S. M. Yang, 1993. Characteristics of the critical heat flux for downward flow in a vertical tube at low flow rate and low pressure conditions. Exp. Th. Fluid Sci., I, pp. 296-306.

11. Carey, V. P., 1992. Liquid-vapor phase-change phenomena. Washington: Hemisphere.

12. Lienhard, J. H., 1988. Burnout on cylinders. $J$. Heat Transfer, 110, Supplement, pp. 12711286.

13. Celata, G. P., 1993. Recent achievements in the thermal hydraulics of high heat flux components in fusion reactors. Exp. Thermal Sci., 7, pp. 263-278.

14. Katto, Y., 1994. Critical heat flux. Int. J. Multiphase Flow, 20 Suppl., pp. 53-90. 
15. Nishikawa, K., Y. Fujita, S. Uchida and $\mathrm{H}$. Ohta, 1983. Effect of heating surface orientation on nucleate boiling heat transfer. Proc., ASMEJSME Thermal Engr. Joint Conf., Honolulu, vol. 1, pp. 129-136.

16. Gersey, C. O., and I. Mudawar, 1993. Orientation effects on critical heat flux from discrete, in-line heat sources in a flow channel. $J$. Heat Transfer, 115, pp. 973-985.

17. Zuber, N., 1959. Hydrodynamic aspects of boiling heat transfer. Ph.D. thesis, U.C.L.A. Also available as AEC tech. report AECU-4439, Phys. and Math

18. Kutateladze, S. S., 1952. Heat transfer in condensation and boiling, 2nd ed. Moscow: State Sci. and Tech. Pubs. of Lit. on Mach. (Russian). Also available as AEC translation AEC-tr-3770, Phys.and Math., 1959.

19. Kroebel, D. H., S. D. Harris, B. Crain and R. M. Biderman, 1973. Forced-convection subcooled critical heat flux. Tech. report DP1306, Savannah River Lab., Aiken, S. C., February.

20. Williams, C. L., and S. G. Beus, 1980. Critical heat flux experiments in a circular tube with heavy water and light water. Tech. report WAPD-TM-1462, Bettis Atomic Power Lab., West Mifflin, Pa., May.

21. Bui, T. D., and V. K. Dhir, 1985. Film boiling heat trrasnfer on an isothermal vertical surface. J. Heat Transfer, 107, pp. 764-771.

22. McGillis, W. R., V. P. Carey and B. D. Strom, 1991. Geometry effects on critical heat flux for subcooled convective boiling from an array of heated elements. J. Heat Transfer, 113, pp. 463-471.

23. Bergeles, A. E., 1988. Some perspectives on enhanced heat transfer --- second-generation heat transfer technology. J. Heat Transfer, 110, pp. 1082-1096.

24. Falter, H. D., H. Altman, Ch. Baxi, G. H. desChamps, R. S. Hemsworth, D. Martin and P. Massmann, 1992. Thermal test results of the JET divertor plates. Tech. report JET-P(92)48, Joint European Torus, Abingdon, England.

25. Falter, H. D., and E. Thompson, 1995. Performance of Hypervapotron beam stopping elements in JET. Manuscript, JET Joint Undertaking. Abingdon/Oxon, OX14 3EA, UK.

26. Cattadori, G., G. P. Gaspari, G. P. Celata, M. Cumo, A. Mariani and G. Zummo, 1993. Hypervapotron technique in subcooled flow boiling CHF. Exp. Thermal Sci., 7, pp. 230240.

27. Baker, E., 1972. Liquid cooling of microelectronic devices by free and forced convection. Microelectronics and Reliability, 12 , pp. 163-173.

28. Samant, K. R., and T. W. Simon, 1986. Heat transfer from a small heated region to $\mathrm{R}-113$ and FC-72. AIAA/ASME 4th Thermophys, and Heat Transfer Conf., Boston, June.

29. Lee, T. Y., and T. W. Simon, 1989. High-heatflux forcec convection boiling from small regions. Heat Transfer in Electronics, ASME HTD-Vol. 111 (1989 National Heat Transfer Conf.), pp. 7-16.

30. Mudawar, I., and D. E. Maddox, 1989. Critical heat flux in subcooled flow boiling of fluorocarbon liquid on a simulated electronic chip in a vertical rectangular channel. Int. $J$. Heat Mass Transfer, 32, pp. 379-394.

31. Galloway, J. E., and I. Mudawar, 1992. Critical heat flux enhancement by means of liquid subcooling and centrifugal force induced by flow curvature. Int. J. Heat Mass Transfer, 35, pp. 1247-1260.

32. Willingham, T. C., and I. Mudawar, 1992. Forced-convection boiling and critical heat flux from a linear array of discrete heat sources. Int. J. Heat Mass Transfer, 34, pp. 2879-2890.

33. Leland, J. E., and L. C. Chow, 1993. Forced convection boiling from a nonflush simulated electronic chip. J. Thermophys. Heat Trans., 7 , pp. 588-594.

34. Galloway, J. E., and I. Mudawar, 1993. CHF mechanism in flow boiling from a short heated wall - II. Theoretical CHF model. Int. J. Heat Mass Transfer, 36, pp. 2527-2540.

35. Wu, P. S., and T. W. Simon, 1994. Critical heat flux and subcooled flow boiling with small heated regions on straight and concave-curved walls. 
Proc., 10th Int. Heat Transfer Conf. (G.

F. Hewitt, Ed.), Vol 7, pp. 569-574,

36. Desta, G. G., and T. W. Simon, 1995. Experimental studies of boiling performance in curved channels with a two-phase approach flow. ASME HTD-Vol. 134 (National Heat Transfer Conf., Portland, Ore.), pp. 125-132.

37. Katto, Y., and C. Kurata, 1980. Critical heat flux of saturated convective boiling on uniformly heated plates in a parallel flow. Int. $J$. Multiphase Flow, $\underline{6}$, pp. 575-582.

38. Katto, Y., 1995. Personal communication, Nihon Univ., Kanda-Surugadai 1-8, Chiyoda-ku, Tokyo, 11 May.

39. Mudawar, I., and D. C. Wadsworth, 1991. Critical heat flux from a simulated chip to a confined rectangular impinging jet of dielectric liquid. Int. J. Heat Mass Transfer, 34, pp. 1465-1479.

40. Beutheret, Ch., 1967. Perfectionnements aux dispositifs d'echange de chaleur entre une paroi et un liquide. French patent No. 1,502,797, 16 Oct. 1967.

41. Falter, H. D., D. Martin, P. Massmann, H. Altman, G. H. desChamps, E. B. Deksnis, R. S. Hemsworth, R. Tivey and E. Thompson, 1990. Power loading tests of the JET pumped divertor plates. Proc., 16th Symp. Fusion Tech, London, Sep.

42. Baxi, C., and H. D. Falter, 1992. A model for analytical performance prediction of Hypervapotron. Tech. report JET-P(92)56, Joint European Torus, Abingdon, England.

43. Falter, H. D., 1995. Personal communication, Joint European Torus, Abingdon, England, 8 June.

44. Davis, C. B., 1995. Personal communication, Idaho National Engineering Laboratory, 23 March.

45. Shaw, R. A., 1995. Personal communication, Idaho National Engineering Laboratory, 15 August.

46. Tolli, J., 1991. Implementation of heavy water thermodynamic properties and transport properties in RELAP5. Tech. report EGGEAST-9984, Idaho National Engineering Laboratory, November.

47. Reynolds, W. C., 1979. Thermodynamic properties in SI. Palo Alto: Mech. Engr. Dept., Stanford Univ.

48. Ulrych, G., 1984. Properties of liquid heavy water. Heat Exchanger Design Handbook, Sec. 5.5.9, Washington: Hemisphere. 


\section{OPTIMIZATION OF TREATMENT PLANNING FOR BNCT TREATMENT PLANNING}

\section{F. J. Wheeler, (INEL)}

Treatment planning for epithermal NCT applications to date has relied on rigorous Monte Carlo calculations for dose predictions. Although many improvements have been made, the Monte Carlo process still requires a large amount of computer time and planning labor. With single-field, fixed-aperture irradiations, a near-optimum field can be found with an intuition-aided trial and error approach, however methods to more rapidly determine an optimum irradiation configuration will significantly aid the planning process. As treatment efforts become more aggressive, with the ability to select aperture size and number of fields, it will be a tremendous effort to manually find the optimum plan for a given patient. Also, as the modality moves to clinical applications, patient throughput will not permit the labor resource-expenditure currently utilized in clinical trials.

An approach to improvement in the planning process has been initiated. Improvement requires: 1) a rapid method to calculate (or closely approximate) three-dimensional dose patterns; 2) an organized method to investigate variation in aperture size and beam orientation for one or more fields; 3) validation of the results of the optimization and; 4) a method of presenting results to the evaluator (oncologist).

Currently, evaluation of various plans relies on detailed inspection of dose contours and dose/volume histograms. For the optimization search, an integral measure is required so the process can be automated. For this study, the integral measure used is the tumor control probability (TCP), as defined by Porter. ${ }^{1}$

In the Porter model, TCP is determined by the relationship:

$$
T C P=e^{-N^{*} F S}
$$

where:

$\mathrm{N}$ is the total number of clonegenic tumor cells prior to therapy, and FS is the fractional survival of these tumor cells after therapy.
FS would best be determined with knowledge of the microdistribution of ${ }^{10} \mathrm{~B}$ atoms and use of a microdosimetric cell-kill model, however, lacking this knowledge, it can be estimated as

$$
F S=\int_{\mathrm{V}} e^{\frac{-D(r)}{D_{0}}} d V
$$

where:

$D(r)$ is the effective dose at space point $r$,

$D_{0}$ is the tumor-cell sensitivity, and the integral is evaluated for all volume $\mathrm{V}$ containing tumor cells.

A rapid method ( $<20$ computer seconds per field), using parameter fitting for dose distribution has been developed and tested with good results for obtaining a close approximation of $3 \mathrm{D}$ dose. The method is somewhat analogous to pencil beam methods, used in conventional photon planning software. This method has been implemented into the radiation transport in tissue Monte Carlo (rtt_MC) module of the INEL planning software. Edit directives allow one to specify a range of variation and initiate the search. Optimization software was written which ranks each plan according to TCP and presents the ranking as well as the dose/volume distribution.

As a test, a simple model of a spherical phantom was constructed. This model represented a large sphere of $10 \mathrm{~cm}$ external radius. The outer $1 \mathrm{~cm}$ of the sphere was designated scalp, the next $0.5-\mathrm{cm}$ layer was designated skull and the inner sphere was designated brain. An rtt MC simulation for the BNL $8-\mathrm{cm}$ beam was run. Figure 43 depicts the geometry used for the simulation. Twenty four million histories were simulated with the rtt module in 'NFG' mode, requiring 406 minutes cpu time on a HP 9000/735 workstation. Figure 44 shows resulting calculated fast-dose isocontours at $3.5-\mathrm{cm}$ depth. From the results of this run, a Dose Table was prepared (done automatically by $\mathrm{rtt}$ ) which provided dose for all components as a function of depth along the beam line and radial distance from the beamline. The data were averaged over the azimuthal angle to take advantage of symmetry and reduce variance. 

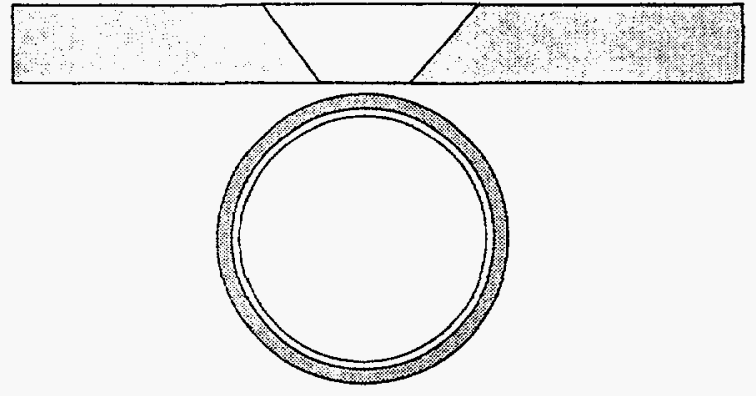

Figure 43. Geometry for simulation of large spherical phantom irradiation, $Z$ axis points into beam portal, $\mathrm{x}$ axis points up, $\mathrm{y}$ axis points to right.
Figure 45 shows calculated fast-dose isocontours for a second $\mathrm{rtt}$ run using ' $\mathrm{T}$ ' mode. This ' $\mathrm{T}$ ' run required only 2 seconds cpu time and used the dose tables from the first run and the quick method for calculating dose versus depth and radius from the beam.

Note that the isolines for the difficult fast-dose component is smoother for the rapid method than for the actual Monte Carlo calculation. This is due to the averaging of dose over azimuithal angle for each depth, radius point in the dose tables.

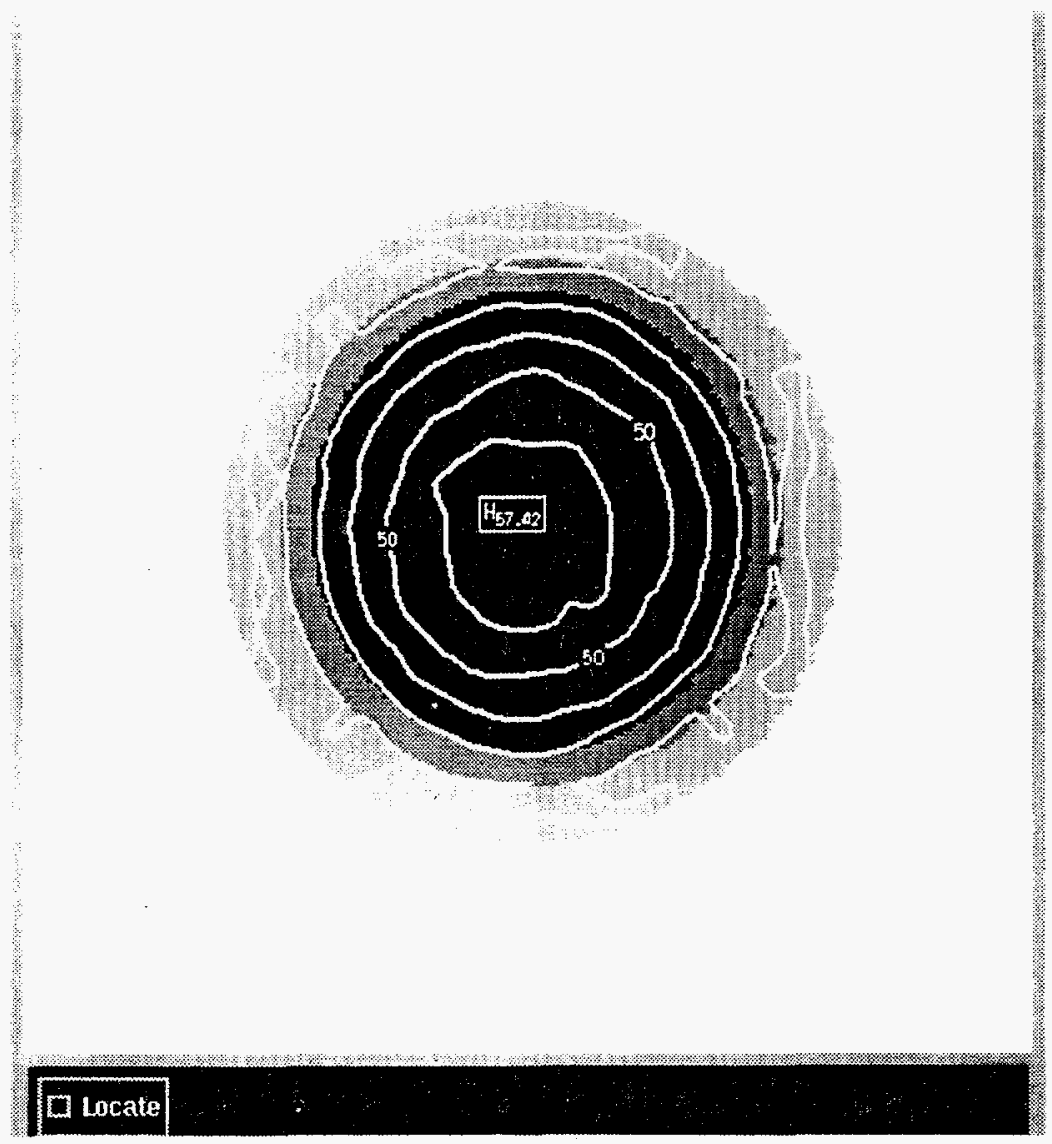

Figure 44. Fast dose iso-contours at $3.5-\mathrm{cm}$ depth perpendicular to beam for $\mathrm{rtt} \mathrm{MC}$ calculation. 


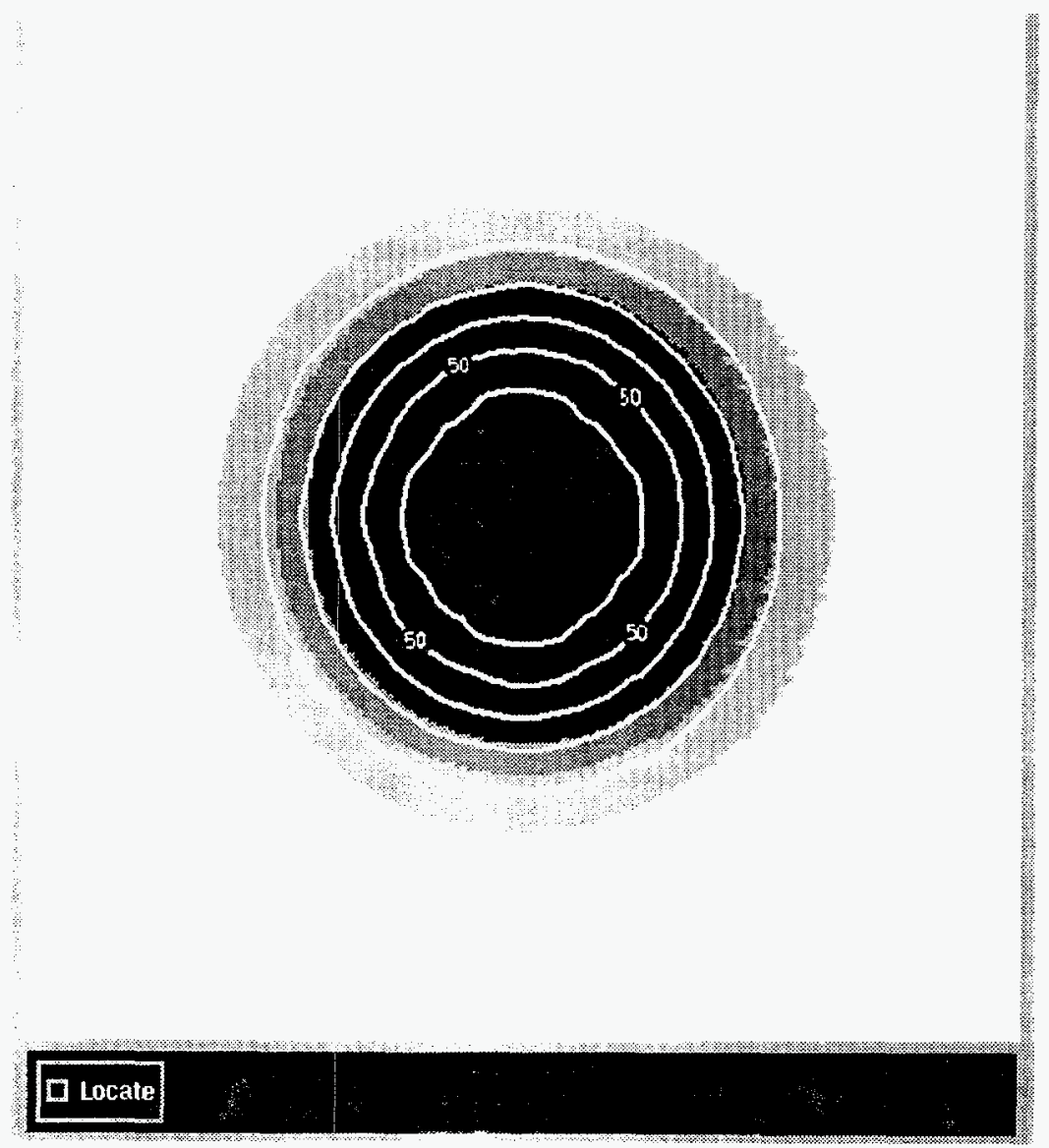

Figure 45. Fast dose iso-contours at $3.5-\mathrm{cm}$ depth perpendicular to beam for $\mathrm{rtt}$ Table Lookup option.

\section{Optimization of TCP for the Sphere}

As a test of the optimization process, a fictitious tumor region was introduced in the spherical model. This region was simply a cylinder on the $y$ axis having radius $1.0 \mathrm{~cm}$ and extending from $\mathrm{y}=-8.0$ $\mathrm{cm}$ to $\mathrm{y}=-4.0 \mathrm{~cm}$. The optimum beam angle for this simple geometry is intuitive. The optimization process was performed and correctly found the optimum beam orientation. A two-dimensional plot of the output is shown in Figure 46 and a three-dimensional representation is shown in Figure 47. The numerical value of TCP here is meaningless and is only used for illustrative purposes. These plots show the TCP versus phi, the polar angle for beam rotation about the patient and theta, the azimuthal angle for beam rotation about the patient.

\section{Optimization for a Human Patient}

As a trial study, the optimization process has been tried for actual patients at BNL. In the present BNL

clinical trials, single-field irradiations and optimization is time-consuming but not too difficult to realize using an intuition-aided trial and error approach. To date, three comparisons have been made. Usually, the automatic beam locator option in rtt results in a beam orientation that is close to optimum. In the first trial, a previously-irradiated patient model was used and the optimizer found a slightly different beam orientation than that resulting from the beam locator. Using rtt in Monte Carlo mode it was found that the optimizer result was indeed slightly better. For the other two trials, the optimizer agreed with the beam locator and a better orientation was found neither by the trial and error method or by the optimizer. Figures 48-50 show results for fractional survival for one patient assuming a tumor-cell sensitivity of Do $=2.3 \mathrm{~Gy}$ equivalent. 


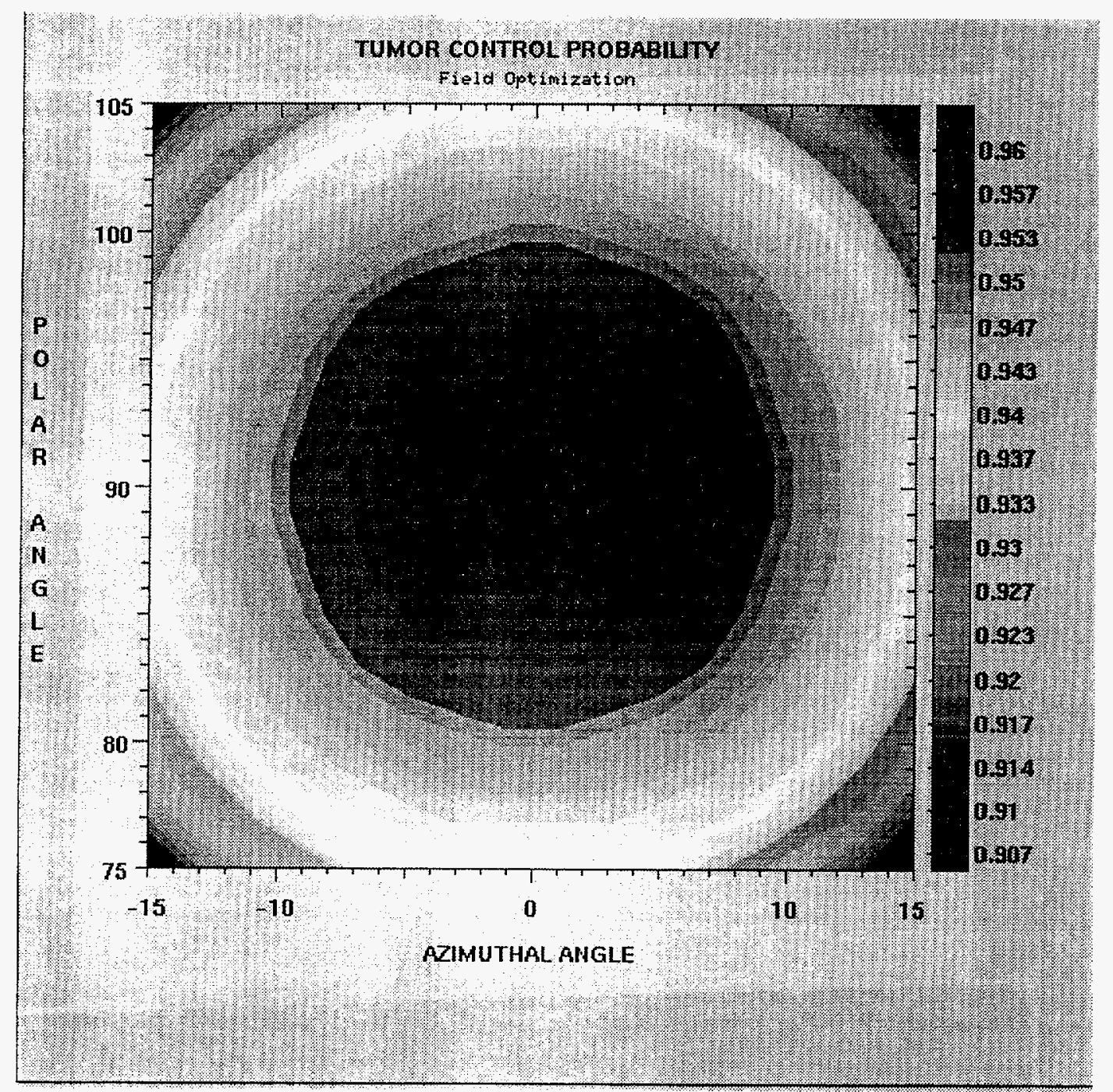

Figure 46. Two-dimensional representation of optimizer output.

\section{FUTURE WORK}

Work needs to be done to find appropriate model parameters for the Porter model. Optimization can be done using 'guesses' at tumor-cell sensitivity and density, and relative values are still valid to perform ranking of various plans, but a realistic estimate of TCP would be of great benefit for improving therapy results and evaluating the usefulness of BNCT.
Also, it is quite difficult optimize when more than one radiation field is applied. For conventional irradiations, it is much more intuitive to select multiple beams because tumor targeting is accomplished geometrically. In BNCT targeting in the case of multiple field applications is not a geometric process and a way to rapidly determine optimum fields needs to be found.

\section{REFERENCE}

1. H. Porter, "The Statistics of dose/cure relationships for irradiated tumores" British Journal of Radiology, 53, 210-227, 1980. 


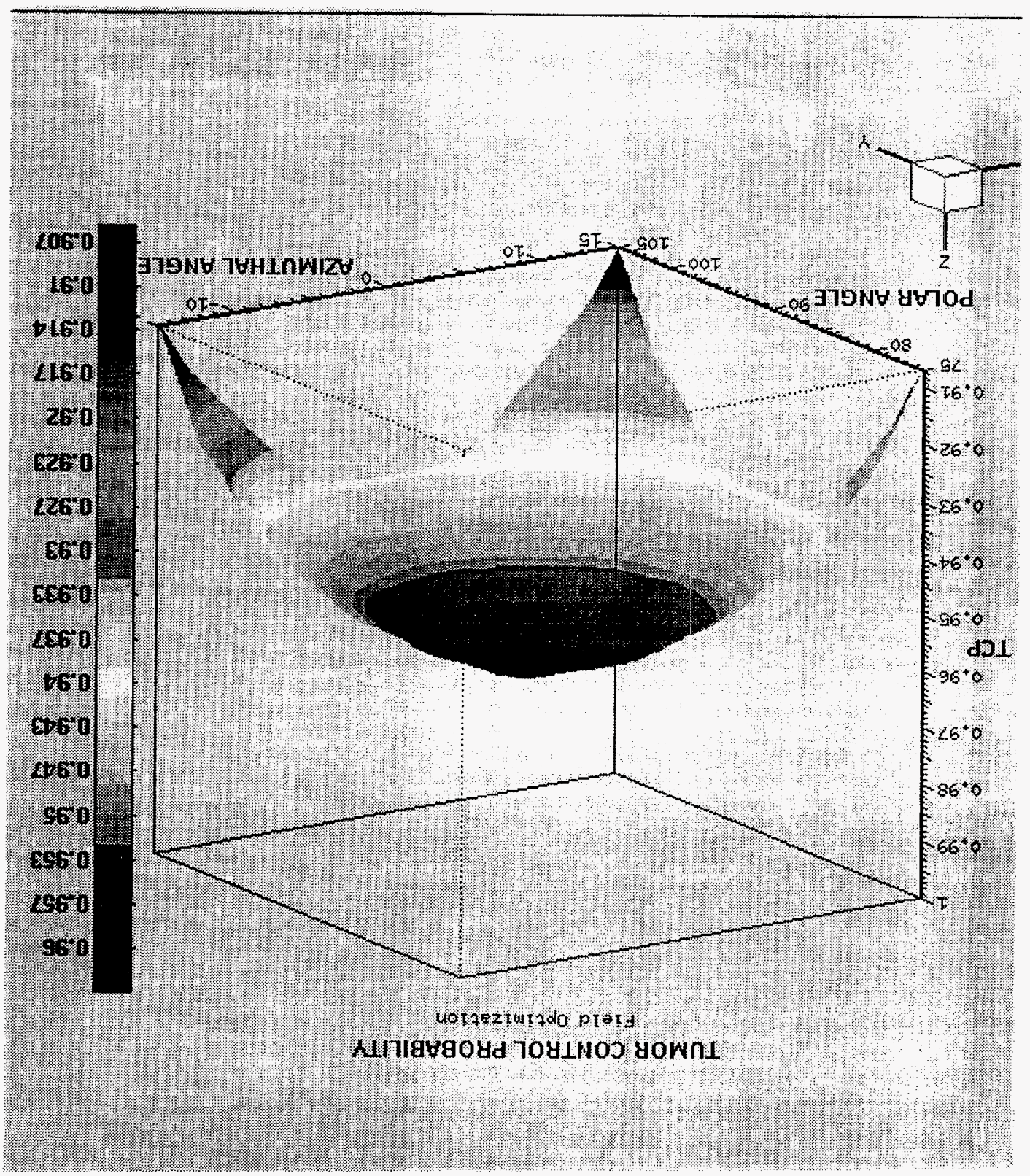




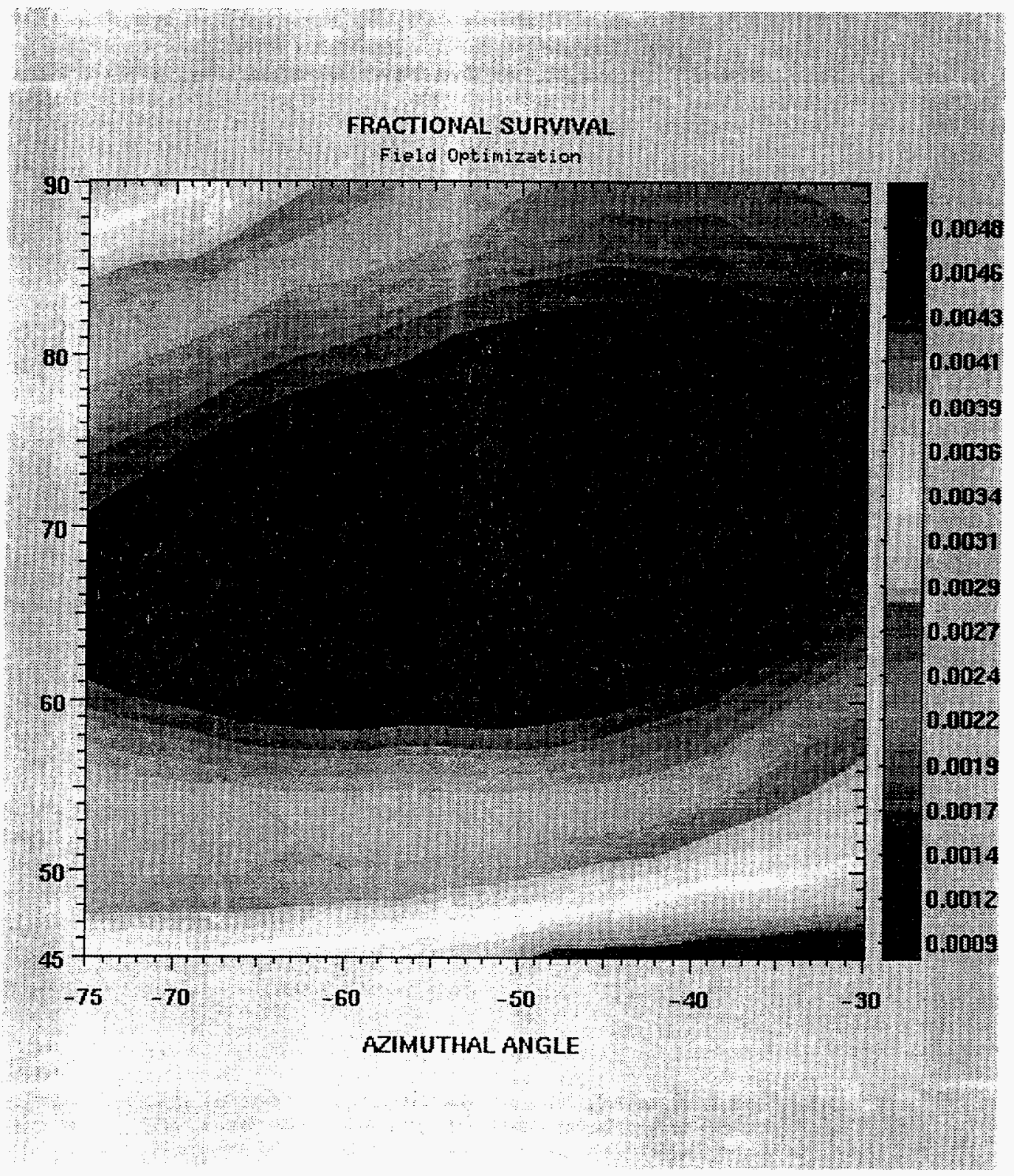

Figure 48. Two-dimensional depiction of optimizer fractional survival results for a human patient. 
FRACTIOHAL SURVIVAL $(D 0=2.3)$

Field Uptimization

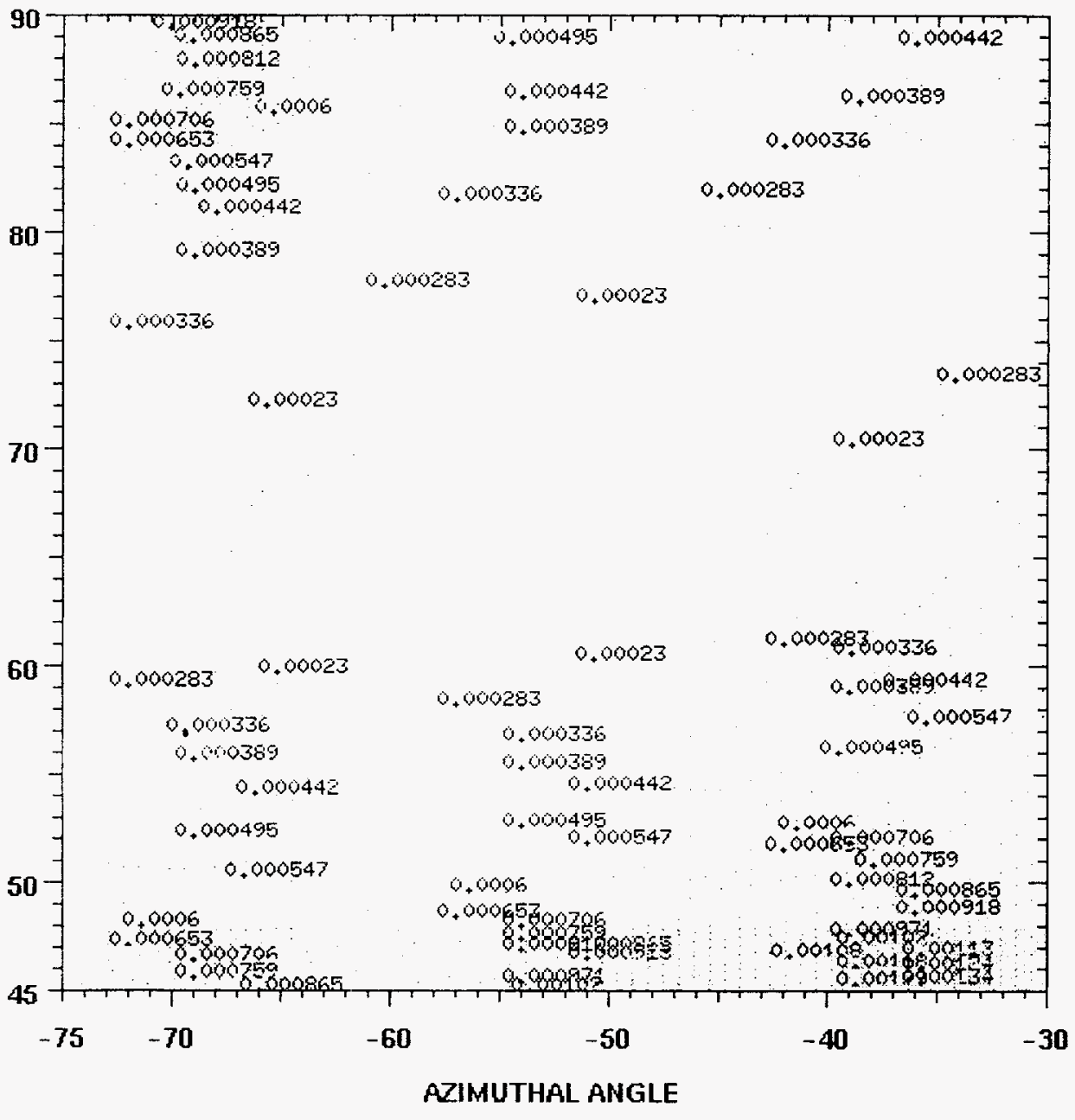

Figure 49. Isocontours representation of optimizer results for human patient. 


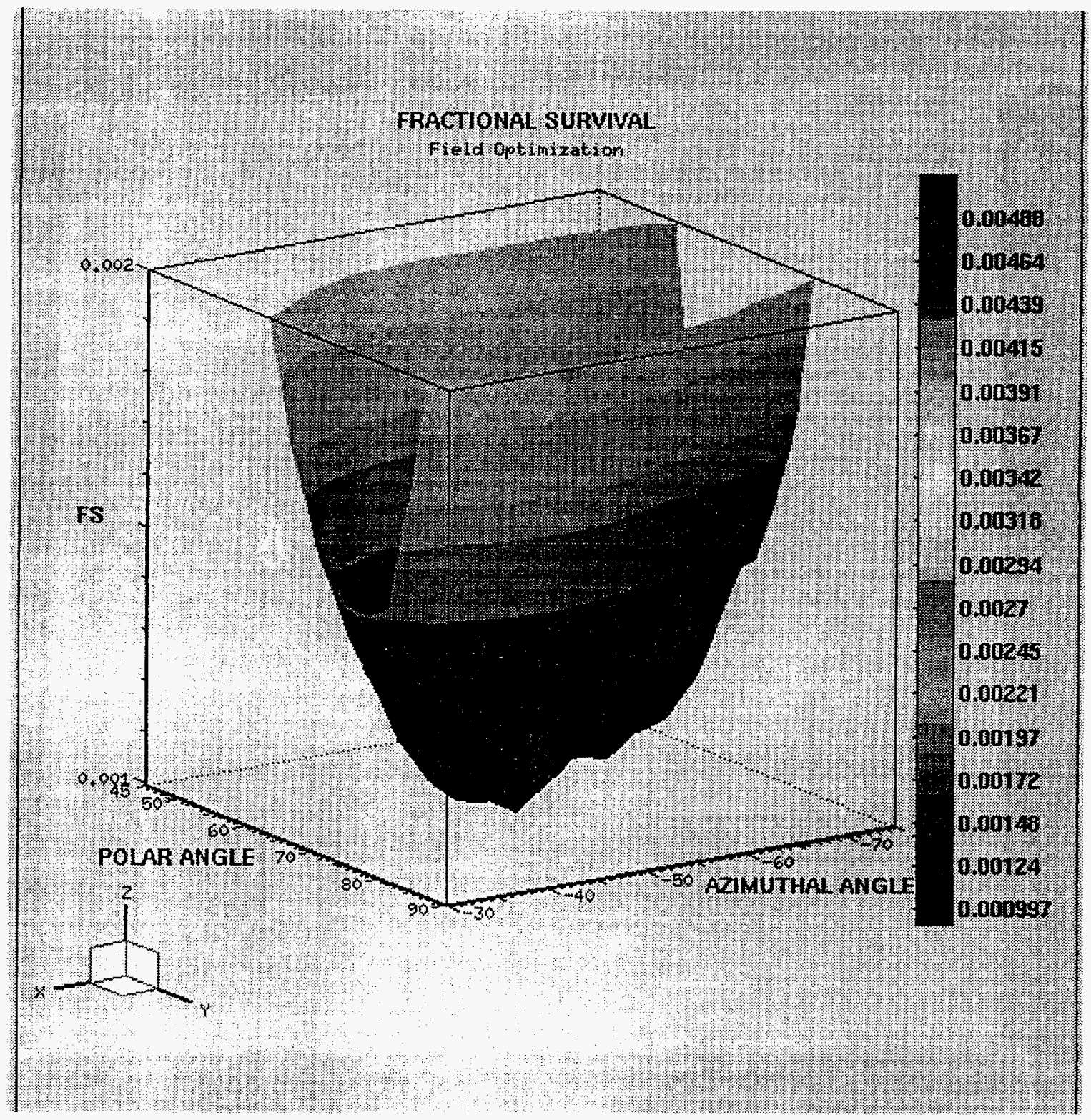

Figure 50. Three-dimensional representation of optimizer results for human patient. 


\section{BNCT-RTPE: BNCT RADIATION TREATMENT PLANNING ENVIRONMENT}

\author{
D. E. Wessol ${ }^{(1)}$, R. S. Babcock ${ }^{(2)}$, J. Evans ${ }^{(2)}$, \\ M. Frandsen ${ }^{(2)}$, G. Harkin ${ }^{(2)}$, D. Starkey ${ }^{(2)}$ \\ L. Voss ${ }^{(2)}$, and F. J. Wheeler ${ }^{(1)}$, (') INEL), \\ ${ }^{(2)}$ Montana State University (MSU)
}

\section{INTRODUCTION}

Several improvements have been developed for the BNCT radiation treatment planning environment (BNCT Rtpe) during 1995 and incorporated into version 1.2 and version $2 . x$. These versions also include the non-proprietary NURBS library and data structures.

\section{DEVELOPMENT OF VERSION 2.X}

In version 2.x of BNCT Rtpe all of the $U$ of $U$ proprietary NURBS libraries were replaced with a non-proprietary set derived from the ARL-CAD distribution. A new ray tracer based entirely on searching a nested hierarchy of bounding volumes enclosing the point of intersection was developed using the new NURBS libraries. This is a much faster method of testing and determining the intersection point than the method which employs a coarser hierachy of bounding volumes coupled with Newton iteration. The cost incurred is the increased random access memory requirements needed to keep the additional number of bounding volumes in computer memory. At this time the new method does not adaptively refine the NURBS surfaces but relies on over-sampling the surface based on the smallest polygon which meets the necessary refinement criteria including "surface cracking". This results in large memory consumption which in the future versions can be mitigated by an adaptive or coarser polygonal mesh. The current scheme does allow the user to specify the level of bounding volumes which can be used to reduce the number of bounding volumes at some sacrifice in geometric accuracy.

All of the Utah data structures, display lists, and macro functions were replaced in version 2.x.

\section{IMAGE PLANE DOSE CONTOURS}

Several improvements were made to the BNCT dose contouring function, Xcontours, which displays the radiation transport in tissue, Monte Carlo

(rtt MC) dose data. New colormap manipulation utilities have been included with Xcontours. Users can now load various colormaps stored in the BNCT resources directory. Colormaps are stored in an easy to read and easy to write fashion that allows users to create different colormaps to suit particular purposes. A colormap tool widget allows users to dynamically change the look of a set of images by manipulating the background and saturation. Other options include rotating the colormap and adjusting the gamma correction. These tools can help enhance image quality and make certain features of an image stand out. Several coding errors were repaired, resulting in more robust code.

\section{IMAGE HANDLING}

A new QSH format conversion utility was developed which includes raw, QSH and Siemens somatom (KOP) formats. The dicom3 standard format will also be incorporated. New image colormap, contrast, and brightness tools have been developed along with a vertically and horizontally scrollable image container widget which will soon be available in both BNCT_Rtpe and Xcontours.

The QSH format conversion utility serves four purposes:

- Images that do not arrive in QSH format can now be easily converted to a raw (byte stream) portion (.qim) and header portion (.qhd), the format called for by BNCT Rtpe. This was created in an effort to integrate some of the more widely used medical image file formats. Allowed input files may be either QSH, raw or somatom. Provisions are being made to also allow for the dicom 3 format.

- An easy to use graphical interface allows users to view and edit header information. This eliminates some of the potential problems of manually editing a header file -- improper capitalization of keys, misspellings, use of old aliases, and repeated or omitted information.

- Old header files, potentially hand created, can be easily converted to the new standards. In an effort to address consistency problems of the QSH header files, users may create an alias file that maps any non-standard key names used to their recognized counterparts. The program then automatically converts the old aliases to the new standards as it reads old header files. 
- An image matrix was created to preview the set of images being converted and to allow the user to selectively remove images. This allows the sequence of images to be easily thinned out, such as keeping every nth image, or to remove unneeded portions at the front or rear of the set.

\section{MISCELLANEOUS NEW FEATURES AND GENERAL CLEANUP}

A context sensitive help menu has been developed for BNCT_Rtpe. Improvements were made to the QSH file handling, general error handling, integration of the surface renderer, and the computed tomography (CT) greyscale window.

The context sensitive help system allows the user to select any visible function of BNCT_Rtpe. The help system searches up the widget hierarchy of the selected widget until a match is found in the resource file. This information is then displayed in a help popup.

There were also some improvements made to the image widget which included a local bodies list and an all bodies list which is positioned next to the slice image. The capability to perform simultaneous edit/measuring was also added to the image widget, This is especially useful when constructing the target margin surrounding the tumor volume.

The dose plotting utilities, histo and simplot, can now be called from the main BNCT_Rtpe program. Both utilities prompt the user to select a rtt_MC output file, ask the user to enter an xmgr plot commands file and then allow the user to select any plot option by clicking toggle buttons before the program is started.

\section{WORK IN PROGRESS}

New interfaces to $\mathrm{rtt} \mathrm{MC}$ are being developed which will allow more interactivity with $\mathrm{rtt}$ MC and allow for better management of the multi-field and fraction treatment protocol.

A single image widget which can simultaneously display multiple images in the same widget is being developed for both BNCT_Rtpe and Xcontours. When completed all the images used in a treatment plan will be contained within a single widget that will allow the images to be scrolled both vertically and horizontally. This is thought to be more convenient then the current image editing method which requires separate image widgets scattered about the screen. Using the multiple image widget, dose data can be previewed on several images at once. The user simply clicks on a preview image to activate it and display a corresponding full size image. Contour lines and masking effects of the active image are preserved in its preview image. The user has the option of viewing different dose components on multiple instances of the same image, or to view how one dose component varies from one image slice to its neighbor. Finally, a replacement for the National Center for Atmospheric Research contouring libraries is also being considered. 


\section{REALTIME PATIENT MONITORING SYSTEM DEVELOPMENT}

\author{
Y. D. Harker, J. K. Hartwell, J. R. Venhuizen, \\ (INEL)
}

The objective of this work is to develop a small dosimetry system that can be remotely read in real time, so that medical personnel can monitor BNCT patient doses in real time during a theraputic irradiation. Presently available neutron dosimeters either are so bulky that their presence would preturb the theraputic beam, or they cannot be read in real time.

Two candidate real time neutron dositmetry systems were tested this year. NNEL and PNNL researchers, along with representatives of IST Corporation (Pullman, WA) conducted inital tests on two candidate real time dosimetry systems.

\section{Scintillating Fiber Optic System}

A technique developed by researchers at PNNL uses a small neutron sensitive fiber optic scintillation detector that has been successful in other applications. ${ }^{1}$ In this device, a short $(1$ to $3 \mathrm{~cm})$ length of neutron-sensitve fiber with a diameter of a few hundred micrometers is coupled to a fiber optic transmission line. Neutron (and gamma-ray) interactions in the scintillating fiber create light pulses that are transmitted to a set of detection electronics that scale the pulses and determine their rate. The detection rate is proportional to the neutron (and gamma-ray) dose rate.

\section{TLD/Fiber Optic System}

A system marketed by IST consists of a small TLD dosimeter chip at the probe end of a fiber-optic transmission cable. The opposite end of the cable is coupled to a set of optical equipment that incorporates a small laser. It is designed to expose the TLD and then remotely read out its response using a laser to heat the TLD. The fiber optic cable serves to both transport the laser light to the TLD to heat the phosphor, and to transport the thermoluminescence light emitted by heating the TLD back to a photo-multiplier tube. The IST TLD chips used in this measurement work were magnesium metaborate TLDs. To accentuate the separation between neutron and gamma-ray response, on set of chips were enriched in neutron-sensitive ${ }^{10} \mathrm{~B}$ while another set was enriched in neutron-insensitive ${ }^{11} \mathrm{~B}$. The electronics system is well packaged and supported by a personal computer.

\section{MEASUREMENTS}

INEL, PNNL, and IST researchers participated in two measurement trips to the WSU TRIGA reactor facility to acquire test data on these candidate dosimetry systems under realistic neutron and gamma-ray dose condidtions. The WSU reactor is configured with a number of beam ports to accomodate a variety of experiments. A crosssectional diagram of the facility is reproduced in Figure 51. BNCT real time dosimeter tests were conducted in beam port T-3, a port of adequate diameter that penetrated to a position just off the core vertical centerline and about $0.64 \mathrm{~m}$ below the core centerline.

The neutron flux with the reactor at full power (1 MW) at three different insertion points was determined. The flux measurements were performed using thin gold foils, bare and cadmium covered, to determine the thermal and epithermal neutron fluxes within the experiment tube at $1 \mathrm{MW}$. The results of those measurements are given in Table 6 . The three positions are identified; i.e., the 0 inch position, the 6 inch position and the 12 inch position. The number indicates the approximate distance in inches from core centerline to the exit of the beam port. Neutron flux measurements were performed during both measurement trips. (There was some uncertainty in the exact reactor conditions during the first measurements.) The results of these measurements are presented in Table 5.

The measured neutron flux levels are in the range of interest for BNCT monitoring; measurements were continued in the $T-3$ beam port.

The gamma ray intensity at the irradiation positions in the T3 beam port were determined by inserting a $\mathrm{RadCal}$ ion chamber probe. Initial measurements were conducted with the probe at the 0 -inch position as the reactor was raised to sequencially higher power levels. These results are displayed in Table 6. Note that the ion chamber saturated at a reactor power of 1 MW. The reactor power was maintained at $100 \mathrm{~kW}$ for the positional gamma-ray dose rate measurements presented in Table 7. 


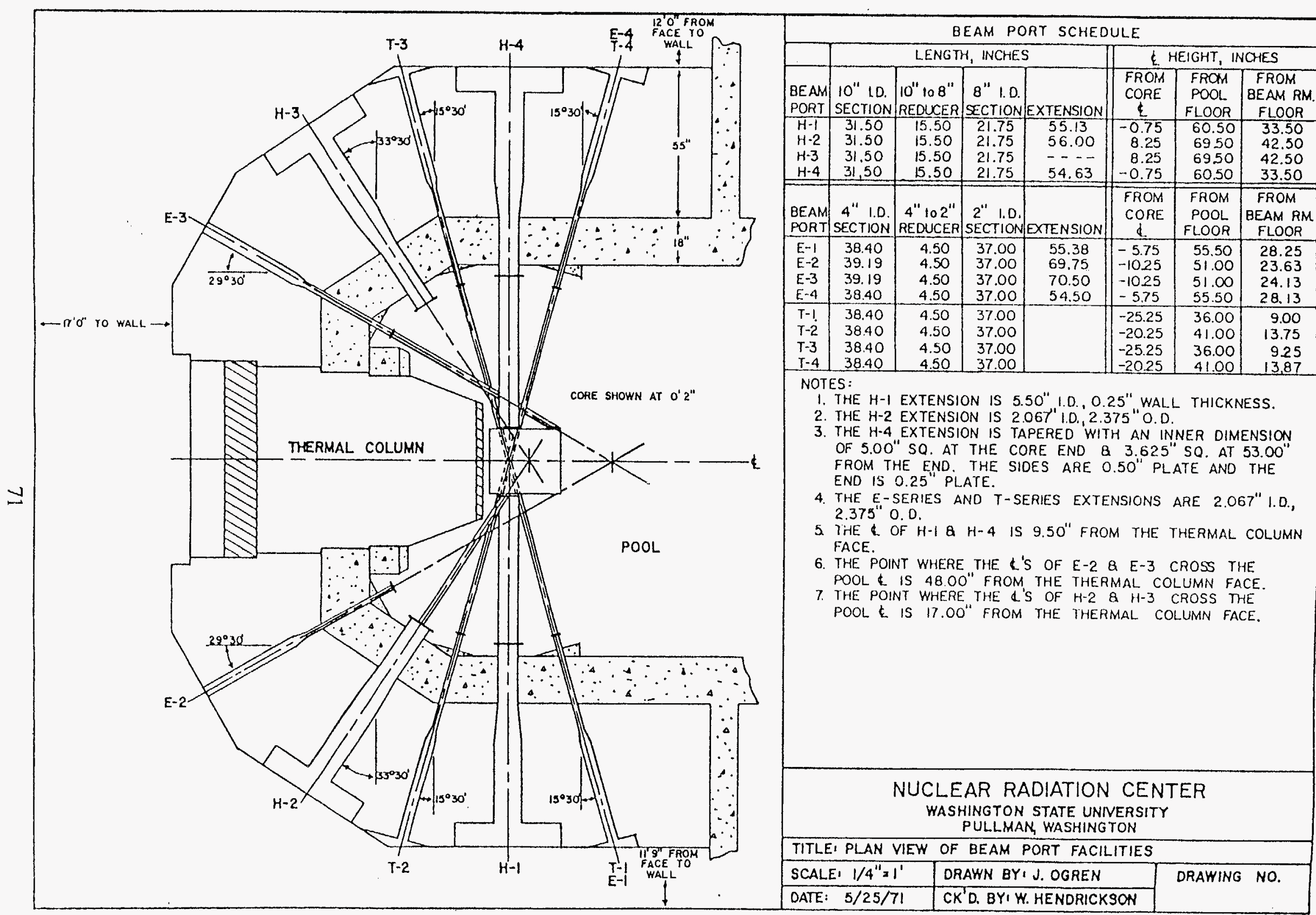

Figure 51. Real time dosimetry development. 
Table 5. Measured (1995) neutron flux levels in the WSU reactor T3 beam port.

\begin{tabular}{lllll}
\hline July 18 visit & & & August 16 visit & \\
\hline & Thermal flux & & \\
(inches) & $\left(\mathrm{n} / \mathrm{s} / \mathrm{cm}^{2}\right)$ & $\begin{array}{l}\text { Epithermal flux } \\
\left(\mathrm{n} / \mathrm{s}^{6} / \mathrm{cm}^{2}\right)\end{array}$ & $\begin{array}{l}\text { Thermal flux } \\
\left(\mathrm{n} / \mathrm{s}^{2} / \mathrm{cm}^{2}\right)\end{array}$ & $\begin{array}{l}\text { Epithermal flux } \\
\left(\mathrm{n} / \mathrm{s} / \mathrm{cm}^{2}\right)\end{array}$ \\
0 & $8.4 \times 10^{9}$ & $6.5 \times 10^{7}$ & $8.3 \times 10^{9}$ & $6.8 \times 10^{7}$ \\
6 & $8.9 \times 10^{9}$ & $7.3 \times 10^{7}$ & $1.0 \times 10^{10}$ & $8.4 \times 10^{7}$ \\
12 & $4.9 \times 10^{9}$ & $3.6 \times 10^{7}$ & $7.7 \times 10^{9}$ & $6.4 \times 10^{7}$ \\
18 & not measured & not measured & $3.7 \times 10^{9}$ & $3.0 \times 10^{7}$ \\
24 & not measured & not measured & $1.3 \times 10^{9}$ & $1 \times 10^{7}$
\end{tabular}

${ }^{a}$ Thermal neutron fluxes determined using the $2200 \mathrm{~m} / \mathrm{s}$ cross section for $197 \mathrm{Au}(98.7 \mathrm{~b})$ from the 1989 Chart of the Nuclides.

${ }^{b}$ Epithermal neutron fluxes are quoted "per unit $\ln (E)$," and were determined using the resonance integral for $197 \mathrm{Au}(1550 \mathrm{~b})$ from the 1989 Chart of the Nuclides.

Table 6. Gamma-ray dose rates measured in the WSU reactor T3 beam port as a function of reactor power.

\begin{tabular}{ll}
\hline Reactor Power & $\gamma$-ray dose rate (R/Minute) \\
\hline 0 & 0.1 \\
$100 \mathrm{~W}$ & 27 \\
$1 \mathrm{~kW}$ & 36 \\
$10 \mathrm{~kW}$ & 130 \\
$100 \mathrm{~kW}$ & 1120 \\
$1 \mathrm{MW}$ & saturated
\end{tabular}

${ }^{a}$ All measurements in this table were taken with an ion-chamber probe located at the 0 -inch position.

Table 7. Gamma-ray dose rates measured in the WSU reactor T3 beam port as a function of irradiation position at a reactor power of $100 \mathrm{~kW}$, ion chamber probe.

\begin{tabular}{ll}
\hline Probe position (inches) & $\gamma$-ray dose rate (R/Minute) \\
\hline 0 & 1120 \\
6 & 1259 \\
12 & 1085 \\
18 & 734 \\
24 & 436 \\
\hline
\end{tabular}

To separate the response of the candidate dosimeters to neutrons and gamma-ray, a gamma-ray response curve was developed for each of the two types of PNNL fibers tested and for the IST remote TLD system. These calibrations were preformed in the WSU ${ }^{60} \mathrm{Co}$ gamma irradiation facility. This facility includes a strong ${ }^{60} \mathrm{Co}$ gamma-ray source that can be remotely removed from a shielding cask. (The entire assembly is at the bottom of the reactor pool, thus the pool water provides an excellent personnel shield.) Items to be irradiated can be precisely positioned at calibrated distances from the irradiation source. The gamma-ray dose rate at each position is well known. The prototype PNNL fiber optic scintillator probes (of two differnet configurations) and both the ${ }^{10} \mathrm{~B}$ - and ${ }^{11} \mathrm{~B}$ - containing IST TLD probes were irradiated at various known dose rates and their gamma-ray response curves determined. 
Two PNNL fiber optic scintillator probes packages, differing in their active fiber length and the method of attachment to the transmission fiber, and and two IST laser TLD probes, one containing neutron sensitive ${ }^{10} \mathrm{~B}$ and one neutron insensitive ${ }^{11} \mathrm{~B}$, were irradiated in the characterized environment of the T-3 beam port. The probes were characterized by determining their neutron detection efficiency and their relative neutron to gamma ray sensitivities. The neutron counting efficiencies of the two PNNL probes, termed " $2 G$ " and " $2 F$ " respectively were $2.5 \times 10^{-4}$ and $8.0 \times 10^{-5}$ counts per neutron per $\mathrm{cm}^{2}$ per second $\left(\mathrm{c} / \mathrm{n} / \mathrm{cm}^{2} / \mathrm{s}\right)$ and the respective neutron-togamma-ray response ratios were 7:1 and 8:1. These are very acceptable results.

The IST TLD probe set, when similarily tested, yeilded neutron counting efficiencies for the ${ }^{10} \mathrm{~B}$ probe of $5.5 \times 10^{-7} \mathrm{c} / \mathrm{n} / \mathrm{cm}^{2} / \mathrm{s}$ and a neutron-to-gamma ray response ratio of $4.4: 1$. These are also acceptable results. An apparent advantage of the IST probe set is the availability of the ${ }^{\text {"1 }} \mathrm{B}$ results for correction of the gamma-ray response of the neutron sensitive TLD. While this works well in the thermal neutron/ high gamma dose rate environment of the WSU beam tube, calculations for the highly filtered and gammaray shielded theraputic beam environment indicate that the slight ${ }^{10} \mathrm{~B}$ content of the ${ }^{11} \mathrm{~B}$ probe will provide an unwanted neutron response that is greater than the desired gamma-ray reading.

The testing performed on these candidate dosimetry probes indicates that either approach has merit for real-time BNCT patient dose monitoring. Certain development issues primarily associated with probe ruggedness and electronic stability of the PNNL fiber optic detectors were identified. IST has suggested that a different suite of TLD chips might provide better dose monitoring in a BNCT beam environment.

\section{REFERENCE}

1. Bliss, P. Reeder, and R. A. Craig, NeutronSensing Scintillating Glass Optical Fiber Detectors, Proceeding of the $35^{\text {th }}$ Annual Meeting of the Institute of Nuclear Materials Management, Volume XXIII, Naples FL, July $12-20,1994$. 


\section{THE EFFECT OF REPEATED BSH DOSE ADMINISTRATION TO RATS}

\author{
T. LaHann, Ph D., Department of Pharmacy, \\ Idaho State University (ISU)
}

\section{INTRODUCTION}

Initial U.S. clinical evaluations of BSH mediated BNCT are likely to employ BSH doses similar to those used in Japan and Europe, i.e., BSH doses no greater than $100 \mathrm{mg} / \mathrm{kg}$ (maximum boron dose: 56 $59 \mathrm{mg} / \mathrm{kg}$, enriched vs natural $\mathrm{BSH}$ ). Clinical efficacy studies (BSH + neutron radiation) using a BSH dose of $100 \mathrm{mg} / \mathrm{kg}$ and an epithermal neutron source are expected to demonstrate a high-quality life extension and/or a cure rate superior to that achieved by the Japanese thermal neutron treatments. Theoretical calculations indicate that the efficacy of BNCT should dramatically increase with increasing BSH dose and the associated increase in tumor levels of boron. Clinical studies will be necessary to validate theoretical predictions but, before these studies can be initiated, additional animal testing will be required to determine the dosing regimen likely to provide safe and maximally effective BNCT.

BSH has been administered clinically in both Japan and Europe (typically at BSH doses less than 100 $\mathrm{mg} / \mathrm{kg}$ ). European and Japanese experience suggests that single doses of BSH in amounts less than 100 $\mathrm{mg} / \mathrm{kg}$ are reasonably safe for healthy volunteers and for the brain tumor patient populations evaluated to date. There are biological reasons to believe that BNCT clinical protocols utilizing fractionated therapy (including repeat dosing of $\mathrm{BSH}$ ) may be superior to those using a single fraction (single dose of BSH). However, the toxicological and pharmacokinetic effects of repeat dosing of BSH are largely unknown.

An early study by Soloway ${ }^{1}$ indicated that repeated, rapid, i.v. infusion of $\mathrm{BSH}$ can kill rabbits. Soloway's New Zealand White rabbits $(2.1-3.1 \mathrm{~kg}$ ) received $40 \mathrm{mg} / \mathrm{kg} \mathrm{B}(68 \mathrm{mg} / \mathrm{kg} \mathrm{BSH})$ once daily for 5 consecutive days. Some rabbits died before receiving all doses. Rabbits that died showed evidence of hemorrhagic infraction of the brain stem and "scar-like foci" in lungs, kidneys and liver. Survivors were observed for 30 days, but exhibited no obvious adverse effects. The significance of the deaths in this study is difficult to judge, since the $\mathrm{BSH}$ formulation apparently contained considerable amounts of the more toxic BSH oxidation products (e.g., BSSB or BSOSB). Buchar ${ }^{2}$ and Janku ${ }^{3}$ reported that repeated, low dose administrations of
BSH to Chinchilla rabbits ( 25 or $50 \mathrm{mg} / \mathrm{kg} /$ day, 7 days) were associated with nephrotoxicity and death. Two of fifteen rabbits died after receiving a cumulative BSH dose of $125 \mathrm{mg} / \mathrm{kg}$, a third rabbit died after receiving a cumulative BSH dose of 250 $\mathrm{mg} / \mathrm{kg}$. Marshal $\mathrm{l}^{4}$ reported that i.v. infusion of $\mathrm{BSH}$ (osmotic minipump) to mice at an average rate of about $1.66 \mathrm{mg} / \mathrm{kg} / \mathrm{hr}$ for 9 days (average total dose of about $350 \mathrm{mg} / \mathrm{kg}$ ) elicited reversible hepatotoxicity but no signs of renal toxicity.

\section{EXPERIMENTS}

During the course of experiments intended to better predict the probable risk associated with clinical use of BSH, ISU researchers determined how the body burden of boron is affected by repeated dosing with BSH. This was accomplished by characterizing the time-course of boron excretion in urine and feces of male, Long Evans rats and subtracting measured boron excretion from measured boron (as BSH) administration. To facilitate extrapolation of animal results to anticipated clinical studies, the source of $\mathrm{BSH}$, number of doses, time of dose administration, rate of dose administration and concentration of $\mathrm{BSH}$ were selected to approximate those parameters anticipated for clinical use of BSH.

Rats received 6 consecutive, daily, i.v. infusions of $\mathrm{BSH}, 125 \mathrm{mg} / \mathrm{kg}$ (Boron Biologicals, Inc.) or vehicle control. $99 \%$ of boron was present as $\mathrm{BSH}$, but the lot was contaminated with $\mathrm{NaCl}$ (W. Bauer, INEL). Sterile solutions of BSH were prepared in distilled water at a target concentration of $50 \mathrm{mg} / \mathrm{mL}$. Direct measurement of boron indicated that over the course of the study, solution concentrations ranged from $96.1 \%$ to $102.6 \%$ of the target value. Room temperature solutions of the $\mathrm{BSH}$ vehicle were made fresh daily, adjusted to $\mathrm{pH}$ 7.2-7.6, purged with nitrogen and used within 8 hours of preparation. Vehicle control was $0.9 \%$ saline adjusted to mimic BSH osmolarity by addition of $105 \mathrm{mg}$ mannitol $/ \mathrm{mL}$. Sterile solutions of room temperature vehicle control were prepared daily, adjusted to $\mathrm{pH}$ $7.2-7.6$, purged with nitrogen and used within 8 hours of preparation. Boron content of biological samples was quantified by inductively coupled plasma atomic emission spectroscopy (W. Bauer, INEL). Background boron levels present in samples of blood and urine before initiation of drug infusions were measured and found to be negligible. Food and water intake were monitored daily; boron content of food and water was measured and found to be negligible. Individual animal urine volumes and 
weights were determined daily and urine was analyzed for boron content. Individual animal feces production was also determined daily and analyzed for boron content. Venous blood samples were drawn on 6 different days (day $0,1,3,6,10$ and 13) and analyzed for boron content. Blood was assumed to represent $5 \%$ of each animals total body weight. Animals were sacrificed 7 days after the last of 6 daily doses.

\section{RESULTS}

The multiple dose administration of BSH was well tolerated by the rats. Animals in the BSH treatment group received $6 \mathrm{BSH}$ doses of $122.3+/-7.4 \mathrm{mg} / \mathrm{kg}$ (mean $+/$-SD); boron levels in the vehicle control solutions were measured and found to be negligible. No significant changes in body weight gain were observed between groups. Compared to the vehicle control group, rats receiving repeated daily infusions of BSH consumed slightly less food and water, and urine and feces production were slightly decreased. Statistical analysis of these differences is ongoing, but it is unlikely that the observed differences are biologically relevant. The kidney was the major pathway for excretion of BSH-boron; $56 \%$ of the boron present in a single dose of BSH was excreted in the urine within a 19 hour period. The daily urinary boron excretion remained relatively constant over the 6 day dosing period, while total body burden of boron increased about three-fold (Figure 52). Upon termination of BSH dosing, daily urinary excretion of boron declined markedly and precipitously. Fecal excretion was never a major route for removal of $\mathrm{BSH}$-boron, at most eliminating a few percent of the administered dose (Figure 53). Only a small fraction of the total administered boron dose remained in the blood. Following termination of BSH administration, the total body burden of boron decreased, but rapidly stabilized (Figure 52). After the 7 day wash-out period, the body burden of boron still exceeded the total amount of boron contained in a single BSH dose of $125 \mathrm{mg} / \mathrm{kg}$ (e.g., $34 \mathrm{mg}$ BSH for a $275 \mathrm{gm}$ rat). Body weight averaged about $200 \mathrm{gm}$ at the start of the study and about $275 \mathrm{gm}$ at study termination. On day 8 of the experiment, rat body weights averaged about $250 \mathrm{gm}$ and body boron burden (boron infused - (boron excreted in urine + boron excreted in feces + boron residing in blood)) averaged about $20.7 \mathrm{mg}$ boron. The distribution of this boron in unknown, but if it were homogeneously distributed throughout nonblood tissue, the average tissue boron concentration would be about $83 \mathrm{ppm}$ (ug B/g body weight). Tumor boron levels achieved after single dose BSH administration are on the order of $30 \mathrm{ppm}$, so unexcreted boron sufficient to achieve average tissue levels of $83 \mathrm{ppm}$ is clearly of concern. Since total body burden in defined as (boron infused - (boron excreted in urine + boron excreted in feces + boron residing in blood)), failure to collect all urine and feces would artificially inflate the total body burden. Even the best experimental technique cannot guarantee collection of $100 \%$ of urine and feces production. However, ISU researchers believe that $>90 \%$ of feces and urine excreted over the course of the study was recovered. Low measured boron levels in urine and feces several days after termination of the $\mathrm{BSH}$ infusions makes it unlikely that urinary or fecal retention significantly biased the data. Blood boron measurements indicated that blood is not a reservoir for BSH-boron. Pulmonary or salivary excretion of boron was not measured, but is unlikely that these represent major routes of excretion.

ISU experimental results (discussed in the 1994 INEL BNCT Research Program annual report) indicate that repeat administration of $\mathrm{BSH}$, under conditions intended to approximate clinical use in BNCT trials, did not significantly impair function in male, Long-Evans rats. Clinical chemistry and histopathology indicated that some reversible renal damage occurred, but in general, animals tolerated the repeat dosing of BSH surprisingly well. Boron retention may restrict BNCT protocols using multiple dose BSH administration because of the potential for healthy tissue toxicity related to boron neutron capture and/or direct drug toxicity. Given the potential implications of this study, it is important to: 1) confirm these results by a repeat study in rats, 2) conduct repeat administration studies in rabbits, to address intraspecies differences in boron retention, 3) determine the biodistribution of retained boron, 4) determine the time course of boron retention (e.g., is boron accumulation a long-lived phenomenon?) and 5) determine the mechanism(s) responsible for boron retention in tissue (understanding the underlying mechanism (2) may suggest solutions). Until the clinical implications of boron retention are better understood, clinical protocols using repeat dosing of BSH followed by neutron radiation may be premature and should proceed with caution.

\section{REFERENCES}

1. Soloway, Hatanaka H. And Davis M.: Penetration of Brai and Brain Tumor, VII. Tumor-Binding Sulfhydryl Boron Compounds. J. Med. Chem 10; 714-717, 1967.

2. Buchar E., Bednarova S., Gruner B., Walder, P. Strouf O., and Janku, I.; Dose-dependent 
disposition kietics and tissue accumulation of boron after intravenous injections of sodium mercaptoundecahydrododecaborate in rabbits. Cancer Chemother. Pharmacol. 29:450-454, 1992.

3. Janku, I., Buchar E. And Jiricka Z; Nephrotocicity of Borocaptate After Short-Term Administration in Rabbits. Toxicology 79:99108, 1993.
4. Marshall P., Miller M., Grand S., Micca P. And Slatkiln D.; Toxicities of $\mathrm{Na}_{2} \mathrm{~B}_{12} \mathrm{H}_{11} \mathrm{SH}$ and $\mathrm{Na}_{4} \mathrm{~B}_{24} \mathrm{H}_{22} \mathrm{~S}_{2}$ in Mice, In Clinical Aspects of Neutron Capture Therapy, Ed: Fairchild R., Bond V. And Woohead, A. 1989, Plenum Press, pp. 333-351. 


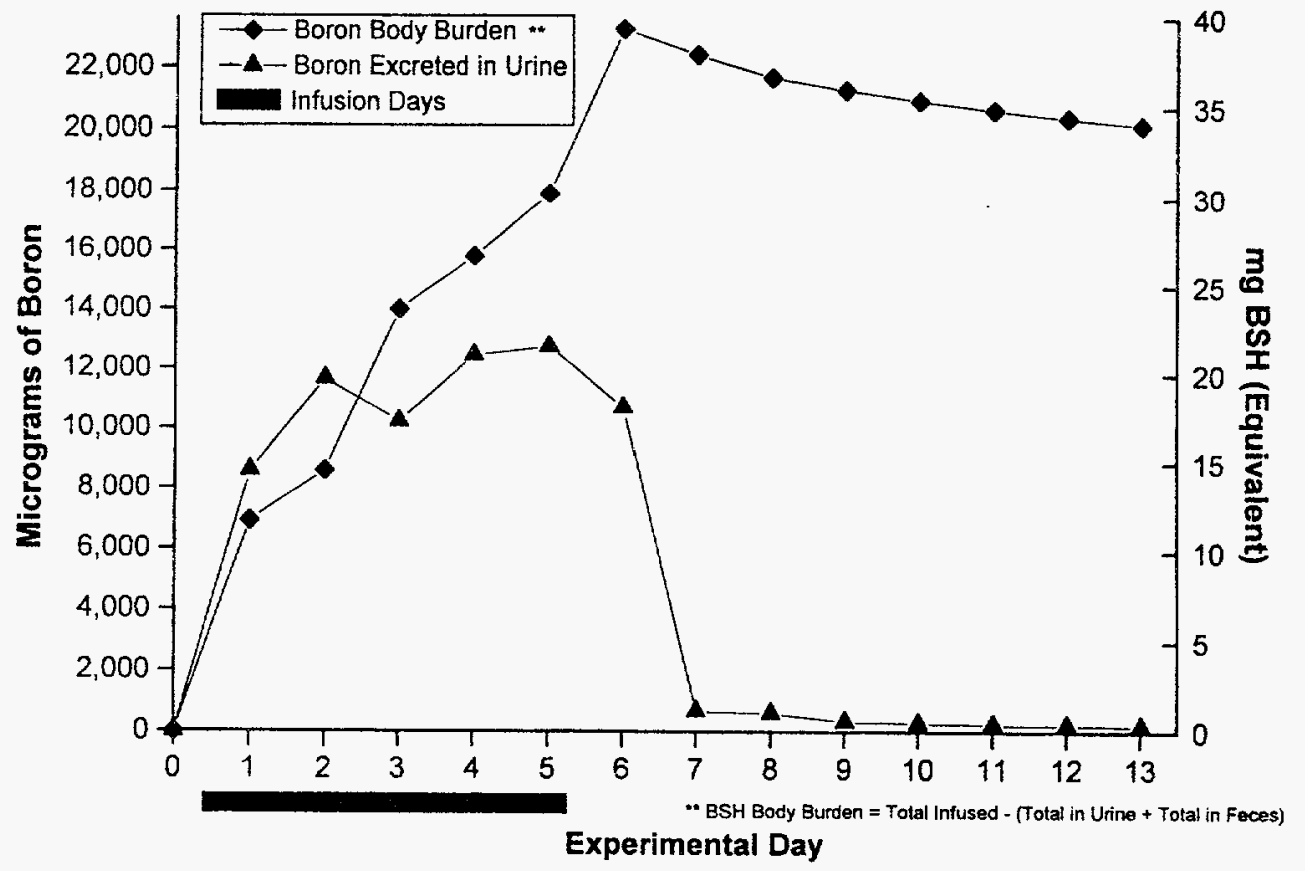

Figure 52. Mean Daily Body Burden vs Urinary Excretion of Boron Repeat Dosing of BSH $(6 \times 125 \mathrm{mg} / \mathrm{Kg}$, i.v., Rats).

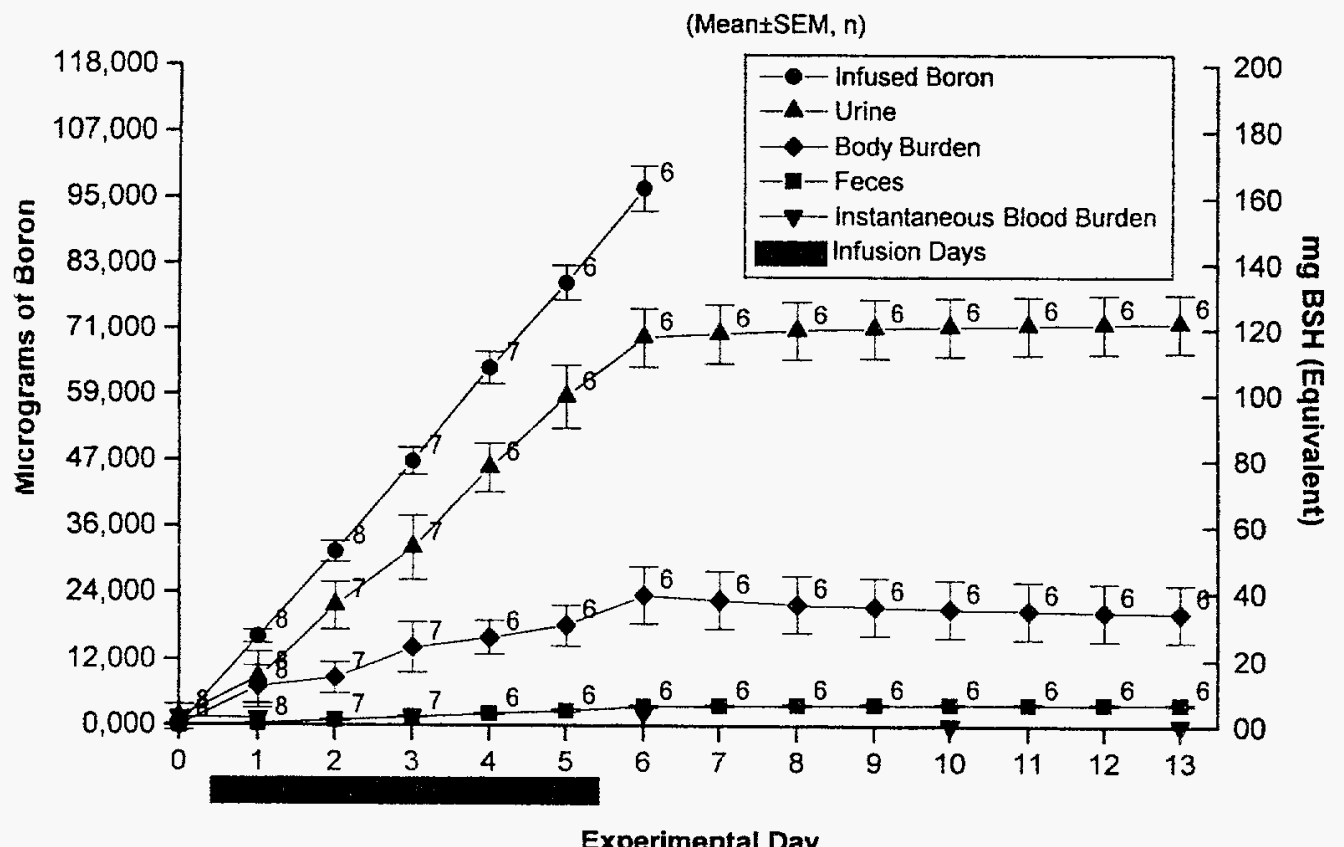

Figure 53. Boron Pharmacokinetics Cumulative Administration, Excretion, and Retention Repeat Dosing of BSH $(6 \times 125 \mathrm{mg} / \mathrm{Kg}$, i.v., Rats). 
